\title{
Do You KnOW That I KnOW That You KnOW...? HigheR-ORDER BELIEFS IN SURVEY DATA
}

\author{
Olivier Coibion \\ UT Austin and \\ NBER
}

\author{
Yuriy Gorodnichenko \\ UC Berkeley and \\ NBER
}

\author{
Saten Kumar \\ Auckland University \\ of Technology
}

\author{
Jane Ryngaert \\ Wake Forest \\ University
}

This draft: August 22 $2^{\text {nd }}, 2018$

\begin{abstract}
We implement a new survey of firms, focusing on their higher-order macroeconomic expectations. The survey provides a novel set of stylized facts regarding the relationship between first-order and higher-order expectations of economic agents, including how they adjust their beliefs in response to a variety of information treatments and how these adjustments affect their economic decisions. We show how these facts can be used to calibrate key parameters of noisy-information models with infinite regress as well as to test predictions made by this class of models. The survey also quantifies cognitive limits of agents in the form of level- $k$ thinking. We find little evidence that this departure from infinite regress helps reconcile the data and theory.
\end{abstract}

JEL: E31, C83, D84

Keywords: survey, inflation expectations, firms, managers

Acknowledgement: We are grateful to Jennifer La'O for thoughtful discussions at the 2018 ASSA Conference and 2018 NBER Summer Institute, seminar participants at the Federal Reserve Bank of Cleveland and the Ridge August 2018 Workshop on Inflation Expectations as well as Hassan Afrouzi, George-Marios Angeletos, John Leahy, Ricardo Reis, Dmitriy Sergeyev, and Michael Woodford for helpful comments. 


\section{Introduction}

Economists have long understood the importance of higher-order expectations. Keynes (1936) emphasized the beauty contest nature of financial markets, Harsanyi (1967) formalized the role of higher-order beliefs in decision-making, and Morris and Shin (2002) demonstrate how strategic complementarity in the actions of agents can make the public provision of information suboptimal when agents also have private sources of information, as public information disproportionately affects higher-order beliefs. The role of higherorder beliefs has also become increasingly recognized and studied in the macroeconomic context. For example, Woodford (2003) shows how noisy private information can lead firms to change their prices gradually because of slow-moving higher-order beliefs about the actions of other firms. More recent work has considered how different assumptions about higher-order beliefs can alleviate the "forward guidance" puzzle $^{1}$ (e.g. Angeletos and Lian 2018, Gabaix 2016, Fahri and Werning 2017).

One stumbling block to this literature has been the absence of empirical evidence, other than that of the experimental literature, on the higher-order beliefs of economic agents, especially when it comes to their expectations of macroeconomic variables. ${ }^{2}$ This paper takes a first step at filling this gap by studying the higher-order macroeconomic expectations of firm managers using a novel survey of firms in New Zealand. This survey asks managers not only about their expectations over macroeconomic variables, but also about what they think other managers expect for these same variables. We also provide new evidence on the learning process through a variety of randomized information treatments that characterize how agents' first-order and higher-order beliefs respond to different kinds of information about the economy. Using a follow-up wave, we can also measure the persistence of changes in beliefs and how changes in beliefs translate into firms' economic decisions. Jointly, these data provide a novel set of empirical facts that can be used to discipline and test models of higher-order thinking. We document a number of dimensions along which noisy-information models with higher-order expectations are (and are not) consistent with the stylized facts from the survey.

The survey builds on earlier surveys of firms in New Zealand described in Coibion, Gorodnichenko and Kumar (2018; henceforth CGK) and Kumar et al. (2015). Relative to this earlier work, we rely on two new waves of the survey run in 2017Q4-2018Q1 using a fresh draw of firms. These firms were asked to report not just what they expect inflation to be over the next twelve months (their "first-order" expectations) but also what they believe other firms expect future inflation to be (their "higher-order" expectations). We

\footnotetext{
${ }^{1}$ Standard New Keynesian models that abstract from information frictions imply that announcements about monetary policy in the distant future can have unrealistically larger contemporaneous economic effects.

${ }^{2}$ The experimental literature has documented a number of striking features about higher-order expectations, and we explicitly build on this previous work. The main differences are that we study actual macroeconomic expectations of actual firm managers, rather than much more narrowly-defined expectations of undergraduates in typical experiments.
} 
highlight several features of this unique data set. First, the average higher-order forecast of inflation across firms is close to the average first-order forecast of inflation: $3.5 \%$ vs 3.4\% respectively. Second, the crosssectional standard deviation of higher-order beliefs (disagreement) is smaller (by about 20\%) than the dispersion in first-order beliefs about inflation. Similarly, the average uncertainty around firms' higherorder beliefs inflation is significantly lower than their uncertainty around their own forecasts. Fourth, we find in the cross-section that firms with larger forecasts of inflation also tend to have larger higher-order inflation forecasts, with a slope coefficient of less than one.

These stylized facts provide a unique way to calibrate and test noisy-information models with infinite regress (i.e. when agents can correctly infer what others think about what they think about what others think...). For example, we show that this type of model is consistent with both the lower disagreement and uncertainty around higher-order forecasts than first-order forecasts. In addition, the relative levels of each are determined by the same underlying parameter in the model, providing an overidentification test that is not rejected by the data. Similarly, the model is consistent with the slope coefficient when we regress higher-order forecasts on first-order forecasts of firms. From this combination of empirical moments, we show how one can identify the underlying parameters of the model, including the level of the fundamental, the level of the public signal, and the precision of signals. ${ }^{3}$

More challenging for noisy-information models to explain is a separate set of empirical facts that we document in the survey. Specifically, we characterize how managers update both their first- and higherorder beliefs in the face of new information. This is done by providing random subsets of managers with different types of information at the end of the initial wave of the survey, after which we immediately present them with new questions about their expectations. We consider a number of different information treatments (as well as a control group that receives no information), including telling some firms what other firms expect about inflation (average first-order expectation), telling another set of firms about the average higher-order expectations of firms in the survey, and telling yet another set of firms about the most recent rate of inflation. A noisy-information model would imply that, if agents treated the measurement error in different signals as equal, they should adjust their expectations more strongly to information about the average forecast of other firms than to information about the average higher-order belief of other firms. This is because higher-order beliefs load more strongly on public than private signals, but it is the latter which a firm does not know about other firms. Our empirical evidence goes precisely in the opposite direction: there is a much stronger response of both the first-order and higher-order beliefs of firms to information about the higher-order beliefs of other firms than to information about their first-order beliefs. Explaining this through measurement error in the treatments would require measurement error to be almost

\footnotetext{
${ }^{3}$ The only exception is the degree of strategic complementarity in the model. This can be quantified using a separate set of questions in the survey, as in Afrouzi (2018).
} 
ten times larger for first-order beliefs than higher-order beliefs, an unlikely possibility.

Another challenge for noisy information models stems from how firms' decisions respond to changes in their inflation expectations. ${ }^{4}$ Using the follow-up wave, we can characterize how exogenously-generated changes in firms' inflation expectations (via information treatments) affect firms' economic decisions. Consistent with CGK, we find that firms with higher inflation expectations increased their employment and investment relative to the control group but not their prices or wages, regardless of which information treatment was the source of the change in inflation expectations. Thus, changes in inflation expectations have a causal effect on firms' decisions. But the way in which they respond is not through prices, which is the margin that noisy-information models typically focus on, but rather employment and investment.

While reconciling all of the differences between our empirical facts and noisy-information models with infinite regress is beyond the scope of the paper, we consider one departure from the baseline model which has been the topic of recent work. For example, Fahri and Werning (2017) show that limits to higherorder reasoning in the form of level- $k$ thinking can help resolve the "forward guidance" puzzle and GarciaSchmidt and Woodford (2015) use level- $k$ reasoning to show that monetary policy commitments to keep the nominal interest rate very low need not be deflationary. While infinite regress of higher-order expectations requires that agents solve a problem in which they iterate over how their actions affect others then how the actions of others affect them etc., models of level- $k$ thinking assume that this reasoning process is computationally expensive and difficult, leading agents to stop at some finite " $k$ " level of iteration. The experimental literature has documented in laboratory settings that agents generally display very limited “degrees of reasoning”, often stopping at 2 or 3 iterations of a problem (Nagel and Duffy 1997, Nagel 1995, Camerer, Ho, and Chong 2004, Stahl and Wilson 1995, Costa-Gomes and Crawford 2006).

We provide novel evidence on this dimension of higher-order thinking as well by asking respondents questions aimed to measure their degree of $k$-level thinking. Specifically, we follow the experimental literature and ask them to pick a number between 0 and 100, with the winning number being the one that is two-thirds of the average guess across all respondents. While some respondents answer seemingly random numbers, answers for respondents who spent more than 20 seconds answering the question line up squarely on traditional values assigned with different level $k$ (33 for $k=1,22$ for $k=2$, etc...) yielding clear metrics of the degree of level- $k$ thinking done by these respondents. The resulting distribution is much more heavily tilted toward higher levels of reasoning than is commonly found in the experimental literature, with over twenty-five percent of respondents displaying levels of thinking of $k=3$ or more, compared to $9 \%$ in Nagel (1995) and 13\% in Camerer et al. (2004).

Unlike the experimental literature, we also asked respondents to guess about the distribution of

\footnotetext{
${ }^{4}$ Armantier et al. (2015) provide some evidence of this type for households.
} 
other managers' answers (by assigning corresponding weights to ranges of possible answers). This novel question allows us to ascertain what each manager believes the mean answer to be (and whether they therefore pick a number that is two-thirds of that) and whether they think other managers are dispersed in their level of thinking. We document several departures from standard modeling approaches of level- $k$ thinking. First, most managers believe other managers will report an answer in the same range as theirs, so they are not picking a value equal to two-thirds of their expected mean. Second, managers generally believe that some of the other managers are higher-level thinkers than they are, whereas standard models assume that an agent acts as if all other players are lower-level thinkers relative to them. Third, managers dramatically underestimate the actual dispersion of answers, so they seem largely unaware of the actual distribution of level- $k$ thinking, even among their peers. Finally, we find no systematic relationship between an agent's degree of level- $k$ thinking and either how they revise their beliefs in light of new information or how changes in their information affect their actions. These facts present a challenge relative to the typical assumptions used when applying level- $k$ thinking to macroeconomic models.

Our results speak directly to a growing body of work in macroeconomics on the expectations formation of economic agents and implications thereof for macroeconomic dynamics. Angeletos and La'O (2009), for example, highlight the importance of considering higher-order beliefs separately from an agent's own beliefs. Bacchetta and Wincoop (2008) show that the difference between higher-order and own expectations is important for determining the pricing volatility of assets as well as the link between asset pricing and expectations of future asset payoffs. These findings are also informative for the design of policymakers' communication (e.g., Coibion et al. 2018).

The remainder of the paper is organized as follows. We first describe in section 2 how the survey was implemented. Section 3 presents the key empirical findings from the survey and information treatments. Section 4 considers how well a model of higher-order expectations under strategic complementarities in prices and infinite regress in expectations can account for the empirical patterns as well as how the data can be used to calibrate parameters of the model. Section 5 then presents additional empirical results focusing on cognitive constraints of agents as represented by $k$-level thinking as well as whether these constraints help explain features of the data. Section 6 concludes.

\section{Survey}

This paper utilizes two additional waves of the survey of firm managers in New Zealand described in CGK. The first wave was implemented between 2017Q4 and 2018Q1. The follow-up ran from 2018Q1 to 2018Q2, such that each firm manager from the first wave was invited to participate in the second wave three months after his or her initial interview. The first wave included 1,025 firms, with 515 of these participating in the second wave. 


\subsection{Sampling Frame and Protocol}

We obtained information on the population firms in New Zealand from two sources: Kompass New Zealand (KNZ) and Equifax (EQ). Following the Australia and New Zealand Standard Industrial Classification 2006 (ANZSIC06), firms are classified into one of four broad industries: manufacturing, trade, construction and transportation, and professional and financial services. Following CGK, we focus on firms with six or more employees. We targeted for two thirds of the sample to come from professional and financial services and manufacturing as these industries account for relatively large shares of New Zealand's GDP (New Zealand Treasury, 2016). ${ }^{5}$ The remainder of the sample comes from firms in other industries, i.e. trade, construction, communication and transportation. We excluded industries related to the government, community service, agriculture, fishing and mining, and energy, gas and water from the sample. These sectors are often dominated by a few extensively regulated firms or by very small firms. Within each industry, firms are classified as small (6-19 workers), medium (20-49 workers) and large (50 or more workers). To make the survey population more representative, we oversampled firms with 50-99 workers and 100+ workers in each industry. To this end, we contacted all firms that fall into these two employment size groups. We then computed the relative shares of firms in the remaining employment size groups and include enough firms to match the relative share of their size and industry.

To achieve the target of 1,000 firms in the sample, we invited 10,100 firms to participate in the survey. Each firm's general manager received an email containing an information sheet and survey questionnaire about ten days before receiving a phone call to collect responses. Note that the initial questionnaire sent to managers did not include the treatment information and the subsequent related questions. We called each firm three times to elicit responses. After the third round of calls, we examined the response rates for sectors, subsectors and employment size groups. We then targeted groups in which responses rates were low. We continued contacting firms until we hit the target sample size. Appendix C reports response rates by industry and size.

Responses were collected over the phone. A research assistant (RA) called the general manager and recorded answers by hand while also recording the phone call. An independent RA then listened to the recording and confirmed the accuracy of the handwritten responses. For the confidentiality of the participants, the recordings were deleted following data collection. The handwritten questionnaires were then entered into a spreadsheet, with two independent RAs verifying that the handwritten and spreadsheet responses matched. As discussed in CGK, responses of managers are consistent with information available

\footnotetext{
${ }^{5}$ New Zealand Treasury (2016), New Zealand: Economic and Financial Overview 2016, Wellington. See https://treasury.govt.nz/sites/default/files/2010-04/nzefo-16.pdf.
} 
from other sources and the quality of the survey is reasonably high. ${ }^{6}$ Descriptive statistics are provided in Appendix Table 1.

The second wave (follow-up) of the survey was implemented three months after the initial wave. For the follow-up, we contacted all firms that participated in the main wave of the survey. The response rate was approximately 50 percent. We achieved a high response rate because we provided respondents with a monetary incentive of $\$ 50$ gift voucher and dinner and entertainment ticket worth $\$ 50$. Further, respondents enter into a pool draw to win a cash prize of $\$ 5,000$. The main reason for non-participation was that the general manager was too busy to respond in a reasonable time frame. Appendix Table 2 examines whether participation in the second wave is correlated with firm/manager characteristics. We find that firms non-participating in the second round are missing at random.

\subsection{Survey instrument}

After collecting basic demographic information about firms, the survey asks respondents to report their beliefs about future aggregate variables (inflation, unemployment rate, and wages) and about firm-specific outcomes (employment, fixed assets, prices, and wages). The horizon for aggregate variables is one-year ahead. The horizon for firm-specific variables is three-month ahead (which was determined by the timing of the follow-up) and six-month ahead. Firms were also asked to report their perceptions and nowcasts (e.g., their perception of inflation over the previous twelve months). The survey asks a few hypothetical questions to provide us with estimates of parameters that would be difficult to identify otherwise.

Consistent with recommendations in Coibion et al. (2018), expectations were elicited in two ways. First, firms were asked to assign probabilities for possible outcomes (see Appendix Table 3 for specific formulation of questions). These distributional questions are similar to the questions asked in the Survey of Consumer Expectations (SCE) run by the Federal Reserve Bank of New York. Second, firms were asked

\footnotetext{
${ }^{6}$ We verified our survey data against the publicly available online information in four ways. First, we verified managers' responses about the age of the firm using the information from the Companies Office or their website. We find that the reported age in the survey match exactly with the information available in the Companies Office or their website for 1012 firms. Information about age of 20 firms is not available in any other source. Second, we verified whether the firm exports or not. Firms that indicated in the survey that they export overseas, this information is available in their websites. Third, we asked in the survey about the number of Directors, number of shareholders and the number of shares issued in the business. There are 862 firms classified as Companies in this survey, i.e. public or private companies. We find that more than 98 percent of these firms' responses match with the information available in the Companies Office. Last, we verified survey responses on firms' products and prices. To do this, we randomly selected around 20 percent of the firms (206 firms) and asked them about their main product and price of the main product. For 203 firms, details about their main products are available in their websites. 43 out of 203 firms list their prices online in their websites. The reported prices of main products do not match the online information for only 4 firms; this is equivalent to 1 percent. For firms whose prices are not listed online, we made phone enquiries about the price of their main products. These were general customer enquiries about their prices. To this end, we made 163 phone enquiries and 94 percent of the firms' reported price matched with the quotes provided.
} 
to provide point predictions for future inflation and other variables. We do not restrict responses for this type of questions in any way (e.g., we do not censor responses or prompt respondents to reconsider if responses are outside some range). In contrast to previous surveys, we collect information not only about managers' own expectations about future inflation but also about what managers think about other managers' inflation expectations.

The survey has two additional novel parts. First, after the core part of the survey is complete, respondents are invited to participate in a strategic game to infer their level of thinking. This game is similar to Nagel (1995) and we provide more details in section 5.1. Second, after the game, firms are randomly assigned into control and treatment groups. Firms in treatment groups are provided with different pieces of information, while firms in the control group are told nothing. The treatments are described in section 3.2, but some include information about the higher-order expectations of other firms. We use these treatments to study how firms form their expectations and how they use these expectations to set prices, wages, employment, and fixed assets.

\section{Survey Results}

In this section, we describe results of the survey. We first focus on unconditional moments of firms' firstorder and higher-order inflation expectations. Second, we present novel experimental findings on how managers respond to different types of information, including information about higher-order beliefs, and how each type of information affects their economic decisions.

\subsection{Unconditional Moments of Higher-Order Expectations}

To gauge firms' expectations of inflation as well as their expectations of what other managers expect about inflation, we rely primarily on probability distribution questions. Firms were first asked to assign probabilities to a wide range of different possible outcomes for overall price changes over the next 12 months, following CGK. From the probabilities that they assign, we construct implied forecasts of each manager using mid-point values of each bin. We also measure the uncertainty in their forecast (standard deviation of probabilities across bins). To measure their higher-order expectations, firms were asked an equivalent distributional question (Appendix Table 3) with respect to what they believe "other managers (drawn from all sectors of the New Zealand economy in a representative way) think will happen to overall prices in the economy." Using this question, we construct the implied forecast and uncertainty of each manager for their higher-order expectation. To the best of our knowledge, this is the first time anyone has surveyed firm managers about their higher-order expectations of macroeconomic variables.

Summary results are presented in Table 1 . In terms of inflation expectations, the results closely follow CGK. The average forecast of inflation across managers is $3.4 \%$, significantly above actual inflation 
at the time. Managers are quite uncertain about their forecasts, with an average standard deviation in their forecasts of 1.1 percentage point. They also display significant disagreement: the cross-sectional standard deviation in forecasts is $3 \%$. These results are also similar to the moments of households' inflation expectations in the SCE (Kumar et al. 2015).

More novel are the results for the higher-order inflation expectations of managers. First, we find that the mean higher-order inflation expectation is almost identical to the mean first-order inflation expectation (3.5\% vs 3.4\%), and we cannot reject the null of equality for the two. At the individual level, there is a strong positive correlation (0.68) between a manager's inflation forecast and their higher-order expectation. This is illustrated graphically in Figure 1. Managers who expect higher inflation also tend to believe that other managers expect higher inflation as well. The slope coefficient between the two is strongly positive at 0.66 and statistically significant at all standard levels. As we document in subsequent sections, a strongly positive correlation between first- and higher-order expectations is consistent with simple noisy-information models.

Table 1 reveals two other striking facts about higher-order inflation beliefs of managers in New Zealand. First, we find significantly lower cross-sectional disagreement about higher-order beliefs than we do for first-order beliefs: the cross-sectional standard deviation of higher-order beliefs is $2.4 \%$, well below the $3.1 \%$ found for first-order beliefs. We can strongly reject the null of equality for these two values. Second, we find that managers are generally less uncertain about their higher-order inflation forecasts than they are about their first-order forecasts: the average uncertainty in higher-order forecasts is $0.9 \%$ whereas it is $1.1 \%$ for first-order forecasts. We can again strongly reject the null of equality for these two levels of uncertainty. As discussed in subsequent sections, both of these results are also consistent with simple models of noisy information.

\subsection{Effect of Information Treatments on Expectations}

During the initial survey following questions asking firms about their inflation expectations and higherorder expectations, we performed the following experiment. We divided managers into five groups. Group A is a control group and did not receive any information. Group B received information about the average beliefs of survey participants about inflation. Group $\mathrm{C}$ received information about the average higher-order inflation expectations of survey participants. Group D's signal consisted of both information about average expectations and average higher-order expectations. We utilize Group E to compare the impact of information about other managers' beliefs to information about lagged inflation, as in CGK.

Immediately after providing firms with information, ${ }^{7}$ we asked them to report their point predictions for inflation (one-year ahead) and for their beliefs about what other managers predict for

\footnotetext{
${ }^{7}$ For the control group we simply continue with the questions.
} 
inflation (one-year head). Measuring revisions in expectations immediately after the treatment allows us to obtain the instantaneous effect of the treatment on firms' beliefs. Note that priors are measured as mean expected inflation implied by the reported distribution of future inflation while the posteriors are measured as point predictions. In the follow-up wave (three months after the initial wave), we asked firms to report distributions of their beliefs about future inflation. Using responses from the follow-up survey, we construct another measure of posteriors as the mean expected inflation implied by the reported distribution. This set of posteriors provides a sense of the persistence of the treatment effects of information on expectations.

To assess the influence of various information treatments on managers' beliefs, we use the following econometric specification:

$$
\text { Posterior }_{i}=\text { constant }+b \times \text { Prior }_{i}+\text { erro }_{i}
$$

where slope $b$ captures the strength of the prior relative to the treatment, and the value associated with the treatment is absorbed into the constant term (since it is common across firms within that group). More informative priors should be associated with high values of $b$. If the estimated slope $\hat{b}$ is equal to zero, the treatment is treated as a completely informative signal which causes managers to discard their priors in favor of the signal. If $0<\hat{b}<1$, the treatment is treated as a partially informative signal and managers will update their posterior somewhat, but will still rely partially on the prior. If $\hat{b}$ is approximately one, managers see the information provided as uninformative and do not update their prior beliefs at all. Note that because we use point predictions for posteriors and implied means for priors, the estimated slope may be biased up or down depending on how well firms respond to probability distribution questions (see e.g. Kleinjans and van Soest 2010, Fischhoff and Bruine de Bruin 1999, Bruine de Bruin et al. 2000). We can capture these effects by examining "revisions" in the control group. Because we are interested in how managers respond not only to new information but also to different kinds of information, we estimate specification (1) for each treatment separately.

Table 2 reports the estimated coefficients on the prior expectation for both own inflation expectations and higher-order inflation expectations in specification (1). We find that when no information is provided, the point estimate of the slope is approximately 0.7 (row 1). This estimate does not mean that firms revise their beliefs in the absence of information treatment by large amounts. Instead, this estimate likely highlights differences between expectations elicited as point predictions and expectations elicited as probability distributions. Indeed, when we use point predictions for future inflation that were elicited before the informational treatment was provided, we find that the slope is close to one for the control group (Appendix Table 4).

With this benchmark in mind, we turn to Treatment B (provide firms with $\bar{E}[\pi]$, row 2 in Table 2). When we elicit expectations immediately after the treatment, firms assign 0.50 weight on the prior when they update their first-order inflation expectations (column 1) and 0.43 weight when they update their high- 
order inflation expectations (column 2). ${ }^{8}$ These weights are statistically different from the weights assigned by the control group. If we normalize these weights by the weights in the control group, the adjusted weights are approximately 0.7 and 0.6 for first-order and high-order beliefs respectively. Thus, Treatment B has useful information content that leads firms for revise their beliefs.

For firms in treatment group C (provide firms with $\bar{E}^{2}[\pi]$, row 3 in Table 2), the estimated weights on priors are considerably smaller: 0.09 and 0.12 for low- and high-order beliefs. These estimates suggest that firms perceive the information about firms' higher-order expectations as a very informative signal that leads them to place little weight on their prior beliefs. The weights on the prior are similar in Treatment D (provide firms with $\bar{E}^{2}[\pi]$ and $\bar{E}[\pi]$, row 4 in Table 2 ). We interpret this result as indicating that information in $\bar{E}[\pi]$ has relatively little incremental content relative to information in $\bar{E}^{2}[\pi]$.

For firms receiving information about the past realization of inflation (Treatment E, row 5 in Table 2), the weight on the prior is 0.059 for low-order expectations and 0.062 for high-order expectations. This confirms an earlier result in CGK. Strikingly, firms seem to view information about other firms' higherorder beliefs as being almost as informative as information about recent inflation.

Conducting the same analysis using the posterior belief reported in the follow-up wave (three months after the treatment) produces similar results (see columns (4) and (5) of Table 2). We see mean reversion in the reported responses of the control group. Treatments C, D and E result in low weights on priors while Treatment B yields weights approximately half-way between the control group and the other treatment groups. These results indicate that the effect of information is persistent after three months and that the size of treatment effects continue to depend on the type of signal that the firm received. ${ }^{9}$

\subsection{Effect of Information on Actions}

CGK and Coibion, Gorodnichenko and Ropele (2018) document that information treatments lead not only to revisions of inflation expectations but also to changes in firms' behavior. Treatments in these earlier studies provide firms with information about the inflation target of the central bank, professional forecasts, or past inflation. Little is known about how firms react to treatments that involve information about highorder beliefs. While the previous section finds that revisions of beliefs are similar for low- and high-order inflation expectations, a priori one may observe considerable heterogeneity in employment/investment/etc. responses across these information treatments. Indeed, it is critical to establish that firms act upon their self-

\footnotetext{
${ }^{8}$ Appendix Figures 1 through 4 shows scatter plots of posteriors against priors.

${ }^{9}$ CGK and Cavallo et al. (2017) find that the difference in beliefs for treatment and control groups largely disappears six months after the treatment. We reconcile these results by using the findings in Coibion, Gorodnichenko and Ropele (2018) who study a long panel of firms to document that informational treatments have significant effects on expectations after three months but vanish after six months.
} 
reported expectations because the formation of expectations is relevant to policymakers only if expectations influence the choices of firms (prices, employment, investment).

To estimate the effect of changes in inflation expectations on the choices of firms, our approach follows CGK. Specifically, before firms were treated in the first wave, they were asked about their threemonth-ahead plans for future employment, investment, wages, and prices. Three months after the initial wave, we surveyed firms again and asked them to report changes in these four variables over the preceding three months. Using this information, we compute forecast error for each variable. The key advantage of using forecast errors is that they effectively difference out firm-fixed effects and thus reduce the size of idiosyncratic variation in the data.

In the next step, we regress forecast errors on changes in inflation expectations:

$$
F E_{i}(X)=\text { constant }+b \times\left(E_{i}^{\text {posterior }}(\pi)-E_{i}^{\text {prior }}(\pi)\right)+\text { error }_{i}
$$

where $F E_{i}(X)$ is the forecast error for variable $X, E_{i}^{\text {prior }}(\pi)$ is the pre-treatment expected inflation, $E_{i}^{\text {posterior }}(\pi)$ is the post-treatment expected inflation. For $E_{i}^{\text {posterior }}(\pi)$, we use beliefs of firms measured immediately after the treatment. The revision in expectations following an information treatment $\left(E_{i}^{\text {posterior }}(\pi)-E_{i}^{\text {prior }}(\pi)\right)$ should be proportional to the difference between the signal and the expected value of the signal, that is, the surprise induced by a treatment (see section 4.3 for a formal derivation). Because we know pre-treatment values of $E_{i}(\pi), E_{i}(\bar{E}(\pi))$ and $E_{i}\left(\pi_{t-1}\right)$, we calculate the surprise and use it as an instrument for $\left(E_{i}^{\text {posterior }}(\pi)-E_{i}^{\text {prior }}(\pi)\right)$. Note that for the control group the surprise is zero because firms in this group are not provided with any information. For Group D, which receives both the first- and higher-order expectations, we construct the average surprise in expectations. When we estimate specification (2), we do it on data combining the control group and a given treatment group.

Table 3 reports estimates of $b$ for various treatments using the revisions in first-order inflation expectations on the right-hand side of equation (2). While treatments vary in their ability to move inflation expectations, the results in Table 3 suggest that conditional on moving inflation expectations a given amount, the reaction of firms to a given change in expectations is largely similar across treatments. Consistent with CGK, we find that raising inflation expectations by one percentage point generates an approximately 0.4 percentage point increase in employment (column 1), an approximately 0.2 percentage point increase in fixed assets (column 2), and no effect on firms' prices (column 3) or wages (column 4) over the three months following the treatment. ${ }^{10}$ The IV estimates of the effects are approximately double

\footnotetext{
10 The survey also collects information about 6-month-ahead plans for firm-specific outcomes in the initial survey and 3-month-ahead plans for the same outcomes in the follow-up survey. This design allows us to also study the response of revisions in plans to information treatments (that is, the outcome variable in specification (2) is 3-month-ahead plan in the follow-up wave minus the 6-month-ahead plan in the initial wave). We find that while information treatments
} 
the OLS estimates (Appendix Table 6). We also find similar results when we replace first-order inflation expectations as the regressor in equation (2) with higher-order inflation expectations (Appendix Table 7).

Note that these causal estimates measure the "total" effects of the information treatment, that is, the combined influence of a treatment on both first- and higher-order inflation expectations. Since Treatments B, C, and E have only one signal, we cannot separately identify the contribution of first- and higher-order beliefs on firms' actions. Treatment D contains two signals (two instruments) and thus offers us an opportunity to run a horserace regression with first- and higher-order expectations included in specification (2). We find (Table 4) that none of the expectations systematically dominates the other and, more generally, few estimates are statistically significantly different from zero. These inconclusive results likely reflect the strong correlation in revisions of first- and higher-order expectations, which limits our ability to identify the independent effects of various orders of expectations.

\subsection{Summary}

Using a novel survey of the higher-order expectations of firm managers in New Zealand, we document several stylized facts. First, the mean higher-order inflation expectations of managers are very close to the mean first-order inflation expectations, and the two are highly correlated at the individual level. Second, higher-order inflation expectations are less dispersed across agents and are associated with less uncertainty on average than first-order inflation expectations. Third, when provided with information about the higherorder inflation expectations of other firms, managers change both their first- and higher-order inflation expectations by much more than they do when presented with information about the first-order inflation expectations of other firms. Finally, the responses of firms' actions to different information treatments are broadly similar regardless of the source of the information treatment, after conditioning on the magnitude of the change in inflation expectations associated with each treatment. In the next section, we consider to what extent these facts are consistent with simple noisy-information models as well as how these stylized facts can potentially be used to shed new light on underlying parameters of these models.

\section{Interpreting Survey Results through a Noisy-Information Model}

Our results demonstrate that not only can one measure the higher-order expectations of economic agents but also that these can play an important role in shaping beliefs. This is illustrated for example by the large revisions in firms' first-order inflation expectations when presented with information about other firms' higher-order expectations. How should we think about these results on the higher-order beliefs of firms? Strategic complementarities in pricing behavior require that firms think not only of their own expectations of

tend to increase planned investment, these treatments have no statistically significant effect on plans for employment, prices, and wages (see Appendix Table 5). 
a fundamental, but also of other firms' expectations and actions. Firm A must think about the fundamental and what Firm B thinks of the fundamental. Firm B then anticipates the fundamental, what firm A thinks of the fundamental, and what Firm A thinks that Firm B thinks. Firm A's expectations must respond accordingly, etc. As firms anticipate each other's actions, they must form higher-order beliefs that involve iterating a problem to progressively higher levels of reasoning. A similar logic applies to households when they consider how changes in their consumption affects other households' incomes, which in turn affect those households' consumption and therefore the initial households' income. Angeletos and Lian (2017) focus on a similar logic with intertemporal effects. In this section, we use the static model of Morris and Shin (2002) to demonstrate how the expectations and higher-order expectations of the firms in our survey compare to the predictions of a model of strategic complementarities where firms perform infinite regress in their expectations.

\subsection{A Simple Model of Expectations Formation and Price-Setting}

Firm $i \in[0,1]$ chooses to set its optimal price, $p_{i}$, as a linear combination of its expectations of a fundamental, $m$, and its expectation of the aggregate price level in the economy, $\bar{p}$ :

$$
p_{i}=(1-\alpha) E_{i}[m]+\alpha E_{i}[\bar{p}]
$$

Parameter $\alpha \in(0,1)$ describes the degree of complementarity in pricing. Because $\bar{p} \equiv \int_{0}^{1} p_{j} d j$, manager $i$ can iterate the optimal price equation forward by substituting the average optimal price equation for the aggregate price level to obtain:

$$
p_{i}=(1-\alpha) E_{i}[m]+\alpha E_{i}\left[\int p_{j} d j\right]
$$

Define the average expectation in the economy for variable $m$ as $\bar{E}[m] \equiv\left[\int_{0}^{1} E_{j}(m) d j\right]$ and let $E_{i}[\bar{E}[m]]$ be the expectation of manager $i$ about the average expectation in the economy. In a similar spirit, $E_{i}[\bar{p}]$ is the first-order ("own") expectation about the price level, $E_{i}[\bar{E}[\bar{p}]]$ is a higher-order expectation about the price level in the sense that this is an expectation of manager $i$ about what other managers think about the price level. We can iterate these expectations to $k^{\text {th }}$ higher orders recursively: $\bar{E}^{k}[X] \equiv$ $\left[\int_{0}^{1} E_{j}\left(\bar{E}^{k-1}[X]\right) d j\right]$.

Using the definition of the price level and repeated substitutions in equation (3'), we find that the aggregate price level becomes an average of progressively higher-order expectations of the fundamental, weighted by the complementarities present at each step:

$$
\bar{p}=(1-\alpha) \bar{E}[m]+\alpha(1-\alpha) \bar{E}^{2}[m]+\alpha^{2}(1-\alpha) \bar{E}^{3}[m]+\cdots .
$$

It follows that the optimal choice of $p_{i}$ depends on the manager's expectation of each event in equation (4).

$$
p_{i}=(1-\alpha) E_{i}[m]+\alpha(1-\alpha) E_{i}[\bar{E}[m]]+\alpha^{2}(1-\alpha) E_{i}\left[\bar{E}^{2}[m]\right]+\cdots
$$


Firms operate under imperfect information. This means that, rather than observing $m$ completely, they see noisy public and private signals that include the true value of $m$ and some noise. ${ }^{11}$ Specifically, allow a public signal about the fundamental to take the following form: $y=m+\varepsilon$ where $\varepsilon \sim N\left(0, \kappa_{y}^{-1}\right)$. Firm $i$ also receives a private signal about $m: x_{i}=m+v_{i}$ with $v_{i} \sim N\left(0, \kappa_{x}^{-1}\right)$ where $\varepsilon$ and $v_{i}$ are uncorrelated. Firms weigh their signals according to the relative noise in each to obtain an individual expectation of $m$ :

$$
E_{i}[m]=\frac{\kappa_{y}}{\kappa} y+\frac{\kappa_{x}}{\kappa} x_{i}=(1-\delta) y+\delta x_{i},
$$

where $\kappa=\kappa_{x}+\kappa_{y}$ and, for ease of notation, we denote $\frac{\kappa_{x}}{\kappa}$ and $\frac{\kappa_{y}}{\kappa}$ as $\delta$ and $1-\delta$, respectively, for the remainder of the paper. Aggregating equation (6) across managers gives the average expectation about the fundamental in the economy:

$$
\bar{E}[m]=(1-\delta) y+\delta m \text {. }
$$

Manager $i$ 's expectation about the average expectation of other managers in the economy is

$$
E_{i}[\bar{E}[m]]=(1-\delta) y+\delta E_{i}[m]=\left(1-\delta^{2}\right) y+\delta^{2} x_{i}
$$

One can obtain progressively higher-order expectations of $m$ by continuing to substitute $E_{i}[m]$ for $m$ to find:

$$
E_{i}\left[\bar{E}^{k}[m]\right]=\left(1-\delta^{k-1}\right) y+\delta^{k-1} E_{i}\left[\bar{E}^{k-1}[m]\right]=\left(1-\delta^{k}\right) y+\delta^{k} x_{i} .
$$

Equation (9) shows that higher-orders of reasoning will depend more heavily on the public signal as they rely more on average, rather than idiosyncratic, beliefs.

Using the firm's optimal price-setting in equation (5), we can substitute for manager $i$ 's expectations of $m$ at various orders to obtain the optimal price as a function of received signals:

$$
p_{i}=(1-\alpha) \sum_{k=0}^{\infty} \alpha^{k}\left[\left[1-\delta^{k+1}\right] y+\delta^{k+1} x_{i}\right] .
$$

It follows that every agent sets the optimal price at:

$$
p_{i}=\phi_{y} y+\phi_{x} x_{i}
$$

where $\phi_{y}=\frac{1-\delta}{(1-\alpha) \delta+(1-\delta)}$ and $\phi_{x}=\frac{(1-\alpha) \delta}{(1-\alpha) \delta+(1-\delta)}$. The realization of the aggregate price is the integral of equation (11) across the support of all managers:

$$
\bar{p} \equiv \int_{0}^{1} p_{j} d j=\phi_{y} y+\phi_{x} m .
$$

Using these results, we can derive expectations of manager $i$ about the price level:

\footnotetext{
${ }^{11}$ We treat $m$ as a fixed parameter. An alternative formulation is to assume that $m \sim N\left(m^{*}, \kappa_{0}^{-1}\right)$ where $\kappa_{0}$ may be interpreted as the precision of a common prior. With this formulation, we cannot distinguish $\kappa_{0}$ and $\kappa_{y}$ (precision of the public signal $y$ ) with our data because we observe only $\kappa_{0}+\kappa_{y}$. Therefore, if one believes that $m$ is stochastic, he should interpret our results as providing an estimate of $\kappa_{0}+\kappa_{y}$, that is, the combined precision of the public signal and the common prior.
} 


$$
E_{i}[\bar{p}]=\phi_{y} y+\phi_{x}\left((1-\delta) y+\delta x_{i}\right)=\left(1-\phi_{x} \delta\right) y+\phi_{x} \delta x_{i}
$$

Aggregating across agents gives the average expectation about the price level:

$$
\bar{E}[\bar{p}]=\phi_{y} y+\phi_{x}((1-\delta) y+\delta m)=\left(1-\phi_{x} \delta\right) y+\phi_{x} \delta m
$$

The individual expectation of the left-hand side in equation (14) is an individual manager's higher-order expectation:

$$
E_{i}[\bar{E}[\bar{p}]]=\phi_{y} y+\phi_{x}\left[\left(1-\delta^{2}\right) y+\delta^{2} x_{i}\right]=\left(1-\phi_{x} \delta^{2}\right) y+\phi_{x} \delta^{2} x_{i} .
$$

Aggregating equation (15) gives the mean of the higher-order expectation:

$$
\bar{E}^{2}[\bar{p}]=\phi_{y} y+\phi_{x}\left[\left(1-\delta^{2}\right) y+\delta^{2} m\right]=\left(1-\phi_{x} \delta^{2}\right) y+\phi_{x} \delta^{2} m
$$

These derivations demonstrate that firms in the noisy-information model have two sources of uncertainty: noise in the public signal and noise in the private signal. When firms make inferences about the fundamental $m$ or when we consider unconditional distributions of $\bar{p}$, both sources of uncertainty appear. However, for a given time period, firms observe $y$ and thus firms do not face uncertainty about what other firms observe. Indeed, equation (12) demonstrates that the price level is a function of public signal $y$ (observed) and fundamental $m$ (unobserved). Because for firm $i$ the expected value of $m$ is a linear combination of $y$ and private signal $x_{i}$, the only source of uncertainty about $\bar{p}$ is the realized private signals of other firms. As a result, uncertainty about $\bar{p}$ is described by distributions conditional on $y$. Specifically, one can show that the unconditional distribution of these expectations is

$$
\begin{aligned}
& E_{i}[\bar{p}] \sim N\left(m,\left(1-\phi_{x} \delta\right)^{2} \kappa_{y}^{-1}+\left(\phi_{x} \delta\right)^{2} \kappa_{x}^{-1}\right), \\
& \bar{E}[\bar{p}] \sim N\left(m,\left(1-\phi_{x} \delta\right)^{2} \kappa_{y}^{-1}\right), \\
& E_{i}[\bar{E}[\bar{p}]] \sim N\left(m,\left(1-\phi_{x} \delta^{2}\right)^{2} \kappa_{y}^{-1}+\left(\phi_{x} \delta^{2}\right)^{2} \kappa_{x}^{-1}\right), \\
& \bar{E}^{2}[\bar{p}] \sim N\left(m,\left(1-\phi_{x} \delta^{2}\right)^{2} \kappa_{y}^{-1}\right),
\end{aligned}
$$

while the distributions conditional on the public signal (that is, the distributions of beliefs about $\bar{p}$ in a given cross-section of managers for a point in time) are:

$$
\begin{aligned}
& E_{i}[\bar{p}] \mid y \sim N\left(\left[\phi_{y}+\phi_{x}(1-\delta)\right] y+\phi_{x} \delta m,\left(\phi_{x} \delta\right)^{2} \kappa_{x}^{-1}\right), \\
& \bar{E}[\bar{p}] \mid y \sim N\left(\left[\phi_{y}+\phi_{x}(1-\delta)\right] y+\phi_{x} \delta m, 0\right), \\
& E_{i}[\bar{E}[\bar{p}]] \mid y \sim N\left(\left[\phi_{y}+\phi_{x}\left(1-\delta^{2}\right)\right] y+\phi_{x} \delta^{2} m,\left(\phi_{x} \delta^{2}\right)^{2} \kappa_{x}^{-1}\right), \\
& \bar{E}^{2}[\bar{p}] \mid y \sim N\left(\left[\phi_{y}+\phi_{x}\left(1-\delta^{2}\right)\right] y+\phi_{x} \delta^{2} m, 0\right) .
\end{aligned}
$$

Note that in this canonical noisy-information model, uncertainty in first-order expectations $\left(\Omega_{\left\{E_{i}[\bar{p}] \mid y\right\}} \equiv\right.$ $\left(\phi_{x} \delta\right)^{2} \kappa_{x}^{-1}$ given by equation (18a)) is equal to the cross-sectional dispersion of point forecasts $\operatorname{Var}\left(E_{i}[\bar{p}] \mid y\right)$ and the same result applies to higher-order expectations: $\Omega_{\left\{E_{i}[\bar{E}[\bar{p}]] \mid y\right\}}=\operatorname{Var}\left(E_{i}[\bar{E}[\bar{p}]] \mid y\right)$. 


\subsection{Mapping the Model to Unconditional Moments of the Survey Data}

Our survey data on the higher-order inflation expectations of firms yielded four key facts: 1) the mean higher-order inflation expectation was almost identical to the mean first-order inflation expectation, 2) disagreement was lower for higher-order than lower order inflation expectations, 3) uncertainty was lower for higher-order than lower order inflation expectations, and 4) there is a strong positive correlation, with a slope less than one, between first-order and higher-order inflation expectations. We now consider whether a simple noisy-information model is consistent with these facts and how we can use the quantitative values from the survey to calibrate key parameters of the model.

\subsubsection{Means}

The model predicts that the mean of the distribution of firms' own expectations of the aggregate price level $\left(E_{i}[\bar{p}]\right)$ could be similar to that of the firms' higher-order expectation of the aggregate price level $\left(E_{i}[\bar{E}[\bar{p}]]\right)$, that is, their expectation of other managers' expectation. Specifically, equations (18a) and (18c) show that for a given realization of public signal $y$, higher-order expectations assign a larger weight to the public signal and a smaller weight to the private signal (recall that $\delta<1$ ). The difference between $E_{i}[\bar{p}]$ and $E_{i}[\bar{E}[\bar{p}]]$ depends on how far $y$ is from $m$. Indeed,

$$
\left(\bar{E}[\bar{p}]-\bar{E}^{2}[\bar{p}]\right) \mid y=\phi_{x}(1-\delta) \delta[m-y] .
$$

Thus, even without knowing $\phi_{x}$ and $\delta$, we can sign $[m-y]$ using the observed difference in average expectations for high and low orders.

Table 1 shows that, in our sample, $\bar{E}[\pi] \mid y$ is 3.41 and $\bar{E}^{2}[\pi] \mid y$ is 3.50 . The negative difference between these two measures is consistent with $y$ being greater than $m$ (that is, the public signal is more "inflationary" than the fundamental). Whether the difference is large or small depends on the magnitudes of $\phi_{x}$ and $\delta$, but since $\phi_{x}, \delta \in(0,1)$ we expect that $m-y<-0.09$. As we show later, $\delta \approx 0.8$ and $\phi_{x} \approx$ 0.55 so that $m-y \approx-1$. Incidentally, the survey responses were collected at a time when oil prices continued to rise possibly sending an "inflationary" public signal. ${ }^{12}$

\subsubsection{Disagreement}

Private signals are the reason why agents disagree about macroeconomic variables in the noisy-information model. Equations (18a) and (18c) predict that the cross-sectional variance of higher-order expectations

\footnotetext{
${ }^{12}$ Coibion and Gorodnichenko (2015) document that households' inflation expectations are sensitive to the price of oil, gasoline and similar goods. Kumar et al. (2015) and CGK present suggestive evidence of high sensitivity of managers' inflation expectations to changes in oil prices and other energy products frequently purchased by consumers.
} 
$\left(\phi_{x} \delta^{2}\right)^{2} \kappa_{x}^{-1}$ will be smaller than the variance of the managers' own expectations $\left(\phi_{x} \delta\right)^{2} \kappa_{x}^{-1}$. This happens as higher-order expectations become more weighted toward the common signal, which is observed by all agents. Note that the ratio of cross-sectional variances for $E_{i}[\bar{E}[\bar{p}]] \mid y$ and $E_{i}[\bar{p}] \mid y$ gives us

$$
\frac{\operatorname{Var}\left(E_{i}[\bar{E}[\bar{p}]] \mid y\right)}{\operatorname{Var}\left(E_{i}[\bar{p}] \mid y\right)}=\frac{\left(\phi_{x} \delta^{2}\right)^{2} \kappa_{x}^{-1}}{\left(\phi_{x} \delta\right)^{2} \kappa_{x}^{-1}}=\delta^{2}<1
$$

and, thus, the relative cross-sectional dispersions of higher-order vs first-order expectations can uniquely pin down $\delta$, which itself measures the relative importance of private and public signals (recall that $\delta \equiv \frac{\kappa_{x}}{\kappa_{x}+\kappa_{y}}$ ).

Consistent with the theoretical prediction of $\delta<1$, we documented in Table 1 that disagreement is larger for low-order inflation expectations (standard deviation is 3.06) than for high-order inflation expectations (standard deviation is 2.43). The ratio of these two standard deviations implies $\delta \approx 0.8$, that is, the precision of the private signal is about four times larger than the precision of the public signal.

Because $\operatorname{Var}\left(E_{i}[\bar{p}] \mid y\right)=\left(\phi_{x} \delta\right)^{2} \kappa_{x}^{-1}$, we can go even further and use the amount of disagreement in the data to precisely identify the levels of precision in each signal $\left(\kappa_{x}\right.$ and $\left.\kappa_{y}\right)$ if we know both $\delta$ and $\phi_{x}$.

As we derived above, $\phi_{x}=\frac{(1-\alpha) \delta}{(1-\alpha) \delta+(1-\delta)}$ and so we can estimate $\phi_{x}$ if we have an estimate of strategic complementarity $\alpha$ along with our estimate of $\delta$. While we cannot obtain $\alpha$ directly from moments of inflation expectations, we can recover this parameter from a series of hypothetical questions that were also included in the survey:

For the next three questions, suppose that neither you nor your competitors face any costs in changing your prices. Also suppose that you get news that the general level of prices went up by $10 \%$ in the economy:

a. By what percentage do you think your competitors would raise their prices on average?

b. By what percentage would your firm raise its price on average?

c. By what percentage would your firm raise its price if your competitors did not change their price at all in response to this news?

Afrouzi (2018) shows that $\alpha$ is the slope in the regression of \{the answer in "b" minus the answer in "c"\} on $\{$ the answer in "a" $\}$. When we implement this regression in our sample, we find $\hat{\alpha} \approx 0.7$ (standard error 0.02 ). It follows that $\phi_{x} \approx 0.55$, that is, firms put $55 \%$ weight on their private signals and $45 \%$ on the public signal when setting prices.

With this value of $\phi_{x}$, we can now pin down the precision of private and public signals. Because in the data disagreement is $\operatorname{Var}\left(E_{i}[\bar{p}] \mid y\right)=\left(\phi_{x} \delta\right)^{2} \kappa_{x}^{-1}=3.06^{2}$, it follows that $\kappa_{x} \approx 0.02$. Using $\delta \equiv$ $\frac{\kappa_{x}}{\kappa_{x}+\kappa_{y}}$, we find that $\kappa_{y}=0.005$. These estimates suggest that both signals could be rather imprecise. However, this imprecision is in agreement with the notion that firms should pay little attention to inflation if inflation is stable and low (e.g., Sims 2003, Mackowiak and Wiederholt 2009), which is the case in New Zealand, an early adopter of inflation targeting. Hence, the data on disagreement in both first- and higher- 
order expectations can, when combined with an independent estimate of strategic complementarity, pin down all of the relevant structural parameters in the model.

\subsubsection{Uncertainty}

We can alternatively use firms' uncertainty about aggregate variables to back out parameters of the model. First, note that, as with disagreement, the ratio of uncertainty in high-order expectations to uncertainty in low-order expectations also uniquely pins down $\delta$ since $\Omega_{\left\{E_{i}[\bar{E}[\bar{p}]] \mid y\right\}} / \Omega_{\left\{E_{i}[\bar{p}] \mid y\right\}}=\frac{\left(\phi_{x} \delta^{2}\right)^{2} \kappa_{x}^{-1}}{\left(\phi_{x} \delta\right)^{2} \kappa_{x}^{-1}}=\delta^{2}<1$.

Hence, having data on both uncertainty and disagreement over-identifies $\delta$. Strikingly, column (4) of Table 1 shows that the ratio of standard deviations implied by the reported distributions for own expectations of inflation (=1.11) and for expectations about other managers $(=0.89)$ is 0.8 , the same value as found using data on disagreement. Hence, despite using two different moments to pin down the same parameter, we find comparable values across the two approaches.

Second, the model predicts that the level of disagreement (cross-sectional standard deviation of point predictions) and the level of uncertainty (the average standard deviation implied by reported distributions for future inflation) should be the same and equal to $\left(\phi_{x} \delta\right)^{2} \kappa_{x}^{-1}$. Indeed, both are determined by the variance of the noise in the private signals. In the data, uncertainty is about a third of disagreement, so this restriction implied by the canonical model is at odds with the data. ${ }^{13}$ If we use uncertainty instead of disagreement to recover $\kappa_{x}$ and $\kappa_{y}, \operatorname{Var}\left(E_{i}[\bar{p}] \mid y\right)=\left(\phi_{x} \delta\right)^{2} \kappa_{x}^{-1}$. Because in the data uncertainty is $\operatorname{Var}\left(E_{i}[\bar{p}] \mid y\right)=1.11^{2}$, it follows that $\kappa_{x} \approx 0.15$ and $\kappa_{y} \approx 0.04$. While the levels are not identical to those implied by the level of disagreement, they still imply rather imprecise signals.

\subsubsection{Relationship between First-Order and Higher-Order Expectations}

Because the private signal $x_{i}$ is the only source of cross-sectional variation in expectations, our model predicts a perfect correlation between higher- and lower-order expectations. Given measurement errors in expectations data and other idiosyncratic variation in survey responses, a perfect correlation is unlikely to be borne out in the data. Indeed, we observe a high correlation $\operatorname{Corr}\left(E_{i}[\bar{p}], E_{i}[\bar{E}[\bar{p}]]\right) \approx 0.6$ in our sample, but this is still well below one. Perhaps a more interesting prediction is that variation in low-order

\footnotetext{
${ }^{13}$ One possible way to rationalize the difference in the levels of uncertainty and disagreement in the data is if agents in the model report beliefs as in Patton and Timmermann (2010). Specifically, suppose that the reported forecast is a weighted average of the signal-based forecast and the individual's belief about the long-run average: $\hat{E}_{i}[\bar{p}]=\omega \mu_{i}+$ $(1-\omega) E_{i}\left[\bar{p} \mid x_{i}, y\right]$ where $\mu_{i}$ is individual's belief about the long-run average, $\kappa^{2}$ is the variance (uncertainty) of this belief, and $\omega=\operatorname{Var}\left(E_{i}\left[\bar{p} \mid x_{i}, y\right]\right) /\left(\operatorname{Var}\left(E_{i}\left[\bar{p} \mid x_{i}, y\right]\right)+\kappa^{2}\right)$. Note that cross-sectional dispersion of long-run beliefs $\operatorname{Var}\left(\mu_{i}\right)$ is decoupled from the uncertainty in the belief $\kappa^{2}$. In this case, the cross-sectional variance of the mean predicted price level is $\omega^{2} \operatorname{Var}\left(\mu_{i}\right)+(1-\omega)^{2} \operatorname{Var}\left(E_{i}\left[\bar{p} \mid x_{i}, y\right]\right)$ while uncertainty is $\omega^{2} \kappa^{2}+(1-$ $\omega)^{2} \operatorname{Var}\left(E_{i}\left[\bar{p} \mid x_{i}, y\right]\right)$ which is smaller than disagreement if $\operatorname{Var}\left(\mu_{i}\right)>\kappa^{2}$.
} 
expectations $E_{i}[\bar{p}]$ should translate in less than one-to-one changes in high-order expectations $E_{i}[\bar{E}[\bar{p}]]$. Specifically, the model implies that regressing $E_{i}[\bar{E}[\bar{p}]]$ on $E_{i}[\bar{p}]$ should yield a slope coefficient equal to

$$
\beta=\frac{\operatorname{Cov}\left(E_{i}[\bar{p}], E_{i}[\bar{E}[\bar{p}]]\right)}{\operatorname{Var}\left(E_{i}[\bar{p}]\right)}=\frac{\phi_{x}^{2} \delta^{3} \kappa_{x}^{-1}}{\phi_{x}^{2} \delta^{2} \kappa_{x}^{-1}}=\delta<1 .
$$

Hence, a regression of first-order expectations on higher-order expectations provides a third way to pin down $\delta$. As shown in Figure 1, the estimated slope of the regression in our survey data is between 0 and 1 , consistent with the theory. But its value of 0.66 is significantly smaller than the value of 0.80 found using either disagreement or uncertainty moments. One interpretation is that this discrepancy could be due to measurement error in survey measures of expectations. If we treat the value of $\delta=0.80$ from disagreement and uncertainty moments as the true value, we can infer how much measurement error is needed to generate an estimated slope of 0.66. Assuming classical measurement error, we find an implied variance of the measurement error of $0.5 \%$, which seems reasonable given the nature of survey questions.

The joint distribution of first- and higher-order beliefs can also inform us about the level of the public signal $y$ and the fundamental $m$. Note that when $E_{i}[\bar{p}]=E_{i}[\bar{E}[\bar{p}]]$, equations (13) and (15) imply that $E_{i}[\bar{p}]=E_{i}[\bar{E}[\bar{p}]]=x_{i}=y$. Our regression estimates suggest that this point (that is, when the fitted regression line crosses the 45-dergee line in Figure 1) occurs at $E_{i}[\bar{p}]=E_{i}[\bar{E}[\bar{p}]]=3.6$ and therefore $y=$ 3.6. In section 4.2.1, we derive that $m-y \approx-1$ and so we can infer $m \approx 2.6$. In other words, the underlying inflation in New Zealand is approximately 2.6 percent during this period but firms systematically believe inflation is higher because of an inflationary public signal. Strikingly, the implied fundamental is close to actual inflation: CPI and PPI inflation rates in 2018Q1 were 2.2 and 2.7 percent respectively.

\subsection{Interpreting Treatment Effects in a Noisy-Information Model}

We now consider how to interpret the experimental evidence described in section 3 in terms of a model of noisy information. Equations (11) and (13) imply that manager $i$ 's own expectation about the price level is a linear combination of the public signal $y$ and their expectation about the fundamental $m$, that is, $E_{i}(m)$. When firms are provided with new private information, they revise their beliefs about $m$ and, correspondingly, about the price level. Specifically, a unit increase in $E_{i}(m)$ translates into $\phi_{x}$ unit increase in $E_{i}[\bar{p}]$ and $\phi_{x} \delta$ unit increase in $E_{i}[\bar{E}[\bar{p}]]$.

$$
E_{i}\left[\begin{array}{c}
\bar{p} \\
\bar{E}[\bar{p}]
\end{array}\right]=\left[\begin{array}{c}
\phi_{y} \\
\phi_{y}+\phi_{x}(1-\delta)
\end{array}\right] y+\left[\begin{array}{c}
\phi_{x} \\
\delta \phi_{x}
\end{array}\right] E_{i}[m] .
$$

We consider three types of signals provided to firms to be consistent with the experiment done in the survey. First, we provide firms with $\bar{E}[\bar{p}]$ (that is, the average of managers' own expectations about 
inflation), $\bar{E}^{2}[\bar{p}]$ (that is, the average expectation about other managers' expectation about inflation), and past inflation. Equations (18b) and (18d) indicate that if firms believe that this information has no noise, then they can infer from these signals the exact value of $m$. In this case, their beliefs would all converge to the same full information value. In the survey, it is clear that beliefs of different agents do not fully converge after the provision of these information treatments. One potential way to avoid this extreme prediction from the model is to assume that firms interpret received signals as having some noise. For example, the signal for $\bar{E}[\bar{p}]$ is given by

$$
s_{B}=\bar{E}[\bar{p}]+\xi_{B},
$$

where $\xi_{B} \sim N\left(0, \kappa_{B}^{-1}\right)$ and $\xi_{B}$ is uncorrelated with noise $\varepsilon$ and $v_{i} \cdot{ }^{14}$ Note that because $\bar{E}[\bar{p}]=\left(1-\phi_{x} \delta\right) y+$ $\phi_{x} \delta m$ and firms observe $y$ directly, signal $s_{B}$ has the same content as signal $\tilde{s}_{B}=\phi_{x} \delta m+\xi_{B}=H_{B} m+$ $\xi_{B}$ with $H_{B} \equiv \phi_{x} \delta$. Using Bayes rule, we can derive beliefs about $m$ after observing $\tilde{s}_{B}$

$$
E_{i}\left(m \mid \tilde{s}_{B}, x_{i}, y\right)=E_{i}\left(m \mid x_{i}, y\right)+P\left(\tilde{s}_{B}-\phi_{x} \delta E_{i}\left(m \mid x_{i}, y\right)\right),
$$

where $P_{B}=\delta \kappa^{-1} \phi_{x} \delta\left(\kappa_{B}^{-1}+\left(\phi_{x} \delta\right)^{2} \delta \kappa^{-1}\right)^{-1}$ is the gain of the Kalman filter and $\kappa$ is the precision of the prior $E_{i}\left(m \mid x_{i}, y\right)$. We can re-write this equation as:

$$
E_{i}^{\text {post }}(m)=\left(1-P_{B} H_{B}\right) E_{i}^{\text {pre }}(m)+P_{B} \tilde{S}_{B}=\frac{\kappa_{B}^{-1}}{\kappa_{B}^{-1}+\left(\phi_{x} \delta\right)^{2} \delta \kappa^{-1}} E_{i}^{p r e}(m)+P_{B} \tilde{s}_{B},
$$

where $E_{i}^{\text {post }}(m)$ denotes expectations after receiving the additional information while $E_{i}^{\text {pre }}(m)$ denotes expectations before receiving additional information. Importantly, the coefficient on the prior belief $E_{i}^{\text {pre }}(m)$ can identify $\kappa_{B}$, the precision of the signal $\tilde{s}_{B}$. This is because we can measure $\left(\phi_{x} \delta\right)^{2} \delta \kappa^{-1}$ directly as this is equal to the uncertainty of the prior belief (equation 18c). The uncertainty in the posterior beliefs $E_{i}^{\text {post }}(m)$ is given by $\delta \kappa^{-1} \frac{\kappa_{B}^{-1}}{\kappa_{B}^{-1}+\left(\phi_{x} \delta\right)^{2} \delta \kappa^{-1}}$. Hence, under the assumption that agents perceive the information treatment as a noisy signal, the coefficient on the prior beliefs should help us recover the perceived precision of that signal.

One can derive similar expressions for the signal about higher-order expectations:

$$
s_{C}=\bar{E}^{2}[\bar{p}]+\xi_{C}=\left(1-\phi_{x} \delta^{2}\right) y+\phi_{x} \delta^{2} m+\xi_{C}
$$

with $\xi_{C} \sim N\left(0, \kappa_{C}^{-1}\right)$ and an equivalent signal $\tilde{s}_{C}=\phi_{x} \delta^{2} m+\xi_{C}=H_{C} m+\xi_{C}$ with $H_{C} \equiv \phi_{x} \delta^{2}$ so that

$$
E_{i}^{\text {post }}(m)=\left(1-P_{C} H_{C}\right) E_{i}^{\text {pre }}(m)+P_{C} \tilde{s}_{C}=\frac{\kappa_{C}^{-1}}{\kappa_{C}^{-1}+\left(\phi_{x} \delta^{2}\right)^{2} \delta \kappa^{-1}} E_{i}^{\text {pre }}(m)+P_{C} \tilde{S}_{C}
$$

which has variance $\delta \kappa^{-1} \frac{\kappa_{C}^{-1}}{\kappa_{C}^{-1}+\left(\phi_{x} \delta^{2}\right)^{2} \delta \kappa^{-1}}$ and $P_{C}=\delta \kappa^{-1} \phi_{x} \delta^{2}\left(\kappa_{C}^{-1}+\left(\phi_{x} \delta^{2}\right)^{2} \delta \kappa^{-1}\right)^{-1}$ is the gain from the Kalman filter. Note that even if signals about first-order and higher-order expectations were perceived

\footnotetext{
${ }^{14}$ Although $s_{B}$ does not have index $i$ (we drop it to simplify notation), we interpret $s_{B}$ as a private signal because we do not tell a firm receiving this signal that other firms receive this signal too.
} 
as equally precise $\left(\kappa_{C}^{-1}=\kappa_{B}^{-1}\right)$, we would have $P_{B}>P_{C}$, that is, signal $s_{B}$ receives a higher weight than signal $s_{C}$ when firms update their beliefs. Intuitively, as we increase the order of expectations in the signal, the signal contains less information about the unobserved $m$ and gets less attention from managers. This result implies that, under equally precise signals, we would expect to observe a stronger response of both first-order and higher-order beliefs to information about the average first-order belief than about the information about the average higher-order belief. Given that we observe the opposite empirically in section 3 , this suggests that signals about higher-order beliefs must be interpreted by agents as being significantly more precise than signals about first-order beliefs.

If both signals are provided and the noise in the signals is uncorrelated, then

$$
E_{i}^{\text {post }}(m)=\left(1-P_{D} H_{D}\right) E_{i}^{\text {pre }}(m)+P_{D} \tilde{S}_{D},
$$

where $H_{D}=\left[\begin{array}{ll}\phi_{x} \delta & \phi_{x} \delta^{2}\end{array}\right]^{\prime}, R_{D}=\operatorname{diag}\left\{\kappa_{B}^{-1}, \kappa_{C}^{-1}\right\}$, and $P_{D}=\delta \kappa^{-1} H_{D}^{\prime}\left(R_{D}+\delta \kappa^{-1} H_{D} H_{D}^{\prime}\right)^{-1}$. When two signals are provided, the variance of $E_{i}^{\text {post }}(m)$ is smaller than in the case when only one signal is provided.

Finally, we assume that providing firms with past inflation is equivalent to giving them signal $s_{E}=$ $\phi_{m} m+\xi_{E}=H_{E} m+\xi_{E}$ where $\xi_{E} \sim N\left(0, \kappa_{E}^{-1}\right), H_{E}=m$, and $\phi_{m}$ measures the persistence of fundamental $m$ from one period to another. In this case,

$$
E_{i}^{\text {post }}(m)=\left(1-P_{E} H_{E}\right) E_{i}^{\text {pre }}(m)+P_{E} \tilde{s}_{E}=\frac{\kappa_{E}^{-1}}{\kappa_{E}^{-1}+\left(\phi_{m}\right)^{2} \delta \kappa^{-1}} E_{i}^{p r e}(m)+P_{E} \tilde{s}_{E} .
$$

Note that this signal provides information about the fundamental directly so that, conditional on the prior, the revision of beliefs in response to this signal does not depend on the strategic behavior of firms.

Equations (25), (27), (28) and (29) can be generalized to a generic signal $\tilde{s}$ :

$$
E_{i}^{\text {Post }}[m]=(1-P H) E_{i}^{\text {Pre }}[m]+P \tilde{s}
$$

which we can estimate by regressing post-treatment expectations on pre-treatment expectations and a constant. Combining equations (22) and (30), one can show that the response of expectations of $\bar{p}$ and $\bar{E}[\bar{p}]$ to information is given by

$$
E_{i}^{\text {Post }}\left[\begin{array}{c}
\bar{p} \\
\bar{E}[\bar{p}]
\end{array}\right]=P H\left[\begin{array}{c}
\phi_{y} \\
\phi_{y}+\phi_{x}(1-\delta)
\end{array}\right] y+(1-P H) E_{i}^{\text {Pre }}\left[\begin{array}{c}
\bar{p} \\
\bar{E}[\bar{p}]
\end{array}\right]+\left[\begin{array}{c}
\phi_{x} \\
\delta \phi_{x}
\end{array}\right] P \tilde{s} .
$$

Note that weight on the prior $(1-P H)$ is the same for low- and high-order expectations about the price level. Equation (31) implies that, for a given signal, agents should update their first-order and second-order beliefs about inflation by the same amount. This is remarkably consistent with what we observe in Table 2 , where we cannot reject the null of equality for responses of first-order and higher-order beliefs to each type of information treatment.

With these results in mind, we revisit the quantitative response of expectations to our information treatments reported in Table 2. When firms were provided with information about the mean forecast of other firms (Treatment B), they assigned a 0.50 weight on the prior when they updated their first-order 
inflation expectations (column 1) and 0.43 weight when they updated their high-order inflation expectations (column 2). If we normalize these weights by the weights in the control group, the adjusted weights are approximately 0.7 and 0.6 for first-order and high-order beliefs respectively. Using equation (25) to compute the precision of information provided in Treatment $\mathrm{B}$ and $b_{B}=1-P_{B} H_{B}\left(b_{B}\right.$ is the estimate slope in the regression of post-treatment expectations on pre-treatment expectations), we find: $\kappa_{B}=\frac{1-b_{B}}{b_{B}} \kappa=$ $\frac{b_{B}}{1-b_{B}} \times \frac{1}{\operatorname{Var}\left(E_{i}[\bar{p}] \mid y\right)} \approx \frac{0.5}{1-0.5} \times \frac{1}{3.06^{2}} \approx 0.1$, that is, the signal is approximately as strong as the precision of pre-treatment beliefs (given by $\kappa_{x}+\kappa_{y}$ ).

We can then do the same analysis for other treatment groups. For group C (treatment with higherorder expectations of other firms), the estimated weights on priors are considerably smaller: 0.09 and 0.12 for low- and high-order beliefs. These estimates suggest that firms would need to perceive a much higher precision of the signal in Treatment $C$ than the precision of the signal in Treatment $B: \kappa_{C}=\frac{1-b_{C}}{b_{C}} \kappa \approx 9 \kappa$. The weights on the prior are similar in Treatment D. Finally, for firms receiving information about the past realization of inflation, the weight on the prior is 0.059 for low-order expectations and 0.062 for high-order expectations. Thus, the precision of the signal about past inflation is $\kappa_{E}=\frac{1-b_{E}}{b_{E}} \kappa \approx 15 \kappa$, which is qualitatively similar to the precision of the signal about $\bar{E}^{2}[\pi]$. Explaining why firms adjust their expectations so much more to information about past inflation or higher-order beliefs than first-order beliefs therefore requires very large differences in implied signal precisions across these treatments.

\subsection{Summary}

We use a simple model of noisy information with infinite regress of expectations to interpret the data on higher-order expectations from the survey. We show that the moments from the survey can be used to recover the realized shocks and the underlying parameters of the model, a feature which should be useful to discipline these models in the future. Furthermore, the model makes over-identifying restrictions on parameters in the sense that different moments can be used to identify the same parameters. Strikingly, we find that these different moments are generally consistent with one another in terms of the parameter values they imply. The model can also rationalize the fact that agents update both their first-order and higher-order expectations by similar amounts in response to an information treatment.

However, we also document several limitations of the canonical noisy-information model with infinite regress in terms of its ability to rationalize the data. First, while first- and higher-order expectations are highly correlated across firms in the data, there is significant heterogeneity that the canonical model cannot easily explain. Second, the model predicts that the level of uncertainty and cross-sectional dispersion of expectations should be the same, a feature we can strongly reject in the data. Third, if we view the 
information treatments as being noisy signals, it is difficult to rationalize the difference in response across types of treatments. This interpretation of the data would require firms to believe that the signal about the higher-order expectations of other firms be almost 10 times more precise than the signal about the firstorder expectations of other firms. Finally, the basic noisy-information model, which lacks capital or any friction other than information rigidity, appears to be too simple to rationalize why firms respond to information treatments by adjusting their employment and investment rather than their prices.

There are a number of potential ways to try and address the differences between our empirical results and the baseline noisy-information model with infinite regress considered here. One approach would be to augment the signal space with a semi-public signal. This could help generate additional idiosyncratic variation in expectations and weaken the predicted link between first-order and higher-order expectations. A second would be to make the model dynamic, which would generate variation in prior beliefs of agents even before they receive their idiosyncratic signals. A third approach is to consider behavioral/cognitive constraints that prevent agents from engaging in the infinite regress used in our stylized model. In the next section, we consider novel empirical evidence to assess one such departure from infinite regress due to level- $k$ thinking.

\section{Level- $k$ Thinking}

Standard noisy-information models assume that agents undertake infinite degrees of reasoning about the pricing decisions of others. Reasoning of this sort is, however, difficult and computationally intensive. Managers are therefore likely, due to either cognitive constraints or recognizing the costs of such reasoning, to limit their degrees of thinking to levels well below infinity. In this section, we discuss the results of a beauty contest done in the survey which allows us to categorize the thinking types of firm managers. While this approach to measuring thinking types is common in the experimental literature, it has not, to our knowledge, been included in a survey that also obtains macroeconomic expectations. We further extend the beauty contest question to study the beliefs of firm managers about the guesses of other managers. This allows us to compare the properties of level- $k$ behavior we observe with the predictions of existing models of degrees of reasoning and cognitive hierarchy. We find that the higher-order beliefs in the guessing game do not correspond with current models of level- $k$ thinking. We further find that a manager's reasoning type does not influence the manager's reaction to information.

\subsection{Categorizing Types}

Following Nagel (1995), Nagel and Duffy (1997) and many others, we characterize managers' degree of reasoning by asking the following question:

"Please choose a number from zero to 100. We will take your number as well as the numbers chosen by other managers to calculate the average pick. The winning number will be the number that is closest to two-thirds (2/3) of the average. The individual(s) with the winning number will 
receive (or share with other winners in case of tie) $\$ 500 . "$

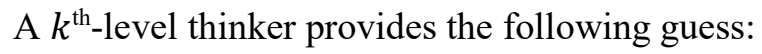

$$
g(k)=\left(\frac{2}{3}\right)^{k} \times 50
$$

The distribution of managers' guesses appears in Figure 2. Guesses appear throughout the entire interval (0-100). However, when we restrict the sample to those managers who spent at least 20 seconds on the question, the guesses pile on integers associated with reasoning types as defined by equation (32) between $k=1$ and $k=5$, with the number of managers of each type declining with $k$. Accordingly, we classify these managers by their guess and assign $k=0$ to those who answer the question in less than 20 seconds. ${ }^{15}$ As a robustness check, we consider an alternative treatment of guesses with short response times: we code responses as level-zero thinking if response times are less than 20 seconds and responses are between 47 and 53; we set level of thinking to missing for other responses with response time less than 20 seconds. We denote this alternative coding with $k^{\prime}$.

The average guess in our sample is 33 when we use all responses and 21 when we use guesses with response time of 20 or more seconds. Camerer (1997) reports that average responses for CEOs at Cal Tech's Board of Trustees, for portfolio managers, and for Wharton's MBA students are 38, 24, and 38 respectively. However, Camerer (1997) reports generally lower average scores for subjects participating in experimental settings. Indeed, the thinking types of managers in our survey appear somewhat more dispersed than in experimental studies. We see a greater density of thinkers at $k=0$, partially due to the way we assign this rating (as anyone who does less than 20 seconds of thinking about the question). In our survey, 36.8 percent of managers are $k=0$, as opposed to 20 to 27.3 percent in the experimental studies. Our sample is also more heavily weighted towards higher thinking types $(k \geq 3)$ than other papers, with roughly a quarter of the sample performing such high degrees of reasoning.

We find that level of thinking is generally uncorrelated with observed characteristics of firms and managers as well as industry fixed effects (Table 5). The only variable that is relatively robustly correlated with level of thinking is the share of domestic sales in total sales. However, even for this variable the quantitative strength of the link is weak: a standard deviation increase in the share is associated with a $0.14-$ point decrease in the level of thinking.

\subsection{Beliefs About Other Managers}

The two primary models of limited reasoning (level- $k$ thinking and cognitive hierarchy) have different approaches to a participant's beliefs about the types of other participants. In the Nagel level- $k$ thinking model,

${ }^{15}$ The guesses associated with $k=0$ therefore fall throughout the $[0,100]$ interval, rather than at 50 as in Nagel (1995). 
a level- $k$ thinker believes that everyone else in the game performs at level $(k-1)$. Camerer, Ho, and Chong (2004) develop a model of "cognitive hierarchy" that allows agents to form beliefs about the distribution of other reasoning types in the sample. A level- $k$ thinker is assumed to observe the correct frequency of thinkers of his type and at levels below his own, but to incorrectly assume that there are no thinkers performing the same or higher degrees of reasoning. As a result, he posits inaccurate relative frequencies of thinkers. As a thinker's reasoning type, $k$, increases and he observes the true frequencies of a greater number of types, his expectation of the density over the sample becomes "increasingly rational" and closer to the true distribution of types. Both of these models emphasize a particularly important aspect of level- $k$ thinking: individuals cannot conceive of thinkers at their own level or levels above. To do this would be to engage in the next level of reasoning. Therefore, by definition, a level- $k$ thinker must believe that he is the smartest player (or among the smartest players) in the game.

We introduce a new question designed to elicit beliefs about the distribution of types so that we may compare these beliefs with the modeling assumptions of these two models. Specifically, we ask managers to provide a probability distribution over ranges of other managers' guesses (this question appears in Table 6). Note that we allow managers to choose dominated strategies (e.g., range 60 to 70 ) to avoid priming of responses.

Table 7 (Appendix Figure 5) shows the average believed distribution of guesses for each thinking level $k$ as well as the true distribution across guesses (column 8) and the average belief across levels of thinking (column 7). All thinking types believe that the majority of managers share their own type and all managers at levels $k \leq 3$ assign probability to bins associated with players at levels both higher and lower than their own. All managers underestimate the true dispersion of guesses. Accordingly, none of the thinking types correctly conjectures the true density of types, nor do beliefs about the density become closer to the truth with increasing $k$, as in Camerer, Ho, and Chong (2004). However, the average density across types (column 7) is relatively close to the actual distribution of guesses (column 8), reflecting the fact that i) a typical manager believes that other managers have the same level of thinking as the manager and ii) as we discuss below, managers appear to not use $2 / 3$ of the average response of other managers. ${ }^{16}$

These results are not fully consistent with either level- $k$ or cognitive hierarchy models. Roughly 80 percent of managers of all reasoning levels assign positive probability to multiple bins, a fact that is not consistent with the Nagel model of reasoning. A level- $k$ thinker as defined by the guess in equation (32) should report positive probability on exactly one bin, the one associated with the level $(k-1)$ guess. A level- $k$ thinker from either model will also not place positive probability on the bin associated with her own guess. For types $k=1,2,3$, managers place an average probability of 0.72 to 0.77 on this bin, meaning they

\footnotetext{
${ }^{16}$ Results are similar for $k^{\prime}$, an alternative coding for level of thinking.
} 
think that between 72 and 77 percent of other managers are the same type as them. All levels, $k \geq 1$, assign positive probability to bins associated with thinkers beneath their own level, consistent with both Nagel (1995) and Camerer, Ho, and Chong (2004). However, only types $k \geq 4$ report believing that a majority of managers will fall into bins associated with lower level thinkers. Thinkers at types $k \leq 3$ also report positive probability on bins associated with levels of $k$ above their own.

These distributions, however, may still be internally consistent in the sense that guesses are equal to two thirds of the average of the conjectured distribution of other managers' guesses. In other words, to win the prize, a manager should submit a guess of two-thirds of their believed average guess of other managers. ${ }^{17}$ To test the consistency of a manager's guess in the beauty contest game with their beliefs about the average guess of other managers, we can estimate the following specification:

$$
\text { Gues }{ }_{i}^{\text {Own }}=b \times E_{i}\left[\text { Guess }^{\mathrm{HO}}\right]+\text { error }_{i}
$$

where Guess $_{i}{ }^{\text {wn }}$ is the guess submitted by manager $i, E_{i}\left[\right.$ Guess $\left.^{H O}\right]$ is manager $i$ 's average guess for other managers' guesses. We find (Table 8 ) that the estimated $b$ is generally close to one for managers with low $k$ and the estimated slope gets closer to $2 / 3$ as $k$ decreases. For example, for $k=4$, we cannot reject the null of $b=2 / 3$ (but we can reject this null for $k=5$ ). Note that when we compute the implied mean of the reported distribution of other managers' beliefs, we use mid-points of the bins provided in the survey question. Generally, the results for low $k$ are insensitive to using alternative assumptions for picking points within bins, while the results for high $k$ tend to be more sensitive to how one assigns weights within bins because bins get increasingly coarse for high levels of thinking. With alternative assumptions, one may get estimates of $b$ closer to $2 / 3$ for $k \geq 3$.

In summary, these results pose a puzzle for popular models in which agents are characterized by varying depths of reasoning. First, managers assign positive probability of other managers having higher levels of thinking. Second, many managers believe that other managers have the same level of thinking. Third, guesses of low-level thinkers appear to be inconsistent with what these thinkers believe about guesses of other managers.

\subsection{Expectations and Actions by Level of Thinking}

In Appendix B, we extend the noisy information model of section 4 to a setting in which agents can be either $k=0,1$ or 2 in their level of thinking. For simplicity, we assume each type of agent believes all other agents are of the same or lower level- $k$ of thinking. In short, this model makes several predictions. First, in this setting, agents with higher levels of thinking place more weight on the public signal as they are more cognizant of the role of other agents' expectations in their own optimal price-setting decisions. Second, mean expected inflation should be broadly similar across level- $k$ types, albeit higher level- $k$ 's would have mean forecasts that

\footnotetext{
${ }^{17}$ It may be the case that when asked directly about other managers, survey participants will engage an additional level of reasoning that was not present when they formed their own guess or expectation.
} 
move more with the public signal. Third, because higher level- $k$ agents place more weight on the public signal, we should observe declining levels of disagreement in both first-order and higher-order forecasts with the level of $k$, and the same prediction should hold for uncertainty in each type of forecast.

To assess these predictions, Table 9 documents how various moments of survey expectations from Nez Zealand vary with the level of $k$ of each agent. Mean expected inflation and disagreement about future inflation decrease in $k$, while uncertainty is approximately constant across $k$. These patterns hold for lowand high-order inflation expectations and are broadly consistent with theoretical predictions: low- $k$ firms should disagree more and should be more likely to have expectations with larger departures from fundamentals. We also observe that as $k$ increases, the degree of complementarity in pricing $\alpha$ tends to increase as well. The precision of signals $\left(\kappa_{x}, \kappa_{y}\right)$, the relative precision of the private signal $(\delta)$, and the weight on the private signal $\left(\phi_{x}\right)$ exhibit an inverted-U shape in $k$. In contrast, our theory predicts that $\phi_{x, k}$ should decrease in $k$ monotonically. Finally, while in our theoretical setting the cross-sectional correlation between low- and high-order inflation expectations is perfect (recall that private signals $x_{i}$ is the only source of variation in the cross-section), one might expect the correlation to be stronger for low-level thinkers because these thinkers do not distinguish between low- and high-level expectations. In fact, we find that the correlation between low- and high-order inflation expectations is weakly increasing in $k$.

Appendix B also extends this level- $k$ model to incorporate responses to information analogous to the experiment described in Table 2. This analysis suggests that the response of managers to new information should vary in the level of thinking, $k$, although the differences may be quantitatively small given the observed strategic complementarity in pricing $(\alpha)$, a high weight on private signals $(\delta)$, and a large share of level-0 managers $\left(\omega_{0}\right)$. To assess the degree of heterogeneity in the weight assigned to priors across $k$, we estimate equation (1) for $k$ equal to 0,1 , and $2+$ and report results in Table 10.

The results are inconsistent with several key predictions made by the theory. First, level-0 firms should not make a distinction between signals $\mathrm{B}$ and $\mathrm{C}$ because giving information about low-order expectations or high-order expectations does not make a difference for this type of agents (these agents iterate forward neither "prices" nor "expectations"). Inconsistent with this prediction, we observe that the weight on the prior is systematically smaller for Treatment $\mathrm{C}$ than for Treatment $\mathrm{B}$ and the magnitudes are similar to what is observed for $k=1$ and $k \geq 2$. Furthermore, level-0 firms should not make a distinction between signals B and D because they do not differentiate between information contained in expectations and information contained in fundamentals. Again, this prediction is not borne out in the data. Hence, level0 managers in our data differentiate between signals just as much as higher-level agents, contrary to the theory. Second, level-1 firms should respond differently to signal E than to signals B, C, or D and should respond similarly to signals $\mathrm{B}$ and $\mathrm{C}$ (firms in this group understand the difference between fundamentals and expectations but do not distinguish among orders of expectations). Again, we find no support for this 
prediction: level-1 managers distinguish sharply between signals $\mathrm{B}$ and $\mathrm{C}$ and between signal $\mathrm{B}$ and $\mathrm{C} / \mathrm{D}$, just like other agents. Finally, our theory predicts that, ceteris paribus, the weight on the prior should be increasing with the level of thinking. In contrast, we find little variation how much weight agents assign to their priors relative to new information across different levels of $k$.

While we find no evidence that agents' level of $k$ affects how they respond to new information, these cognitive constraints could still affect how information translates into their economic decisions. In Table 11, we report the effects of inflation expectations on employment, investment, prices, and wages from estimating equation (2) for each level $k$ separately. We typically cannot reject equality of responses for each outcome variable across different levels of $k$. Thus, not only do firms appear to process information similarly for different levels of $k$, they also transmit revisions in their expectations into their economic decisions in the same way regardless of their level of thinking.

This evidence should be interpreted with caution for several reasons. First, sample sizes are relatively small so the sampling uncertainty in the estimates is relatively large. This could be resolved in future work through the use of larger samples to sharpen inference. Second, the amount of predicted variation in sensitivity of beliefs and possible actions to new information across different $k$ can be quantitatively small depending on underlying parameter values. The fact that we cannot uncover meaningful differences depending on the level of thinking may therefore reflect underlying parameter values rather than a failure of the model. For example, values of $\alpha$ closer to zero would reduce the predicted differences in reactions across $k$. A third caveat to bear in mind is that, while beauty contest questions are commonly used to assess the level of thinking in the experimental literature, these measures may not necessarily be appropriate to measure the levels of thinking used by managers when they revise their inflation expectations or make decisions about employment, investment, etc. In this case, the fact that we do not find variation in expectations or behavior for different levels of $k$ could simply reflect a poor identification of relevant $k$. Future work could consider alternative approaches to measure cognitive abilities of firm managers to assess whether these affect their beliefs and decisions.

\section{Concluding remarks}

This paper presents novel survey evidence on the higher-order expectations of firms and how these expectations affect their decisions. We find evidence that, along a number of key dimensions, is broadly in line with noisy-information models in which firm managers face strategic complementarities in pricing, requiring them to form higher-order beliefs about other managers. We also show how moments from higher-order beliefs, along with first-order expectations, can help calibrate previously unknown parameters in this class of models and test overidentifying restrictions implied by these models. These results can therefore be of immediate practical use for future work using this class of models. 
Our results can also help identify along which dimensions these models could be extended. Indeed, while simple models of noisy information can go a long way in rationalizing observed expectations of firms and households, the mapping from expectations to actions is more complex than is commonly postulated by these models. One increasingly popular departure from the noisy information model with infinite regress is to assume cognitive constraints on agents in the form of level- $k$ thinking. But our results suggest that this approach is unlikely to be fruitful in accounting for apparent deviations between the data and theory. While we are able to identify the level of thinking associated with each manager, we find little evidence that any important dimension of the data is related to these differing levels of thinking.

Particularly challenging for the noisy information model with infinite regress, as well as the extended version of the model with level- $k$ thinking, is understanding why treatments using higher-order beliefs of other firms have such a large effect on the expectations of managers, particularly compared to treatment effects from providing the first-order beliefs of other firms. While these results present a theoretical challenge, they nonetheless should be of immediate interest to policy-makers. For example, our results indicate that not all types of information move inflation expectations equally: providing information about recent inflation and the higher-order expectations of other firms has much larger effects on beliefs than providing them with information about the average expectations of other firms. Using this randomized controlled variation in information received by managers, we also document that these information treatments affect firms' actions, not just their expectations. These results provide a rationale for utilizing survey measures of inflation expectations in policymaking as well as a foundation for policies operating via information treatments. Our findings therefore contribute to a broader research agenda explaining the expectations formation of agents and utilizing these expectations in policymaking.

\section{References}

Afrouzi, Hassan (2018). "Strategic Inattention, Inflation Dynamics and the Non-Neutrality of Money," manuscript.

Angeletos, George-Marios and Chen Lian (2018). "Forward Guidance without Common Knowledge," forthcoming in American Economic Review.

Angeletos, George-Marios and Jennifer La'O (2009). "Incomplete Information, Higher-Order Beliefs and Price Inertia,” Journal of Monetary Economics 56(S1):19-37.

Armantier, Olivier, Wändi Bruine de Bruin, Giorgio Topa, Wilbert van der Klaauw, and Basit Zafar (2015). "Inflation Expectations and Behavior: Do Survey Respondents Act on Their Beliefs?" International Economic Review 56: 505-536.

Bacchetta, Philippe and Eric Van Wincoop (2008). "Higher-order Expectations in Asset Pricing," Journal of Money, Credit, and Banking 40(5): 837-866.

Bruine de Bruin, Wandi, Baruch Fischhoff, Susan Millstein and Bonnie Halpern-Felsher (2000). "Verbal and Numerical Expressions of Probability: It's a Fifty-Fifty Chance," Organizational Behavior and Human Decision Processes 81: 115-131. 
Camerer, Colin F. (1997). "Progress in Behavioral Game Theory," Journal of Economic Perspectives 11(4): 167-188.

Camerer, Colin F., Teck-Hua Ho, and Juin-Kuan Chong (2004). "A Cognitive Hierarchy Model of Games," Quarterly Journal of Economics 119(3): 861-898.

Cavallo, Alberto, Guillermo Cruces, and Ricardo Perez-Truglia (2017). "Inflation Expectations, Learning, and Supermarket Prices: Evidence from Survey Experiments," American Economic Journal: Macroeconomics 9(3): 1-35.

Coibion, Olivier, and Yuriy Gorodnichenko (2015). "Is The Phillips Curve Alive and Well After All? Inflation Expectations and the Missing Disinflation," American Economic Journal Macroeconomics 7(1): 197-232

Coibion, Olivier, Yuriy Gorodnichenko, and Saten Kumar (2018). "How Do Firms Form Their Expectations? New Survey Evidence," forthcoming in American Economic Review.

Coibion, Olivier, Yuriy Gorodnichenko, and Tiziano Ropele (2018). "Inflation Expectations and Firm Decisions: New Causal Evidence," manuscript.

Coibion, Olivier, Yuriy Gorodnichenko, Saten Kumar, and Mathieu Pedemonte (2018). "Inflation Expectations as a Policy Tool?" NBER Working Paper 24788.

Costa-Gomes, Miguel A., and Vincent P. Crawford (2006). "Cognition and Behavior in Two-Person Guessing Games: An Experimental Study," American Economic Review 96(5): 1737-1768.

Fahri, Emmanuel, and Ivan Werning (2017). "Monetary Policy, Bounded Rationality, and Incomplete Markets," Mimeo.

Fischhoff, Baruch, and Wandi Bruine de Bruin (1999). "Fifty-Fifty $=50 \%$ ?" Journal of Behavioral Decision Making 12: 149-163.

Gabaix, Xavier (2016). “A Behavioral New Keynesian Model,” NBER Working Paper 22954

Garcia-Schmidt, Mariana, and Michael Woodford (2015). "Are Low Interest Rates Deflationary? A Paradox of Perfect Foresight Analysis". Mimeo.

Harsanyi, John C. (1967). "Games with incomplete information played by "Bayesian” players, I-III. part I. The Basic Model," Management Science 14(3): 159-182.

Keynes, John (1936). The General Theory of Employment, Interest, and Money. Palgrave Macmillan

Kleinjans, Kristin, and Arthur van Soest (2010). "Rounding, Focal Point Answers and Nonresponse to Subjective Probability Questions," Journal of Applied Econometrics 29(4): 567-585.

Kumar, Saten, Hassan Afrouzi, Olivier Coibion, and Yuriy Gorodnichenko (2015). "Inflation Targeting Does Not Anchor Inflation Expectations: Evidence from Firms in New Zealand," Brookings Papers on Economic Activity 2015 (Fall), 151-225.

Mackowiak, Bartosz, and Mirko Wiederholt (2009). "Optimal Sticky Prices under Rational Inattention," American Economic Review 99(3): 769-803.

Morris, Stephen and Hyun Song Shin (2002). "The Social Value of Public Information," American Economic Review 92 (5): 1521-1534.

Nagel, Rosemarie (1995). "Unraveling in Guessing Games: An Experimental Study," American Economic Review 85 (5): 1313-1326.

Nagel, Rosemarie, and John Duffy (1997). "On the Robustness of Behavior in Experimental BeautyContest," Economic Journal 107(445): 1684-1700.

Patton, Andrew J., and Allan Timmermann (2010). "Why do forecasters disagree? Lessons from the term structure of cross-sectional dispersion," Journal of Monetary Economics 57(7): 803-820.

Sims, Christopher (2003). "Implications of Rational Inattention," Journal of Monetary Economics 50(3): 665-690.

Stahl, Dale O., and Paul W. Wilson (1995). "Cognition and Behavior in Two-Person Guessing Games: An Experimental Study," Games and Economic Behavior 10(1): 218-254.

Woodford, Michael (2002). "Imperfect Common Knowledge and the Effects of Monetary Policy". Knowledge, Information, and Expectations in Modern Macroeconomics: In Honor of Edmund Phelps. Princeton Univ. Press. 
Table 1. Expectations of future inflation and other managers' inflation expectations.

\begin{tabular}{|c|c|c|c|c|c|}
\hline & \# obs. & Mean & $\begin{array}{c}\text { St.dev. } \\
\text { (disagreement) }\end{array}$ & Uncertainty & $\begin{array}{l}\text { Correlation with } \\
\text { expected inflation }\end{array}$ \\
\hline \multicolumn{6}{|l|}{ Initial wave (pre experiment) } \\
\hline Expected inflation expectation of other managers, 12-month ahead & 1,032 & 3.50 & 2.43 & 0.89 & 0.68 \\
\hline p-value for equality of moment & & 0.18 & 0.00 & 0.00 & \\
\hline \multicolumn{6}{|l|}{ Initial wave (post experiment) } \\
\hline p-value for equality of moment & & 0.79 & 0.00 & - & \\
\hline \multicolumn{6}{|l|}{ Follow-up wave } \\
\hline Expected inflation, 12-month ahead & 515 & 3.03 & 2.11 & 0.89 & 1.00 \\
\hline Expected inflation expectation of other managers, 12-month ahead & 515 & 3.49 & 1.74 & 1.14 & 0.70 \\
\hline p-value for equality of moment & & 0.00 & 0.00 & 0.00 & \\
\hline
\end{tabular}

Notes: The table reports basic moments of first-order and higher-order expectations of inflation. Column (3) reports the cross-sectional standard deviation of mean inflation forecasts. Column (4) reports the average (across managers) standard deviation of the reported distribution for future inflation. 
Table 2. Effect of Information Treatment on Expectations. .

\begin{tabular}{|c|c|c|c|c|c|c|c|}
\hline \multirow{3}{*}{ Row } & \multirow{3}{*}{ Treatment } & \multicolumn{3}{|c|}{ Initial wave } & \multicolumn{3}{|c|}{ Follow-up wave } \\
\hline & & $\begin{array}{c}\text { Own } \\
\text { Expectations }\end{array}$ & $\begin{array}{l}\text { Higher-order } \\
\text { Expectations }\end{array}$ & $\begin{array}{l}\mathrm{p} \text {-value } \\
\text { equality }\end{array}$ & $\begin{array}{c}\text { Own } \\
\text { Expectations }\end{array}$ & $\begin{array}{l}\text { Higher-order } \\
\text { Expectations }\end{array}$ & $\begin{array}{l}\text { p-value } \\
\text { equality }\end{array}$ \\
\hline & & (1) & (2) & (3) & (4) & (5) & (6) \\
\hline \multirow[t]{2}{*}{ (1) } & \multirow[t]{2}{*}{ Group A, Control } & $0.727 * * *$ & $0.699 * * *$ & 0.35 & $0.744 * * *$ & $0.708 * * *$ & 0.45 \\
\hline & & $(0.020)$ & $(0.021)$ & & $(0.038)$ & $(0.038)$ & \\
\hline \multirow[t]{2}{*}{ (2) } & \multirow[t]{2}{*}{ Group B, $\bar{E}\left[\pi_{t}\right]$} & $0.502 * * *$ & $0.430 * * *$ & 0.21 & $0.461 * * *$ & $0.513 * * *$ & 0.45 \\
\hline & & $(0.041)$ & $(0.039)$ & & $(0.065)$ & $(0.049)$ & \\
\hline \multirow[t]{2}{*}{ (3) } & \multirow{2}{*}{ Group C, $\bar{E}^{2}\left[\pi_{t}\right]$} & $0.090 * * *$ & $0.118 * * *$ & 0.36 & $0.116^{* * *}$ & $0.146^{* * *}$ & 0.61 \\
\hline & & $(0.018)$ & $(0.024)$ & & $(0.043)$ & $(0.047)$ & \\
\hline \multirow[t]{2}{*}{ (4) } & \multirow{2}{*}{ Group D, $\bar{E}\left[\pi_{t}\right]$ and $\bar{E}^{2}\left[\pi_{t}\right]$} & $0.096 * * *$ & $0.071 * * *$ & 0.37 & $0.155^{* * *}$ & $0.097 * *$ & 0.18 \\
\hline & & $(0.022)$ & $(0.019)$ & & $(0.038)$ & $(0.042)$ & \\
\hline \multirow[t]{4}{*}{ (5) } & Group E, $\pi_{t-1}$ & $0.059 * * *$ & $0.062 * * *$ & 0.90 & $0.088 * *$ & -0.006 & 0.14 \\
\hline & & $(0.015)$ & $(0.021)$ & & $(0.043)$ & $(0.040)$ & \\
\hline & Observations & 1,032 & 1,032 & & 515 & 515 & \\
\hline & $R^{2}$ & 0.757 & 0.759 & & 0.653 & 0.602 & \\
\hline
\end{tabular}

Notes: The table reports the coefficient on managers' pre-treatment inflation expectations in specification (1). The dependent variable in each column is the post-treatment inflation expectation. All inflation expectations are measured at the one-year-ahead horizon. Group B was provided information about the average first-order inflation expectation of other firms $\left(\bar{E}\left[\pi_{t}\right]\right)$, group $\mathrm{C}$ was provided information about the average higher-order inflation expectation $\left(\bar{E}^{2}\left[\pi_{t}\right]\right)$, group D received both pieces of information, while group $\mathrm{E}$ was told the most recent inflation rate $\left(\pi_{t-1}\right)$. Group A is the control group and received no information. Columns (1) and (2) present results for post-treatment inflation expectations measured immediately after treatment. Columns (4) and (5) present results for post-treatment inflation expectations measured three months after treatment. Columns (1) and (4) are for firms' own inflation expectations Columns (2) and (5) present the same results for the expectation of other firms' inflation expectations. Column (3) reports p-values of the null hypothesis that columns (1) and (2) are equal. Column (6) reports p-values of the null hypothesis that columns (4) and (5) are equal. Robust standard errors are reported in parentheses. ${ }^{* *},{ }^{* *}$, and $*$ indicate significance at the $0.01,0.05$ and 0.10 percent levels, respectively. 


\begin{tabular}{|c|c|c|c|c|}
\hline \multirow{3}{*}{$\begin{array}{l}\text { Treatment effect } \\
\text { (relative to control group) }\end{array}$} & \multicolumn{4}{|c|}{ Percent change in: } \\
\hline & Workers & Fixed Assets & $\begin{array}{l}\text { Price of Main } \\
\text { Product }\end{array}$ & Wages \\
\hline & $(1)$ & $(2)$ & (3) & (4) \\
\hline \multicolumn{5}{|l|}{ Treatment B $(\bar{E}[\pi])$} \\
\hline$\left(E_{i}^{\text {posterior }}(\pi)-E_{i}^{\text {prior }}(\pi)\right)$ & $\begin{array}{l}0.407 * * * \\
(0.152)\end{array}$ & $\begin{array}{l}0.342 * * * \\
(0.125)\end{array}$ & $\begin{array}{c}0.141 \\
(0.132)\end{array}$ & $\begin{array}{c}0.003 \\
(0.015)\end{array}$ \\
\hline Observations & 245 & 245 & 245 & 245 \\
\hline $\mathrm{R}^{2}$ & -0.038 & -0.050 & 0.028 & 0.001 \\
\hline $1^{\text {st }}$ stage F-stat & 149.6 & 149.6 & 149.6 & 149.6 \\
\hline \multicolumn{5}{|l|}{ Treatment $\left.\mathrm{C}\left(\bar{E}^{2}[\pi]\right]\right)$} \\
\hline$\left(E_{i}^{\text {posterior }}(\pi)-E_{i}^{\text {prior }}(\pi)\right)$ & $\begin{array}{c}0.493 * \\
(0.260) \\
\end{array}$ & $\begin{array}{l}0.141 * * \\
(0.063)\end{array}$ & $\begin{array}{l}-0.078 \\
(0.072)\end{array}$ & $\begin{array}{c}0.043 * \\
(0.024)\end{array}$ \\
\hline Observations & 252 & 252 & 252 & 252 \\
\hline $\mathrm{R}^{2}$ & -0.097 & 0.103 & -0.043 & -0.198 \\
\hline $1^{\text {st }}$ stage F-stat & 15.47 & 15.47 & 15.47 & 15.47 \\
\hline \multicolumn{5}{|l|}{ Treatment $\mathrm{D}\left(\bar{E}[\pi]\right.$ and $\left.\left.\left.\bar{E}^{2}[\pi]\right]\right)\right)$} \\
\hline$\left(E_{i}^{\text {posterior }}(\pi)-E_{i}^{\text {prior }}(\pi)\right)$ & $\begin{array}{l}-0.264 \\
(0.184)\end{array}$ & $\begin{array}{l}0.214 * * * \\
(0.060)\end{array}$ & $\begin{array}{c}0.019 \\
(0.062)\end{array}$ & $\begin{array}{c}0.016 \\
(0.018)\end{array}$ \\
\hline Observations & 253 & 253 & 253 & 253 \\
\hline $\mathrm{R}^{2}$ & 0.004 & 0.066 & 0.002 & 0.010 \\
\hline $1^{\text {st }}$ stage F-stat & 318.8 & 318.8 & 318.8 & 318.8 \\
\hline \multicolumn{5}{|l|}{ Treatment E: $\left(\pi_{t-1}\right)$} \\
\hline$\left(E_{i}^{\text {posterior }}(\pi)-E_{i}^{\text {prior }}(\pi)\right)$ & $\begin{array}{l}0.352 * * * \\
(0.095)\end{array}$ & $\begin{array}{l}0.251 * * * \\
(0.096)\end{array}$ & $\begin{array}{c}0.096 \\
(0.094)\end{array}$ & $\begin{array}{c}0.021 \\
(0.013)\end{array}$ \\
\hline Observations & 251 & 251 & 251 & 251 \\
\hline $\mathrm{R}^{2}$ & 0.049 & -0.028 & -0.005 & -0.000 \\
\hline $1^{\text {st }}$ stage F-stat & 49.19 & 49.19 & 49.19 & 49.19 \\
\hline
\end{tabular}

Notes: The table reports the coefficient on the revision of a firm's first-order inflation expectation in specification (2). The regressand in each column is the forecast error for a given firm-specific outcome indicated in the second row of the table. The regressor is instrumented with surprise component in the provided signal, that is, the difference between information provided in a treatment and pre-treatment expectation for the variable provided in the treatment. $1^{\text {st }}$ stage F-stat reports the first-stage F-statistic. Robust standard errors are reported in parentheses. $* * *, * *$, and * indicate significance at the $0.01,0.05$ and 0.10 percent levels, respectively. 
Table 4. Horserace regressions.

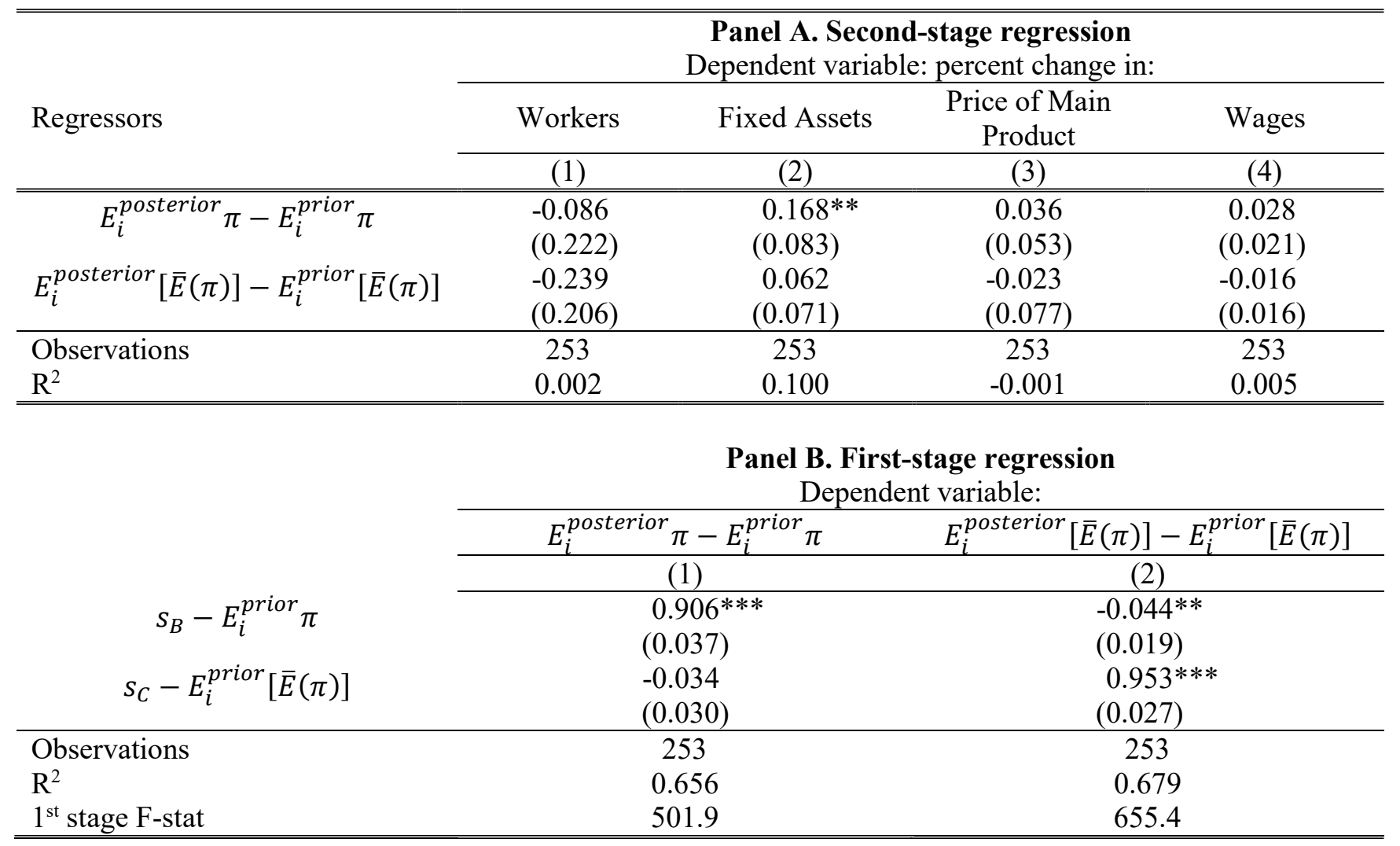

Notes: Panel A of the table reports the coefficient on the revision firms' first-order inflation expectations and the revision of their higher-order inflation expectation in specification (2). The regressand in each column is the forecast error for a given firm-specific outcome indicated in the second row of the table. The regressors are instrumented with surprise component in the provided signals, that is, the difference between information provided in a treatment and pre-treatment expectation for the variable provided in the treatment. The first-stage regression is reported in Panel B. $1^{\text {st }}$ stage F-stat reports the first-stage F-statistic. Robust standard errors are reported in parentheses. ${ }^{* *}, * *$, and $*$ indicate significance at the $0.01,0.05$ and 0.10 percent levels, respectively. 


\begin{tabular}{|c|c|c|c|c|c|c|}
\hline \multirow{3}{*}{$\begin{array}{l}\text { Dependent variable: } \\
k \text {, level of thinking }\end{array}$} & \multicolumn{6}{|c|}{ Sample } \\
\hline & \multicolumn{2}{|c|}{ All responses } & \multicolumn{2}{|c|}{ Responses with $k>0$} & \multicolumn{2}{|c|}{$\begin{array}{l}\text { Responses with non- } \\
\text { missing } k^{\prime}\end{array}$} \\
\hline & (1) & (2) & (3) & (4) & $(5)$ & $(6)$ \\
\hline \multicolumn{7}{|l|}{ Firm characteristics } \\
\hline Ln(Employment) & $\begin{array}{l}-0.314 * * * \\
(0.066)\end{array}$ & $\begin{array}{l}-0.315^{* * *} \\
(0.068)\end{array}$ & $\begin{array}{l}-0.023 \\
(0.088)\end{array}$ & $\begin{array}{l}-0.021 \\
(0.090)\end{array}$ & $\begin{array}{l}-0.131 \\
(0.093)\end{array}$ & $\begin{array}{l}-0.140 \\
(0.095)\end{array}$ \\
\hline Ln(Age) & $\begin{array}{l}-0.038 \\
(0.048)\end{array}$ & $\begin{array}{l}-0.035 \\
(0.048)\end{array}$ & $\begin{array}{c}0.022 \\
(0.055)\end{array}$ & $\begin{array}{c}0.023 \\
(0.055)\end{array}$ & $\begin{array}{l}-0.023 \\
(0.057)\end{array}$ & $\begin{array}{l}-0.017 \\
(0.057)\end{array}$ \\
\hline Share of domestic sales & $\begin{array}{l}-0.013 * * \\
(0.006)\end{array}$ & $\begin{array}{l}-0.011 \\
(0.007)\end{array}$ & $\begin{array}{l}-0.012^{*} \\
(0.007)\end{array}$ & $\begin{array}{l}-0.013^{*} \\
(0.008)\end{array}$ & $\begin{array}{l}-0.017 * * \\
(0.007)\end{array}$ & $\begin{array}{l}-0.019^{* *} \\
(0.008)\end{array}$ \\
\hline Number of competitors & $\begin{array}{l}0.044^{* * *} \\
(0.011)\end{array}$ & $\begin{array}{l}0.043^{* * *} \\
(0.011)\end{array}$ & $\begin{array}{c}0.002 \\
(0.012)\end{array}$ & $\begin{array}{c}0.002 \\
(0.012)\end{array}$ & $\begin{array}{c}0.008 \\
(0.012)\end{array}$ & $\begin{array}{c}0.007 \\
(0.012)\end{array}$ \\
\hline \multicolumn{7}{|l|}{ Manager characteristics } \\
\hline Manager's tenure at the firm & $\begin{array}{l}-0.011 * \\
(0.007)\end{array}$ & $\begin{array}{l}-0.012^{*} \\
(0.006)\end{array}$ & $\begin{array}{l}-0.007 \\
(0.009)\end{array}$ & $\begin{array}{l}-0.006 \\
(0.009)\end{array}$ & $\begin{array}{l}-0.002 \\
(0.009)\end{array}$ & $\begin{array}{l}-0.003 \\
(0.009)\end{array}$ \\
\hline Manager's gender $($ female $=1)$ & $\begin{array}{c}0.006 \\
(0.110)\end{array}$ & $\begin{array}{l}-0.005 \\
(0.111)\end{array}$ & $\begin{array}{c}0.093 \\
(0.126)\end{array}$ & $\begin{array}{c}0.084 \\
(0.129)\end{array}$ & $\begin{array}{l}0.007 \\
(0.133)\end{array}$ & $\begin{array}{l}-0.031 \\
(0.137)\end{array}$ \\
\hline Manager's years of schooling & $\begin{array}{c}0.008 \\
(0.023)\end{array}$ & $\begin{array}{c}0.010 \\
(0.023)\end{array}$ & $\begin{array}{c}0.024 \\
(0.026)\end{array}$ & $\begin{array}{c}0.024 \\
(0.026)\end{array}$ & $\begin{array}{c}0.021 \\
(0.027)\end{array}$ & $\begin{array}{c}0.021 \\
(0.027)\end{array}$ \\
\hline Observations & 1,032 & 1,032 & 654 & 654 & 726 & 726 \\
\hline $\mathrm{R}^{2}$ & 0.144 & 0.148 & 0.009 & 0.011 & 0.019 & 0.022 \\
\hline Industry FE & No & Yes & No & Yes & No & Yes \\
\hline
\end{tabular}

Notes: The table report results of regressing level of thinking $k$ on firm and manager characteristics. Industry fixed effects are at the one-digit level. Coding $k^{\prime}$ for level of thinking sets $k^{\prime}=0$ for responses with response time of 20 seconds or more and responses close to 50 and response time less than 20 seconds. The coding of $k$ and $k^{\prime}$ are identical for $k>0$. Robust standard errors are reported in parentheses. ${ }^{* * *},{ }^{* *}$, and $*$ indicate significance at the $0.01,0.05$ and 0.10 percent levels, respectively.

Table 6. Distribution of beliefs about other managers' guesses in the beauty contest game.

Other managers are asked to guess a number from zero to 100, with the goal of making their guess as close as possible to two-thirds of the average guess of all those participating in the contest. What percentage of other managers' guesses do you think will fall in each of the following ranges?

\begin{tabular}{|c|c|}
\hline Range of Guesses & Percentage of Other Managers \\
\hline From 0 to 9.99 & \\
\hline From 10 to 19.99 & ................. \% \\
\hline From 20 to 29.99 & ................. \% \\
\hline From 30 to 39.99 & ................ \% \\
\hline From 40 to 49.99 & ................ \% \\
\hline From 50 to 59.99 & .................\% \\
\hline From 60 to 69.99 & ................. \% \\
\hline From 70 to 79.99 & ................\% \\
\hline From 80 to 89.99 & ................. \% \\
\hline From 90 to 100 & ............... \% \\
\hline
\end{tabular}

Note: table reports the survey question to elicit manager beliefs about the distribution of guess submitted by other managers. 
Table 7. Beliefs about distribution of other managers' guesses.

\begin{tabular}{|c|c|c|c|c|c|c|c|c|c|}
\hline \multirow{3}{*}{ Range of Guesses } & \multicolumn{6}{|c|}{ Level of thinking } & \multirow{2}{*}{$\begin{array}{c}\text { Average } \\
\text { expected } \\
\text { distribution }\end{array}$} & \multirow{2}{*}{$\begin{array}{c}\text { Actual } \\
\text { distribution }\end{array}$} & \multirow{2}{*}{$\begin{array}{c}\text { memorandum } \\
k^{\prime}=0\end{array}$} \\
\hline & $k=0$ & $k=1$ & $k=2$ & $k=3$ & $k=4$ & $k=5$ & & & \\
\hline & $(1)$ & $(2)$ & (3) & $(4)$ & $(5)$ & (6) & $(7)$ & $(8)$ & $(9)$ \\
\hline From 0 to 9.99 & 5.9 & 0.0 & 1.0 & 9.8 & 25.0 & 79.0 & 8.9 & 8.9 & 1.0 \\
\hline From 10 to 19.99 & 7.1 & 1.6 & 11.9 & 74.5 & 68.7 & 18.8 & 22.4 & 22.4 & 2.2 \\
\hline From 20 to 29.99 & 7.8 & 12.1 & 76.3 & 14.6 & 4.9 & 2.0 & 19.7 & 19.7 & 6.8 \\
\hline From 30 to 39.99 & 7.4 & 72.3 & 10.1 & 1.1 & 1.1 & 0.1 & 19.7 & 19.7 & 11.0 \\
\hline From 40 to 49.99 & 12.7 & 13.2 & 0.7 & 0.0 & 0.2 & 0.0 & 7.5 & 7.5 & 26.3 \\
\hline From 50 to 59.99 & 19.4 & 0.8 & 0.0 & 0.0 & 0.0 & 0.0 & 7.3 & 7.3 & 21.5 \\
\hline From 60 to 69.99 & 13.2 & 0.0 & 0.0 & 0.0 & 0.0 & 0.0 & 4.8 & 4.8 & 14.8 \\
\hline From 70 to 79.99 & 11.3 & 0.0 & 0.0 & 0.0 & 0.0 & 0.0 & 4.2 & 4.2 & 9.0 \\
\hline From 80 to 89.99 & 9.0 & 0.0 & 0.0 & 0.0 & 0.0 & 0.0 & 3.3 & 3.3 & 4.6 \\
\hline From 90 to 100 & 6.0 & 0.0 & 0.0 & 0.0 & 0.0 & 0.0 & 2.2 & 2.2 & 2.8 \\
\hline
\end{tabular}

Notes: The table reports average probabilities assigned to the beliefs of other managers' guesses. Column (7) is the average of columns (1)-(6) weighted by the share of managers with level $k$ thinking. Column (8) shows the actual distribution of guesses. Classification of managers into various level of $k$ is described in section 5.1. Coding $k^{\prime}$ for level of thinking sets $k^{\prime}=0$ for guesses in the beauty contest with response time of 20 seconds or more and responses close to 50 and response time less than 20 seconds. The coding of $k$ and $k^{\prime}$ are identical for $k>0$. Column (9) reports the average probabilities for $k^{\prime}=0$.

Table 8. Test of internal consistency of reported guesses in the beauty contest game.

\begin{tabular}{|c|c|c|c|c|c|c|c|c|}
\hline \multirow{3}{*}{$\begin{array}{l}\text { Dependent } \\
\text { variable: } \\
\text { Guess }_{i}^{\text {Own }}\end{array}$} & \multicolumn{8}{|c|}{ "Estimation sample: } \\
\hline & $\begin{array}{c}\text { All } \\
\text { responses }\end{array}$ & $k>0$ & $k=0$ & $k=1$ & $k=2$ & $k=3$ & $k=4$ & $k=5$ \\
\hline & $(1)$ & $(2)$ & (3) & (4) & $(5)$ & (6) & $(7)$ & $(8)$ \\
\hline$E_{i}\left[\right.$ Guess $\left.^{H O}\right]$ & $\begin{array}{l}0.982 * * * \\
(0.010)\end{array}$ & $\begin{array}{l}0.912 * * * \\
(0.005)\end{array}$ & $\begin{array}{l}1.005^{* * *} \\
(0.014)\end{array}$ & $\begin{array}{l}0.937 * * * \\
(0.005)\end{array}$ & $\begin{array}{l}0.881 * * * \\
(0.007)\end{array}$ & $\begin{array}{l}0.932 * * * \\
(0.012)\end{array}$ & $\begin{array}{l}0.707 * * * \\
(0.031)\end{array}$ & $\begin{array}{l}0.814^{* * *} \\
(0.054)\end{array}$ \\
\hline Observations & 1,032 & 654 & 378 & 216 & 160 & 134 & 110 & 34 \\
\hline $\mathrm{R}^{2}$ & 0.950 & 0.985 & 0.943 & 0.992 & 0.989 & 0.979 & 0.938 & 0.887 \\
\hline p-value $($ slope $=2 / 3)$ & 0.00 & 0.00 & 0.00 & 0.00 & 0.00 & 0.00 & 0.14 & 0.01 \\
\hline
\end{tabular}

Note: The table reports the estimated slope in specification (33) by level of thinking $k$. Classification of managers into various levels of $k$ is described in section 5.1. $\mathrm{p}$-value(slope $=2 / 3$ ) reports the $\mathrm{p}$-value for the null that the estimate is equal to $2 / 3$. Robust standard errors are reported in parentheses. ${ }^{* * *}, * *$, and $*$ indicate significance at the $0.01,0.05$ and 0.10 percent levels, respectively. 
Table 9. Moments of inflation expectations and implied parameter values by level of thinking.

\begin{tabular}{|c|c|c|c|c|c|c|c|}
\hline & \multicolumn{6}{|c|}{ Level of thinking } & \multirow{3}{*}{$\begin{array}{c}\text { memorandum } \\
k^{\prime}=0 \\
(7)\end{array}$} \\
\hline & $k=0$ & $k=1$ & $k=2$ & $k=3$ & $k=4$ & $k=5$ & \\
\hline & $(1)$ & $(2)$ & (3) & $(4)$ & $(5)$ & $(6)$ & \\
\hline \multicolumn{8}{|l|}{ Moment of own inflation expectations } \\
\hline Mean & 5.16 & 2.60 & 2.24 & 2.40 & 2.46 & 1.54 & 3.53 \\
\hline Disagreement & 2.83 & 2.91 & 2.50 & 2.71 & 2.60 & 2.49 & 2.87 \\
\hline Uncertainty & 1.29 & 1.06 & 0.95 & 0.92 & 1.02 & 1.03 & 1.10 \\
\hline \multicolumn{8}{|l|}{ Moment of high-order inflation expectations } \\
\hline Mean & 4.87 & 2.83 & 2.74 & 2.69 & 2.62 & 2.13 & 3.87 \\
\hline Disagreement & 2.09 & 2.40 & 2.17 & 2.32 & 2.20 & 1.58 & 2.54 \\
\hline Uncertainty & 0.88 & 0.95 & 0.80 & 0.92 & 0.93 & 0.86 & 0.90 \\
\hline $\begin{array}{l}\text { Correlation between low- and high-order inflation } \\
\text { expectations }\end{array}$ & 0.48 & 0.66 & 0.68 & 0.70 & 0.71 & 0.79 & 0.65 \\
\hline Strategic complementarity in pricing, $\alpha$ & 0.68 & 0.69 & 0.75 & 0.56 & 0.84 & 0.82 & 0.82 \\
\hline \multicolumn{8}{|l|}{ Implied parameters } \\
\hline$\delta$ & 0.74 & 0.82 & 0.87 & 0.86 & 0.85 & 0.63 & 0.89 \\
\hline$\phi_{x}$ & 0.47 & 0.59 & 0.62 & 0.72 & 0.47 & 0.24 & 0.58 \\
\hline$\kappa_{x}$ & 0.015 & 0.028 & 0.047 & 0.052 & 0.023 & 0.004 & 0.032 \\
\hline$\kappa_{y}$ & 0.004 & 0.007 & 0.012 & 0.013 & 0.006 & 0.001 & 0.008 \\
\hline Observations & 378 & 216 & 160 & 134 & 110 & 34 & 72 \\
\hline
\end{tabular}

Notes: The table reports moments of inflation expectations by level of thinking $k$. Classification of managers into various level of $k$ is described in section 5.1. Coding $k^{\prime}$ for level of thinking sets $k^{\prime}=0$ for guesses in the beauty contest with response time of 20 seconds or more and responses close to 50 and response time less than 20 seconds. The coding of $k$ and $k^{\prime}$ is identical for $k>0$. Disagreement is the cross-sectional standard deviation of mean inflation forecasts. Uncertainty is the average (across managers) standard deviation of the reported distribution for future inflation. Parameters $\alpha, \delta, \phi_{x}, \kappa_{x}, \kappa_{y}$ implied by these moments are calculated as in section 4 . Precision of signals $\kappa_{x}, \kappa_{y}$ is calculated using disagreement in low- and high-order inflation expectations. 
Table 10. Revisions of beliefs by level of thinking

\begin{tabular}{|c|c|c|c|c|c|c|}
\hline & \multicolumn{2}{|c|}{$k=0$} & \multicolumn{2}{|c|}{$k=1$} & \multicolumn{2}{|c|}{$k \geq 2$} \\
\hline & $\begin{array}{c}\text { Own } \\
\text { Expectations }\end{array}$ & $\begin{array}{c}\text { Higher- } \\
\text { order } \\
\text { Expectations }\end{array}$ & $\begin{array}{c}\text { Own } \\
\text { Expectations }\end{array}$ & $\begin{array}{c}\text { Higher- } \\
\text { order } \\
\text { Expectations }\end{array}$ & $\begin{array}{c}\text { Own } \\
\text { Expectations }\end{array}$ & $\begin{array}{c}\text { Higher- } \\
\text { order } \\
\text { Expectations }\end{array}$ \\
\hline & (1) & (2) & (3) & (4) & $(5)$ & (6) \\
\hline Group A, Control & $\begin{array}{l}0.704 * * * \\
(0.042)\end{array}$ & $\begin{array}{l}0.715^{* * * *} \\
(0.028)\end{array}$ & $\begin{array}{l}0.722 * * * \\
(0.033)\end{array}$ & $\begin{array}{l}0.634 * * * \\
(0.058)\end{array}$ & $\begin{array}{l}0.732 * * * \\
(0.035)\end{array}$ & $\begin{array}{l}0.726^{* * * *} \\
(0.028)\end{array}$ \\
\hline Group B, $\bar{E}\left[\pi_{t}\right]$ & $\begin{array}{l}0.554 * * * \\
(0.109)\end{array}$ & $\begin{array}{l}0.284 * * * \\
(0.058)\end{array}$ & $\begin{array}{l}0.522 * * * \\
(0.068)\end{array}$ & $\begin{array}{l}0.521 * * * \\
(0.127)\end{array}$ & $\begin{array}{l}0.446^{* * *} \\
(0.061)\end{array}$ & $\begin{array}{l}0.500^{* * *} \\
(0.054)\end{array}$ \\
\hline Group C, $\bar{E}^{2}\left[\pi_{t}\right]$ & $\begin{array}{l}0.100 * * * \\
(0.031)\end{array}$ & $\begin{array}{l}0.141 * * \\
(0.056)\end{array}$ & $\begin{array}{c}0.029 \\
(0.021)\end{array}$ & $\begin{array}{c}0.053 \\
(0.035)\end{array}$ & $\begin{array}{l}0.098 * * \\
(0.038)\end{array}$ & $\begin{array}{l}0.127 * * * \\
(0.038)\end{array}$ \\
\hline Group D, $\bar{E}\left[\pi_{t}\right]$ and $\bar{E}^{2}\left[\pi_{t}\right]$ & $\begin{array}{l}0.082 * * \\
(0.035)\end{array}$ & $\begin{array}{c}0.079 \\
(0.049)\end{array}$ & $\begin{array}{l}0.107 * * * \\
(0.039)\end{array}$ & $\begin{array}{c}0.028^{*} \\
(0.014)\end{array}$ & $\begin{array}{l}0.090 * * \\
(0.035)\end{array}$ & $\begin{array}{l}0.066^{* *} \\
(0.028)\end{array}$ \\
\hline Group E, $\pi_{t-1}$ & $\begin{array}{c}0.033^{*} \\
(0.019)\end{array}$ & $\begin{array}{c}0.065 \\
(0.048)\end{array}$ & $\begin{array}{l}0.103 * * \\
(0.046)\end{array}$ & $\begin{array}{c}0.036 \\
(0.031)\end{array}$ & $\begin{array}{l}0.071 * * \\
(0.032)\end{array}$ & $\begin{array}{l}0.102 * * \\
(0.044)\end{array}$ \\
\hline $\begin{array}{l}\text { Observations } \\
\mathrm{R}^{2}\end{array}$ & $\begin{array}{c}378 \\
0.753\end{array}$ & $\begin{array}{c}378 \\
0.785\end{array}$ & $\begin{array}{c}216 \\
0.777\end{array}$ & $\begin{array}{c}216 \\
0.755\end{array}$ & $\begin{array}{c}438 \\
0.719\end{array}$ & $\begin{array}{c}438 \\
0.723\end{array}$ \\
\hline
\end{tabular}

Notes: The table reports the coefficient on managers' pre-treatment inflation expectations in specification (1) by level of thinking $k$. Classification of managers into various level of $k$ is described in section 5.1. The dependent variable in each column is the post-treatment inflation expectation measured immediately after treatment. All inflation expectations are measured at the one-year-ahead horizon. Columns (1), (3), and (5) are for firms' own inflation expectations. Columns (2), (4), and (6) present the same results for the expectation of other firms' inflation expectations. Robust standard errors are reported in parentheses. ${ }^{* *},{ }^{* *}$, and $*$ indicate significance at the $0.01,0.05$ and 0.10 percent levels, respectively. 
Table 11. Effect of Information Treatment on Actions.

\begin{tabular}{|c|c|c|c|c|c|}
\hline \multirow{3}{*}{$\begin{array}{l}\text { Treatment effect } \\
\text { (relative to control group) }\end{array}$} & \multirow{3}{*}{$k$-level } & \multicolumn{4}{|c|}{ Percent change in: } \\
\hline & & Workers & Fixed Assets & $\begin{array}{c}\text { Price of } \\
\text { Main Product }\end{array}$ & Wages \\
\hline & & $(1)$ & $(2)$ & (3) & (4) \\
\hline \multicolumn{6}{|l|}{ Treatment B $(\bar{E}[\pi])$} \\
\hline \multirow[t]{5}{*}{$\left(E_{i}^{\text {posterior }}(\pi)-E_{i}^{\text {prior }}(\pi)\right)$} & $k=0$ & $\begin{array}{c}0.597 * \\
(0.311)\end{array}$ & $\begin{array}{l}0.534 * * \\
(0.252)\end{array}$ & $\begin{array}{c}0.178 \\
(0.209)\end{array}$ & $\begin{array}{r}0.034 \\
(0.035)\end{array}$ \\
\hline & $k=1$ & 0.264 & 0.361 & -0.058 & 0.000 \\
\hline & & $(0.188)$ & $(0.240)$ & $(0.102)$ & $(0.000)$ \\
\hline & $k \geq 2$ & 0.365 & 0.259 & 0.211 & -0.027 \\
\hline & & $(0.270)$ & $(0.201)$ & $(0.234)$ & $(0.021)$ \\
\hline \multicolumn{6}{|l|}{ Treatment $\left.\mathrm{C}\left(\bar{E}^{2}[\pi]\right]\right)$} \\
\hline \multirow[t]{5}{*}{$\left(E_{i}^{\text {posterior }}(\pi)-E_{i}^{\text {prior }}(\pi)\right)$} & $k=0$ & $\begin{array}{c}0.222 \\
(0.302)\end{array}$ & $\begin{array}{c}0.160 \\
(0.100)\end{array}$ & $\begin{array}{l}-0.145 \\
(0.133)\end{array}$ & $\begin{array}{r}0.014 \\
(0.020)\end{array}$ \\
\hline & $k=1$ & 1.511 & -0.724 & 2.182 & 1.252 \\
\hline & & $(16.412)$ & $(8.896)$ & $(24.137)$ & $(14.267)$ \\
\hline & $k \geq 2$ & 1.203 & $0.170 *$ & -0.132 & 0.071 \\
\hline & & $(0.780)$ & $(0.088)$ & $(0.127)$ & $(0.052)$ \\
\hline \multicolumn{6}{|l|}{ Treatment $\mathrm{D}\left(\bar{E}[\pi]\right.$ and $\left.\left.\left.\bar{E}^{2}[\pi]\right]\right)\right)$} \\
\hline \multirow[t]{5}{*}{$\left(E_{i}^{\text {posterior }}(\pi)-E_{i}^{\text {prior }}(\pi)\right)$} & $k=0$ & -0.219 & $0.239 * *$ & $0.187^{*}$ & 0.031 \\
\hline & $l_{k}$ & $(0.390)$ & $(0.114)$ & $(0.113)$ & $(0.042)$ \\
\hline & $k=1$ & $\begin{array}{l}-0.40 / \\
(0.425)\end{array}$ & $(0.089)$ & $\begin{array}{l}-0.290 \\
(0.192)\end{array}$ & $\begin{array}{l}0.000 \\
(0.000)\end{array}$ \\
\hline & $k \geq 2$ & -0.425 & $0.242 * * *$ & -0.034 & -0.014 \\
\hline & & $(0.355)$ & $(0.092)$ & $(0.040)$ & $(0.009)$ \\
\hline \multicolumn{6}{|l|}{ Treatment E: $\left(\pi_{t-1}\right)$} \\
\hline \multirow{6}{*}{$\left(E_{i}^{\text {posterior }}(\pi)-E_{i}^{\text {prior }}(\pi)\right)$} & $k=0$ & $0.224^{*}$ & $0.135^{*}$ & 0.006 & 0.005 \\
\hline & & $(0.123)$ & $(0.072)$ & $(0.073)$ & $(0.017)$ \\
\hline & $k=1$ & $0.791 * *$ & $0.525 * *$ & 0.665 & 0.004 \\
\hline & & $(0.319)$ & $(0.232)$ & $(0.605)$ & $(0.004)$ \\
\hline & $k \geq 2$ & $0.390 * * *$ & 0.352 & -0.002 & 0.043 \\
\hline & & $(0.119)$ & $(0.223)$ & $(0.084)$ & $(0.030)$ \\
\hline
\end{tabular}

Notes: The table reports the coefficient on the revision of firms' first-order inflation expectations in specification (2) by level of thinking $k$. Classification of managers into various level of $k$ is described in section 5.1. The regressand in each column is the forecast error for a given firm-specific outcome indicated in the second row of the table. The regressor is instrumented with surprise component in the provided signal, that is, the difference between information provided in a treatment and pre-treatment expectation for the variable provided in the treatment. Robust standard errors are reported in parentheses. $* * * * *$, and * indicate significance at the $0.01,0.05$ and 0.10 percent levels, respectively. 
Figure 1. Own Expectations and Higher-order Expectations.

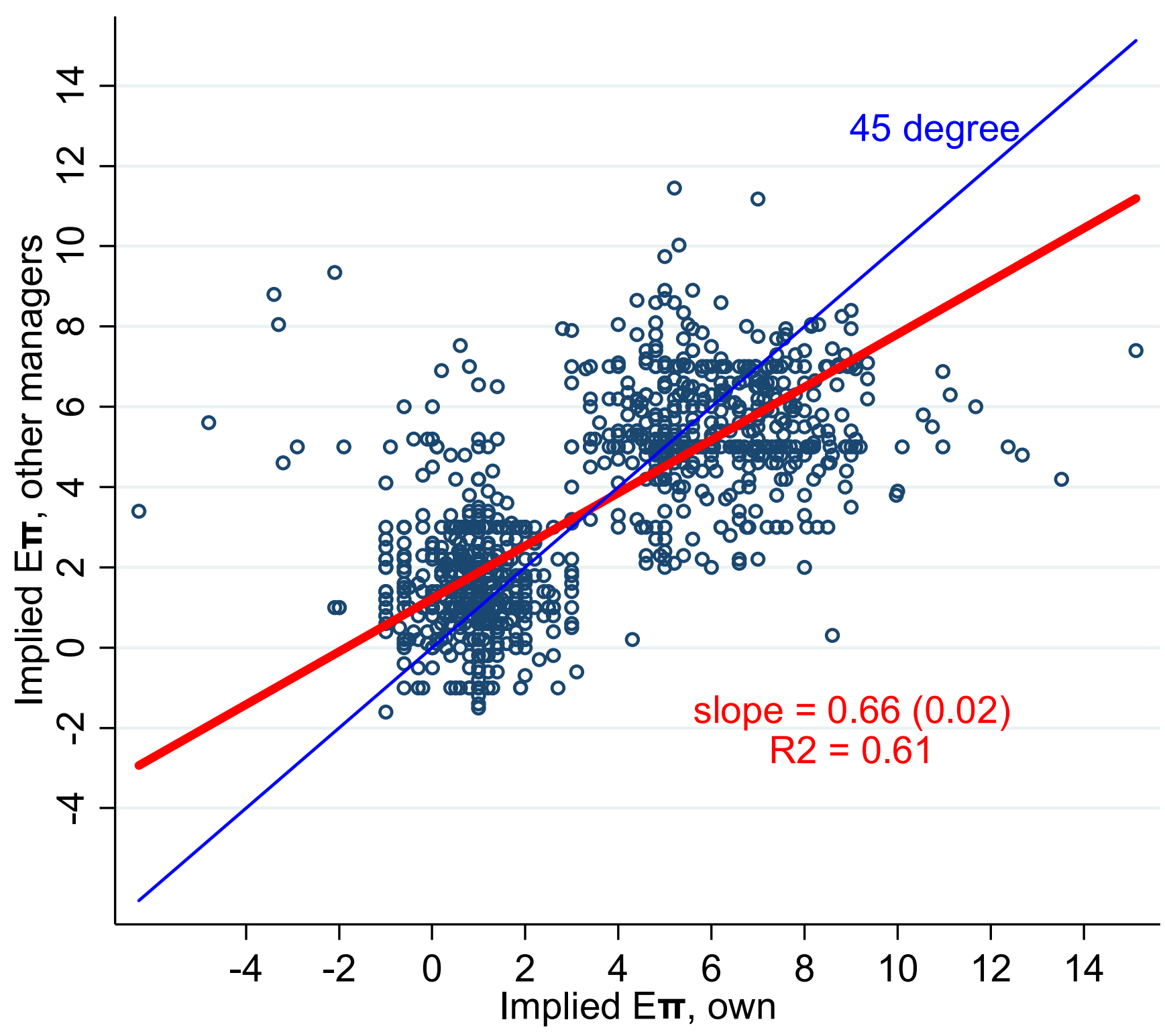

Notes: The figure reports the relationship between a managers' own expectation of inflation and their higher-order expectation of inflation. Expectations are measured as mean expectations implied by the reported probability distributions for future inflation (see Appendix Table 3 for the wording of the questions). Expectations are for the one-year-ahead horizon. 


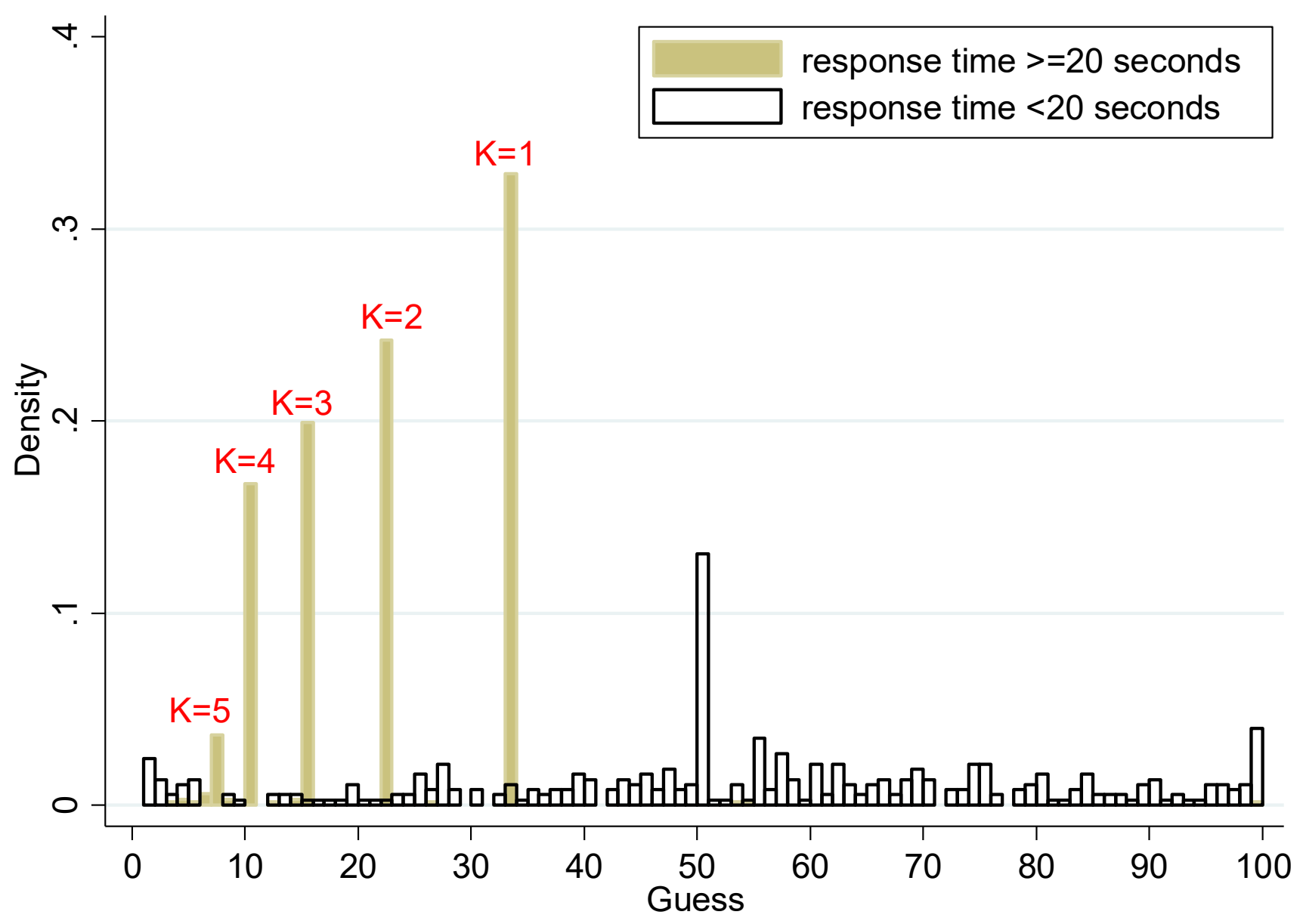

Notes: This figure shows the distribution of guesses from the beauty contest game. We asked managers to provide a guess between zero and 100 with the guess closest to $2 / 3$ of the average guess receiving a prize. For managers who spent at least 20 seconds in considering their guess, we see clumping of guesses at those points which correspond neatly with level- $k$ types as defined in Nagel (1995). Those managers who answered the question in less than 20 seconds made guesses dispersed across the full interval. 


\section{Online Appendix}




\section{Appendix A:}

Additional Tables and Figures 

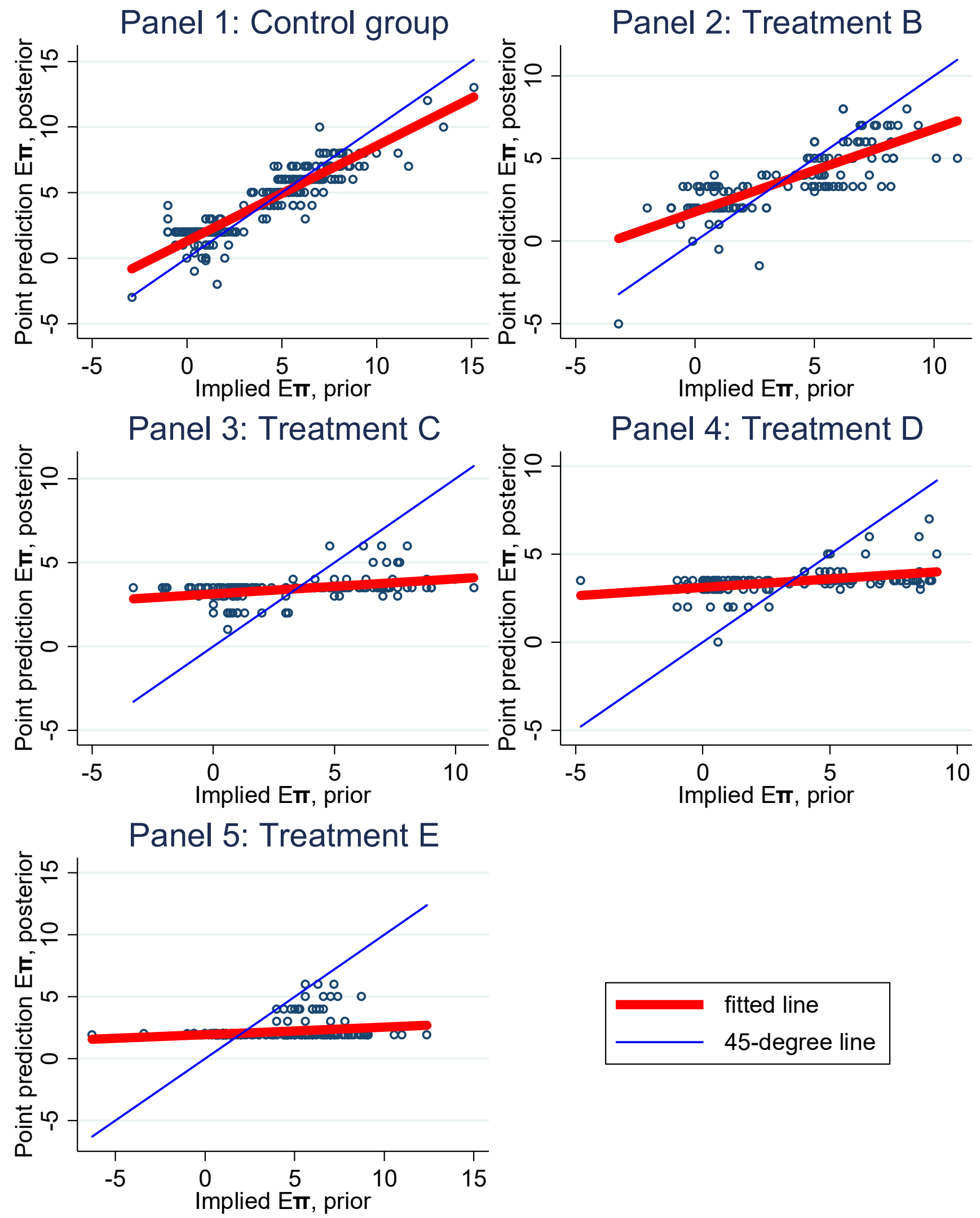

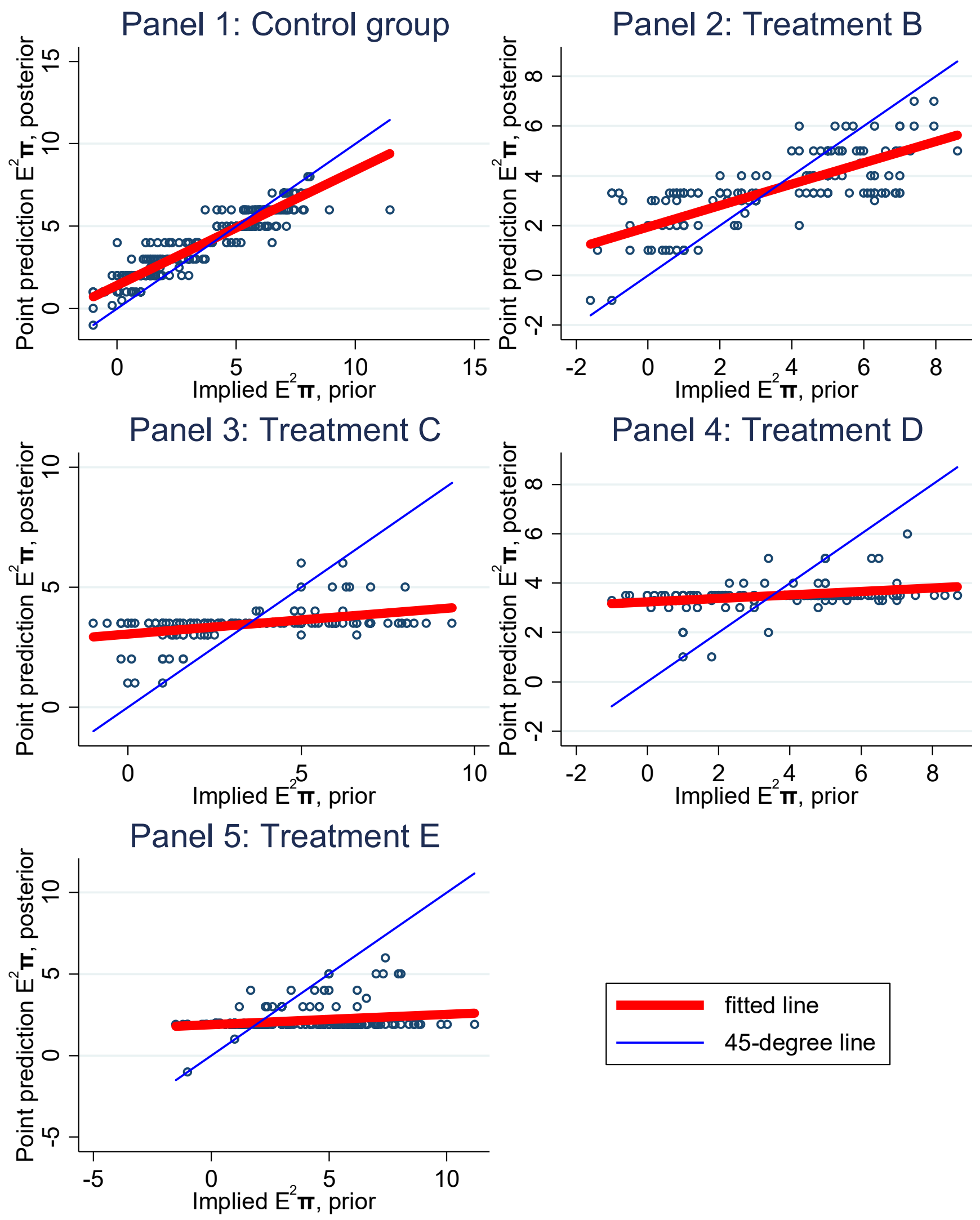

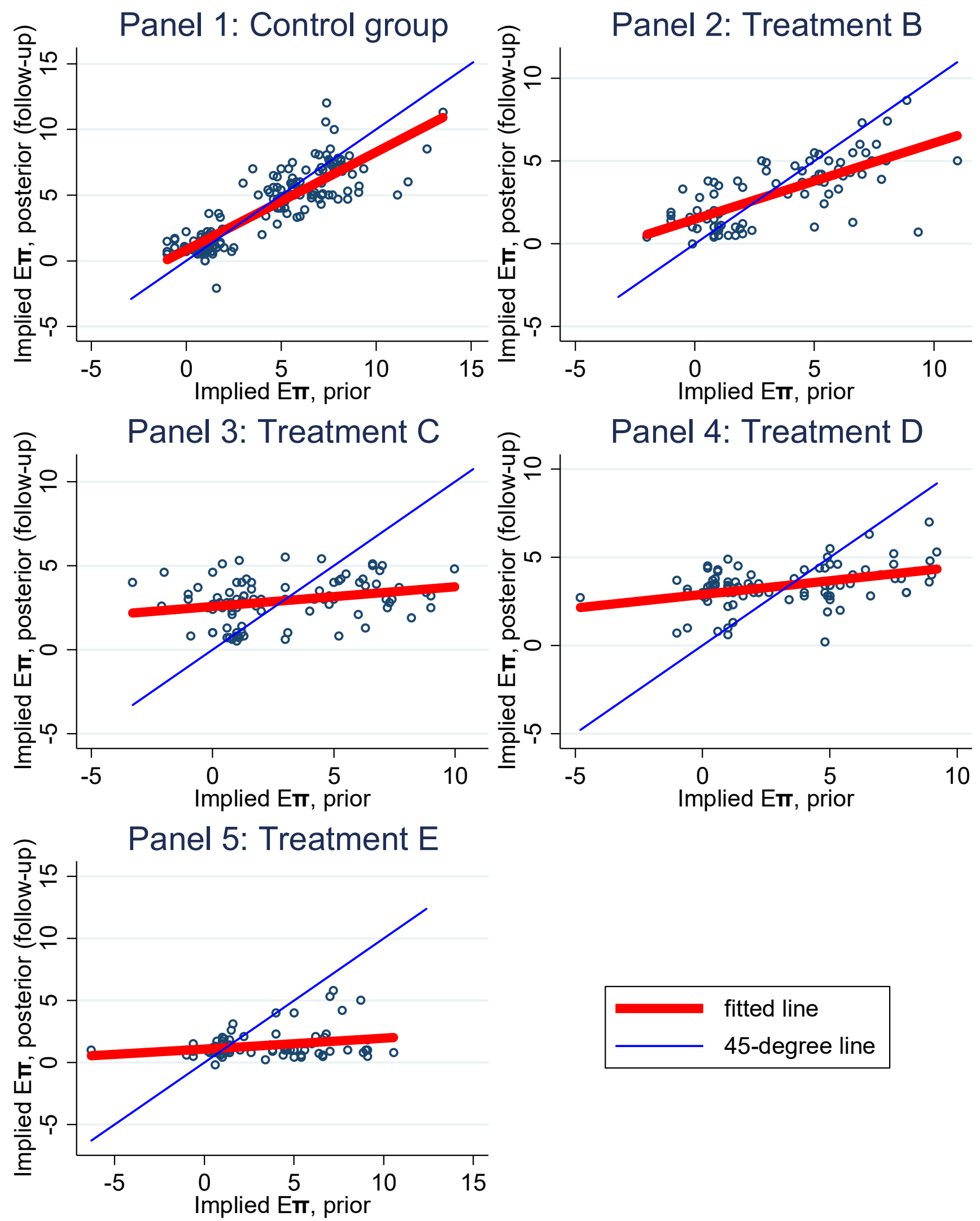

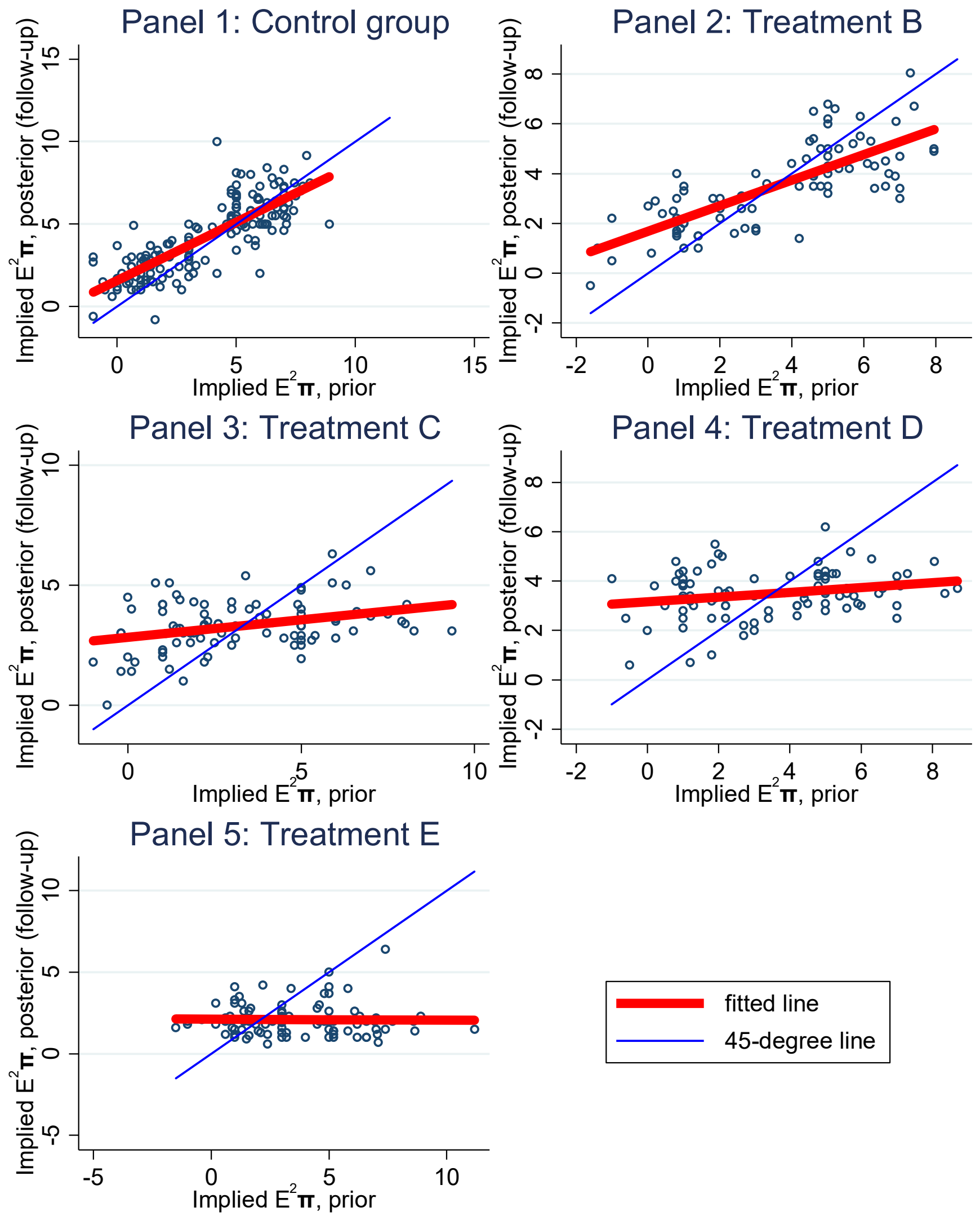


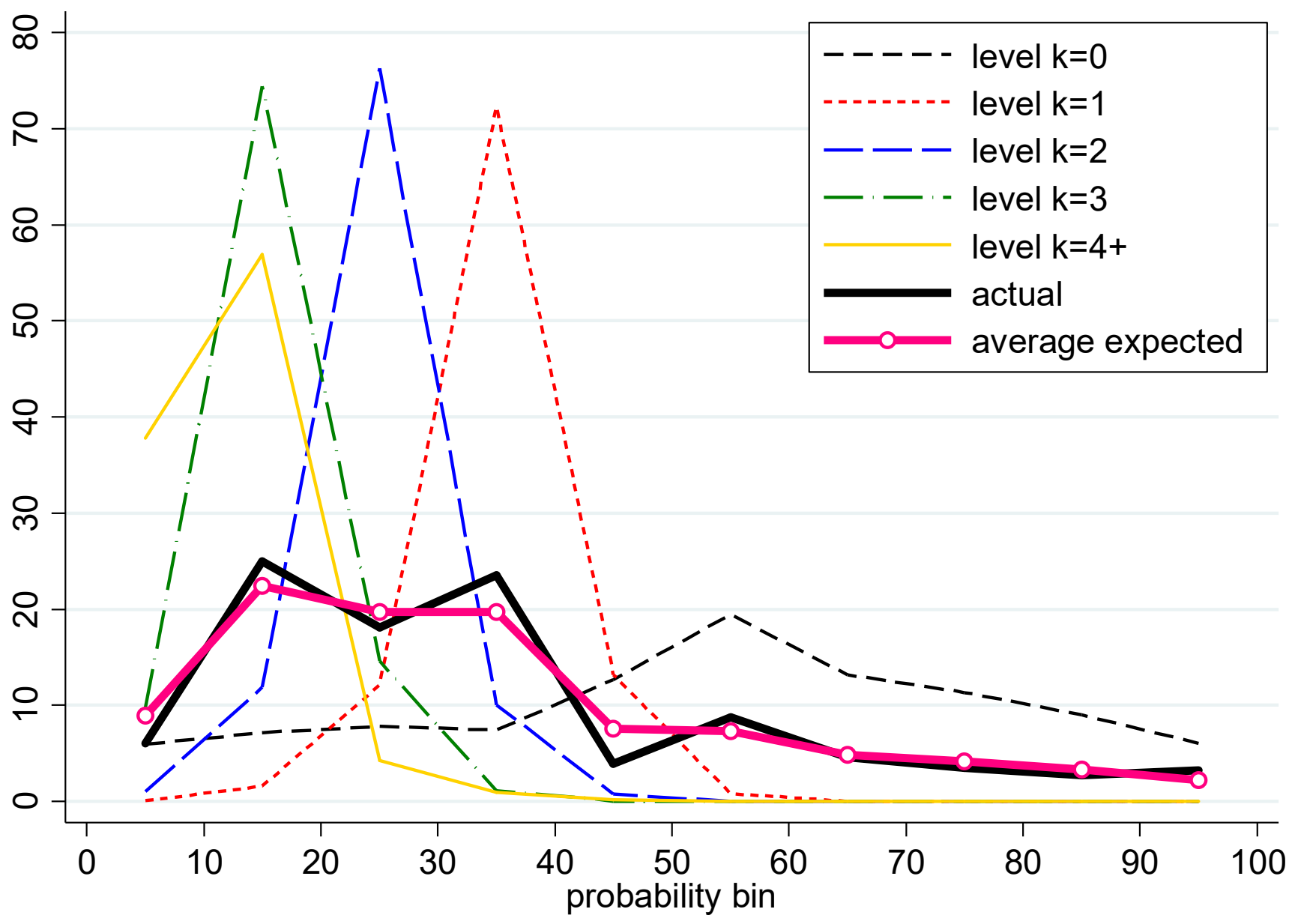

Notes: This figure shows the average belief of each reasoning type $(k=0,1,2, \ldots)$, about other managers' guesses in the beauty contest game. Individuals of each type believe that the majority of other managers provide guesses similar to their own. All thinking types underestimate the true dispersion of guesses. 


\begin{tabular}{lrr}
\hline \hline & $\begin{array}{c}\text { Mean } \\
(1)\end{array}$ & $\begin{array}{c}\text { St.dev. } \\
(2)\end{array}$ \\
\hline \hline Firm characteristics & & \\
$\quad$ Employment & 37.70 & 67.98 \\
Age & 25.97 & 19.23 \\
$\quad$ Share of domestic sales in total sales & 97.19 & 7.69 \\
$\quad$ Number of competitors & 8.78 & 6.26 \\
Manager characteristics & & \\
$\quad$ Tenure at the firm & 11.48 & 7.32 \\
$\quad$ Gender (female=1) & 0.19 & 0.39 \\
$\quad$ Years of schooling & 16.71 & 1.92 \\
Level of thinking & & \\
$\quad k$ & 1.50 & 1.51 \\
$k^{\prime}$ & 2.13 & 1.38 \\
$k \mid k>0$ & 2.37 & 1.24 \\
\hline \hline
\end{tabular}

Notes: the number of observations is 1,032 .

Appendix Table 2. Predictors of selection into the follow-up wave of the survey.

Dependent variable:

Participation in the follow-up wave of the survey

\begin{tabular}{|c|c|c|c|c|}
\hline & $(1)$ & $(2)$ & (3) & (4) \\
\hline Ln(Employment) & $\begin{array}{l}-0.026 \\
(0.023)\end{array}$ & $\begin{array}{l}-0.022 \\
(0.023)\end{array}$ & $\begin{array}{l}-0.020 \\
(0.024)\end{array}$ & $\begin{array}{l}-0.023 \\
(0.024)\end{array}$ \\
\hline Ln(Age) & $\begin{array}{l}-0.028 \\
(0.018)\end{array}$ & $\begin{array}{l}-0.029 \\
(0.018)\end{array}$ & $\begin{array}{l}-0.029 \\
(0.018)\end{array}$ & $\begin{array}{l}-0.027 \\
(0.018)\end{array}$ \\
\hline Share of domestic sales & $\begin{array}{l}-0.002 \\
(0.002)\end{array}$ & $\begin{array}{l}-0.002 \\
(0.002)\end{array}$ & $\begin{array}{l}-0.002 \\
(0.002)\end{array}$ & $\begin{array}{l}-0.003 \\
(0.002)\end{array}$ \\
\hline Number of competitors & $\begin{array}{l}-0.004 \\
(0.003)\end{array}$ & $\begin{array}{l}-0.005 \\
(0.004)\end{array}$ & $\begin{array}{l}-0.005 \\
(0.004)\end{array}$ & $\begin{array}{l}-0.005 \\
(0.004)\end{array}$ \\
\hline Manager's tenure at the firm & & $\begin{array}{l}-0.004 \\
(0.002)\end{array}$ & $\begin{array}{l}-0.004 \\
(0.002)\end{array}$ & $\begin{array}{l}-0.004 \\
(0.002)\end{array}$ \\
\hline Manager's gender $($ male $=1)$ & & $\begin{array}{l}-0.015 \\
(0.039)\end{array}$ & $\begin{array}{l}-0.015 \\
(0.039)\end{array}$ & $\begin{array}{l}-0.023 \\
(0.040)\end{array}$ \\
\hline Manager's years of schooling & & $\begin{array}{c}0.001 \\
(0.008)\end{array}$ & $\begin{array}{c}0.001 \\
(0.008)\end{array}$ & $\begin{array}{c}0.001 \\
(0.008)\end{array}$ \\
\hline Level of thinking, $k$ & & & $\begin{array}{c}0.004 \\
(0.011)\end{array}$ & $\begin{array}{c}0.004 \\
(0.011)\end{array}$ \\
\hline Constant & $\begin{array}{l}0.892 * * * \\
(0.222)\end{array}$ & $\begin{array}{l}0.926^{* * *} \\
(0.259)\end{array}$ & $\begin{array}{l}0.913^{* * * *} \\
(0.262)\end{array}$ & $\begin{array}{l}1.000 * * * \\
(0.268)\end{array}$ \\
\hline Observations & 1,032 & 1,032 & 1,032 & 1,032 \\
\hline R-squared & 0.005 & 0.007 & 0.007 & 0.011 \\
\hline Industry FE & No & No & No & Yes \\
\hline
\end{tabular}

Notes: the table reports estimates of the linear probability model to check selection on observable characteristics of firms and managers. Participation is the dummy variable equal to one if a firm participates in the follow-up and zero otherwise. Industry fixed effects are at the one-digit level. Robust standard errors are reported in parentheses. ${ }^{* * *},{ }^{* *}$, and $*$ indicate significance at the $0.01,0.05$ and 0.10 percent levels, respectively. 
Panel A. Own expectations

Please assign probabilities (from 0-100) to the following ranges of possible overall price changes for the New Zealand economy over the next 12 months: (Note that the probabilities in the column should sum to 100)

\begin{tabular}{|c|c|}
\hline \multicolumn{2}{|c|}{$\begin{array}{c}\text { Percentage Price Changes PER YEAR over the next } 12 \text { months. } \\
\text { Probabilities }\end{array}$} \\
\hline More than 25\%: & .................\% \\
\hline From 15 to $25 \%$ : & ................. \% \\
\hline From 10 to $15 \%$ : & ................. \% \\
\hline From 8 to $10 \%$ : & ................. \% \\
\hline From 6 to $8 \%$ : & .................\% \% \\
\hline From 4 to $6 \%$ : & ................. \% \\
\hline From 2 to $4 \%$ : & ..................\% \\
\hline From 0 to $2 \%$ : & .................\% \\
\hline From -2 to $0 \%$ : & .................\% \\
\hline From -4 to $-2 \%$ : & ................ \% \\
\hline From -6 to $-4 \%$ : & ................ \% \\
\hline From -6 to $-8 \%$ : & ................\% \\
\hline From -8 to $-10 \%$ : & .................\% \\
\hline From -10 to $-15 \%$ : & .................. \% \\
\hline From -15 to $-25 \%$ : & .................\% \\
\hline Less than $-25 \%$ : & ................. \% \\
\hline Total (the column should sum to $100 \%$ ): & 100 \\
\hline
\end{tabular}

\section{Panel B. Expectations of Other Managers' Beliefs}

We would like to know what your opinion is about what other managers (drawn from all sectors of the New Zealand economy in a representative way) think will happen to overall prices in the economy. Please assign probabilities (from $0-100$ ) to the following ranges of beliefs that other managers might hold about overall price changes in the economy over the next 12 months for New Zealand: (Note that the probabilities in the column should sum to 100)

\begin{tabular}{|c|c|}
\hline \multicolumn{2}{|c|}{$\begin{array}{c}\text { Percentage Price Changes PER YEAR over the next } 12 \text { months. } \\
\text { Probabilities }\end{array}$} \\
\hline More than 25\%: & ..................\% \\
\hline From 15 to $25 \%$ : & ............... \% \\
\hline From 10 to $15 \%$ : & ................. \% \\
\hline From 8 to $10 \%$ : & ..................\% \% \\
\hline From 6 to $8 \%$ : & ................. \% \\
\hline From 4 to $6 \%$ : & ................. \% \\
\hline From 2 to $4 \%$ : & .................\% \\
\hline From 0 to $2 \%$ : & ............... \% \\
\hline From -2 to $0 \%$ : & .................\% \\
\hline From -4 to $-2 \%$ : & …............... \% \\
\hline From -6 to $-4 \%$ : & ................ \% \\
\hline From -6 to $-8 \%$ : & .................\% \\
\hline From -8 to $-10 \%$ : & ................\% \\
\hline From -10 to $-15 \%$ : & ................. \% \\
\hline From -15 to $-25 \%$ : & ...................\% \% \\
\hline Less than $-25 \%$ : & ...................\% \% \\
\hline Total (the column should sum to $100 \%$ ): & $100 \quad \%$ \\
\hline
\end{tabular}


Appendix Table 4. Effect of Information Treatment on Expectations.

\begin{tabular}{|c|c|c|c|}
\hline \multirow{3}{*}{ Row } & \multirow{3}{*}{ Treatment } & Initial wave & $\begin{array}{l}\text { Follow-up } \\
\text { wave }\end{array}$ \\
\hline & & $\begin{array}{c}\text { Own } \\
\text { Expectations }\end{array}$ & $\begin{array}{c}\text { Own } \\
\text { Expectations }\end{array}$ \\
\hline & & (1) & (4) \\
\hline \multirow[t]{2}{*}{ (1) } & \multirow[t]{2}{*}{ Group A, Control } & $0.968 * * *$ & $0.973 * * *$ \\
\hline & & $(0.014)$ & $(0.045)$ \\
\hline \multirow[t]{2}{*}{ (2) } & \multirow[t]{2}{*}{ Group B, $\bar{E}\left[\pi_{t}\right]$} & $0.625 * * *$ & $0.574 * * *$ \\
\hline & & $(0.051)$ & $(0.076)$ \\
\hline \multirow[t]{2}{*}{ (3) } & \multirow{2}{*}{ Group C, $\bar{E}^{2}\left[\pi_{t}\right]$} & $0.122 * * *$ & $0.157 * *$ \\
\hline & & $(0.026)$ & $(0.061)$ \\
\hline \multirow[t]{2}{*}{ (4) } & \multirow{2}{*}{ Group D, $\bar{E}\left[\pi_{t}\right]$ and $\bar{E}^{2}\left[\pi_{t}\right]$} & $0.115 * * *$ & $0.175^{* * *}$ \\
\hline & & $(0.031)$ & $(0.049)$ \\
\hline \multirow[t]{4}{*}{ (5) } & \multirow[t]{2}{*}{ Group E, $\pi_{t-1}$} & $0.073 * * *$ & $0.096^{*}$ \\
\hline & & $(0.020)$ & $(0.054)$ \\
\hline & Observations & 1,032 & 515 \\
\hline & $R^{2}$ & 0.840 & 0.672 \\
\hline
\end{tabular}

Notes: the table replicates analysis in Table 2 with the regressor being the point prediction for inflation rather than implied mean. See note to Table 2 for more details. 


\begin{tabular}{|c|c|c|c|c|}
\hline \multirow{3}{*}{$\begin{array}{l}\text { Treatment effect } \\
\text { (relative to control group) }\end{array}$} & \multicolumn{4}{|c|}{ Percent change in: } \\
\hline & Workers & Fixed Assets & $\begin{array}{l}\text { Price of Main } \\
\text { Product }\end{array}$ & Wages \\
\hline & $(1)$ & $(2)$ & $(3)$ & (4) \\
\hline \multicolumn{5}{|l|}{ Treatment B $(\bar{E}[\pi])$} \\
\hline$\left(E_{i}^{\text {posterior }}(\pi)-E_{i}^{\text {prior }}(\pi)\right)$ & 0.004 & $0.491 * *$ & $0.396^{*}$ & -0.015 \\
\hline & $(0.338)$ & $(0.250)$ & $(0.218)$ & $(0.036)$ \\
\hline Observations & 245 & 245 & 245 & 245 \\
\hline $\mathrm{R}^{2}$ & -0.000 & -0.011 & 0.016 & -0.001 \\
\hline $1^{\text {st }}$ stage F-stat & 149.6 & 149.6 & 149.6 & 149.6 \\
\hline \multicolumn{5}{|l|}{ Treatment $\left.\mathrm{C}\left(\bar{E}^{2}[\pi]\right]\right)$} \\
\hline$\left(E_{i}^{\text {posterior }}(\pi)-E_{i}^{\text {prior }}(\pi)\right)$ & 0.017 & 0.027 & -0.140 & 0.098 \\
\hline & $(0.367)$ & $(0.138)$ & $(0.231)$ & $(0.083)$ \\
\hline Observations & 252 & 252 & 252 & 252 \\
\hline $\mathrm{R}^{2}$ & -0.000 & 0.005 & -0.033 & -0.021 \\
\hline $1^{\text {st }}$ stage F-stat & 15.47 & 15.47 & 15.47 & 15.47 \\
\hline \multirow{3}{*}{$\begin{array}{l}\left.\left.\text { Treatment } \mathrm{D}\left(\bar{E}[\pi] \text { and } \bar{E}^{2}[\pi]\right]\right)\right) \\
\qquad\left(E_{i}^{\text {posterior }}(\pi)-E_{i}^{\text {prior }}(\pi)\right)\end{array}$} & & & & \\
\hline & -0.220 & $0.219 * *$ & 0.106 & 0.036 \\
\hline & $(0.187)$ & $(0.093)$ & $(0.125)$ & $(0.055)$ \\
\hline Observations & 253 & 253 & 253 & 253 \\
\hline $\mathrm{R}^{2}$ & 0.008 & 0.006 & 0.002 & 0.009 \\
\hline $1^{\text {st }}$ stage F-stat & 318.8 & 318.8 & 318.8 & 318.8 \\
\hline \multirow{3}{*}{$\begin{array}{l}\text { Treatment E: }\left(\pi_{t-1}\right) \\
\qquad\left(E_{i}^{\text {posterior }}(\pi)-E_{i}^{\text {prior }}(\pi)\right)\end{array}$} & & & & \\
\hline & 0.109 & 0.098 & -0.202 & -0.012 \\
\hline & $(0.204)$ & $(0.121)$ & $(0.148)$ & $(0.030)$ \\
\hline Observations & 251 & 251 & 251 & 251 \\
\hline $\mathrm{R}^{2}$ & 0.001 & 0.007 & -0.024 & -0.004 \\
\hline $1^{\text {st }}$ stage F-stat & 49.19 & 49.19 & 49.19 & 49.19 \\
\hline
\end{tabular}

Notes: The table reports the coefficient on revision of own inflation expectations in specification (2). The regressand in each column is revision in plans for a given firm-specific outcome indicated in the second row of the table; that is, the outcome variable in specification (2) is 3-month-ahead plan in the follow-up wave minus the 6-month-ahead plan in the initial wave. The regressor is instrumented with surprise component in the provided signal, that is, the difference between information provided in a treatment and pre-treatment expectation for the variable provided in the treatment. $1^{\text {st }}$ stage F-stat reports the first-stage F-statistic. Robust standard errors are reported in parentheses. ${ }^{* *}, * *$, and $*$ indicate significance at the $0.01,0.05$ and 0.10 percent levels, respectively. 


\begin{tabular}{|c|c|c|c|c|}
\hline \multirow{3}{*}{$\begin{array}{l}\text { Treatment effect } \\
\text { (relative to control group) }\end{array}$} & \multicolumn{4}{|c|}{ Percent change in: } \\
\hline & Workers & Fixed Assets & $\begin{array}{l}\text { Price of Main } \\
\text { Product }\end{array}$ & Wages \\
\hline & $(1)$ & (2) & (3) & $(4)$ \\
\hline \multicolumn{5}{|l|}{ Treatment B $(\bar{E}[\pi])$} \\
\hline \multirow{2}{*}{$\left(E_{i}^{\text {posterior }}(\pi)-E_{i}^{\text {prior }}(\pi)\right)$} & $0.169 * *$ & $0.145^{* *}$ & $0.146^{* *}$ & 0.003 \\
\hline & $(0.072)$ & $(0.057)$ & $(0.074)$ & $(0.005)$ \\
\hline Observations & 245 & 245 & 245 & 245 \\
\hline $\mathrm{R}^{2}$ & 0.038 & 0.061 & 0.028 & 0.001 \\
\hline \multicolumn{5}{|l|}{ Treatment $\left.\mathrm{C}\left(\bar{E}^{2}[\pi]\right]\right)$} \\
\hline \multirow{2}{*}{$\left(E_{i}^{\text {posterior }}(\pi)-E_{i}^{\text {prior }}(\pi)\right)$} & $0.155^{*}$ & $0.127 * * *$ & 0.010 & 0.008 \\
\hline & $(0.089)$ & $(0.046)$ & $(0.029)$ & $(0.005)$ \\
\hline Observations & 252 & 252 & 252 & 252 \\
\hline $\mathrm{R}^{2}$ & 0.025 & 0.105 & 0.001 & 0.013 \\
\hline \multicolumn{5}{|l|}{ Treatment $\mathrm{D}\left(\bar{E}[\pi]\right.$ and $\left.\left.\left.\bar{E}^{2}[\pi]\right]\right)\right)$} \\
\hline \multirow[t]{2}{*}{$\left(E_{i}^{\text {posterior }}(\pi)-E_{i}^{\text {prior }}(\pi)\right)$} & -0.149 & $0.134 * * *$ & 0.023 & 0.013 \\
\hline & $(0.129)$ & $(0.047)$ & $(0.036)$ & $(0.011)$ \\
\hline Observations & 253 & 253 & 253 & 253 \\
\hline $\mathrm{R}^{2}$ & 0.010 & 0.103 & 0.002 & 0.010 \\
\hline \multirow{3}{*}{$\begin{array}{l}\text { Treatment E: }\left(\pi_{t-1}\right) \\
\qquad\left(E_{i}^{\text {posterior }}(\pi)-E_{i}^{\text {prior }}(\pi)\right)\end{array}$} & & & & \\
\hline & $0.207 * * *$ & $0.117 * * *$ & 0.042 & $0.010 * *$ \\
\hline & $(0.066)$ & $(0.036)$ & $(0.030)$ & $(0.005)$ \\
\hline Observations & 251 & 251 & 251 & 251 \\
\hline $\mathrm{R}^{2}$ & 0.096 & 0.093 & 0.009 & 0.024 \\
\hline
\end{tabular}

Notes: The table reports the OLS coefficient on revision of own inflation expectations in specification (2). The regressand in each column is forecast error for a given firm-specific outcome indicated in the second row of the table. Robust standard errors are reported in parentheses. ${ }^{* * *}, * *$, and $*$ indicate significance at the $0.01,0.05$ and 0.10 percent levels, respectively. 


\begin{tabular}{|c|c|c|c|c|}
\hline \multirow{3}{*}{$\begin{array}{l}\text { Treatment effect } \\
\text { (relative to control group) }\end{array}$} & \multicolumn{4}{|c|}{ Percent change in: } \\
\hline & Workers & Fixed Assets & $\begin{array}{l}\text { Price of Main } \\
\text { Product }\end{array}$ & Wages \\
\hline & (1) & (2) & $(3)$ & (4) \\
\hline \multicolumn{5}{|l|}{ Treatment B $(\bar{E}[\pi])$} \\
\hline \multirow{2}{*}{$E_{i}^{\text {posterior }}[\bar{E}(\pi)]-E_{i}^{\text {prior }}[\bar{E}(\pi)]$} & $0.644 * * *$ & $0.540 * * *$ & 0.223 & 0.005 \\
\hline & $(0.245)$ & $(0.205)$ & $(0.215)$ & $(0.023)$ \\
\hline Observations & 245 & 245 & 245 & 245 \\
\hline & -0.144 & -0.294 & -0.028 & -0.003 \\
\hline $1^{\text {st }}$ stage F-stat & 60.64 & 60.64 & 60.64 & 60.64 \\
\hline \multicolumn{5}{|l|}{ Treatment $\left.\mathrm{C}\left(\bar{E}^{2}[\pi]\right]\right)$} \\
\hline \multirow[t]{2}{*}{$E_{i}^{\text {posterior }}[\bar{E}(\pi)]-E_{i}^{\text {prior }}[\bar{E}(\pi)]$} & $0.326^{* *}$ & $0.093 * *$ & -0.052 & $0.028 * *$ \\
\hline & $(0.162)$ & $(0.043)$ & $(0.046)$ & $(0.014)$ \\
\hline Observations & 252 & 252 & 252 & 252 \\
\hline $\mathrm{R}^{2}$ & 0.039 & 0.022 & -0.009 & 0.047 \\
\hline $1^{\text {st }}$ stage F-stat & 561.8 & 561.8 & 561.8 & 561.8 \\
\hline \multicolumn{5}{|l|}{ Treatment $\mathrm{D}\left(\bar{E}[\pi]\right.$ and $\left.\left.\left.\bar{E}^{2}[\pi]\right]\right)\right)$} \\
\hline \multirow{2}{*}{$E_{i}^{\text {posterior }}[\bar{E}(\pi)]-E_{i}^{\text {prior }}[\bar{E}(\pi)]$} & -0.355 & $0.288 * * *$ & 0.026 & 0.021 \\
\hline & $(0.244)$ & $(0.084)$ & $(0.084)$ & $(0.024)$ \\
\hline Observations & 253 & 253 & 253 & 253 \\
\hline $\mathrm{R}^{2}$ & -0.010 & -0.010 & 0.003 & -0.016 \\
\hline $1^{\text {st }}$ stage F-stat & 182.9 & 182.9 & 182.9 & 182.9 \\
\hline \multicolumn{5}{|l|}{ Treatment E: $\left(\pi_{t-1}\right)$} \\
\hline$E_{i}^{\text {posterior }}[\bar{E}(\pi)]-E_{i}^{\text {prior }}[\bar{E}(\pi)]$ & $0.311 * * *$ & $0.222 * *$ & 0.085 & 0.018 \\
\hline & $(0.095)$ & $(0.089)$ & $(0.085)$ & $(0.012)$ \\
\hline Observations & 251 & 251 & 251 & 251 \\
\hline $\mathrm{R}^{2}$ & 0.035 & 0.033 & -0.012 & 0.000 \\
\hline $1^{\text {st }}$ stage F-stat & 83.65 & 83.65 & 83.65 & 83.65 \\
\hline
\end{tabular}

Notes: The table reports the coefficient on revision of higher-order inflation expectations in specification (2). The regressand in each column is forecast error for a given firm-specific outcome indicated in the second row of the table. The regressor is instrumented with surprise component in the provided signal, that is, the difference between information provided in a treatment and pre-treatment expectation for the variable provided in the treatment. $1^{\text {st }}$ stage F-stat reports the first-stage F-statistic. Robust standard errors are reported in parentheses. $* * * * *$, and $*$ indicate significance at the $0.01,0.05$ and 0.10 percent levels, respectively. 


\section{Appendix B: \\ Response to Information by Level-K}


Our discussion in Section 4 assumes that firms perform infinite iteration of the optimal pricing function. That is, firms are capable of infinite degrees of reasoning, an assumption which models of level- $k$ thinking challenge. To make our model of expectations consistent with level- $k$ thinking, we revise the optimal pricing equation in equation (10) such that firm $i$ will weigh the public and private signals according to

$$
p_{i}(k)=\frac{\sum_{r=0}^{k} \alpha^{r}\left[\left[1-\delta^{r+1}\right] y+\delta^{r+1} x_{i}\right]}{\sum_{r=0}^{k} \alpha^{r}},
$$

where $k$ is the firm's type. We allow firms to fall into one of three different thinking types such that $k=$ $0,1,2$. A level-0 firm will have pricing strategies in equation (11) with $\phi_{x, 0}=\delta$ and $\phi_{y, 0}=1-\delta$. These strategies ignore the strategic complementarity in prices and rely only on the relative precision of the public and private signals. One can show that the strategies for level-1 and level-2 firms will shift weight towards the public signal; that is, $\phi_{x, 0}>\phi_{x, 1}>\phi_{x, 2}$ and $\phi_{y, 0}<\phi_{y, 1}<\phi_{y, 2}$ as $\phi_{x, k}=\delta \frac{1+\alpha \delta+\cdots+(\alpha \delta)^{k}}{1+\alpha+\cdots+\alpha^{k}}$ and $\phi_{y, k}=1-\phi_{x, k}$.

The aggregate price-level will then be a weighted average of the pricing behavior of each type of firm

$$
\bar{p}=\sum_{k=0}^{2} \omega_{k} \overline{p(k)}
$$

where $\omega_{k}$ is the proportion of firms thinking at level- $k$ and $\overline{p(k)}=\phi_{x, k} m+\phi_{y, k} y$.

Heterogeneity in strategies means that firms must consider the distribution of types in forming their expectations. Our data on the expectations of firms about the distribution of other types suggests that firms assign the greatest weight to firms of their own type. For simplicity, we model that all firms behave as if all firms are of their own type.

Level-0 firms will form expectations of the aggregate price level

$$
E_{i, 0}[\bar{p}]=\phi_{x, 0} x_{i}+\left(1-\phi_{x, 0}\right) y=\delta x_{i}+(1-\delta) y .
$$

Just as these firms do not iterate expectations in the price-setting equation, they do not iterate on expectations of the price level. Namely, they fail to substitute their expectation of $m$ into equation (B2).

Level-1 and level-2 firms are capable of iterating their expectation of the price level. Accordingly, their first-order expectations are:

$$
\begin{aligned}
& E_{i, 1}[\bar{p}]=\phi_{x, 1} \delta x_{i}+\left(1-\phi_{x, 1} \delta\right) y \\
& E_{i, 2}[\bar{p}]=\phi_{x, 2} \delta x_{i}+\left(1-\phi_{x, 2} \delta\right) y
\end{aligned}
$$

The aggregate expectation for each type is therefore:

$$
\begin{aligned}
& \bar{E}_{0}[\bar{p}]=\phi_{x, 0} m+\left(1-\phi_{x, 0}\right) y \\
& \bar{E}_{1}[\bar{p}]=\phi_{x, 1} \delta m+\left(1-\phi_{x, 1} \delta\right) y \\
& \bar{E}_{2}[\bar{p}]=\phi_{x, 2} \delta m+\left(1-\phi_{x, 2} \delta\right) y
\end{aligned}
$$

Aggregating across types and firms gives: 


$$
\bar{E}[\bar{p}]=\sum_{k=0}^{2} \omega_{k} \bar{E}_{k}[\bar{p}]=\left(\omega_{0}(1-\delta) \phi_{x, 0}+\bar{\phi}_{x} \delta\right) m+\left(1-\left(\omega_{0}(1-\delta) \phi_{x, 0}+\bar{\phi}_{x} \delta\right)\right) y,
$$

where $\bar{\phi}_{x}=\sum_{k=0}^{2} \omega_{k} \phi_{x, k}$. Because by definition level-0 and level-1 firms are unable to iterate expectations past their first-order expectation, their higher-order expectation is the same as their first-order expectation:

$$
\begin{aligned}
& E_{i, 0}[\bar{E}[\bar{p}]]=\phi_{x, 0} x_{i}+\left(1-\phi_{x, 0}\right) y=\delta x_{i}+(1-\delta) y, \\
& \left.E_{i, 1}[\bar{E}[\bar{p}]]\right]=\phi_{x, 1} E_{i}[m]+\left(1-\phi_{x, 1}\right) y=\phi_{x, 1} \delta x_{i}+\left(1-\phi_{x, 1} \delta\right) y .
\end{aligned}
$$

Unlike level-0 and level-1 firms, level-2 firms will be able to iterate their expectations for a second time, substituting $E_{i}[m]=\delta x_{i}+(1-\delta) y$ :

$$
E_{i, 2}[\bar{E}[\bar{p}]]=\phi_{x, 2} \delta E_{i}[m]+\left(1-\phi_{x, 2} \delta\right) y=\phi_{x, 2} \delta^{2} x_{i}+\left(1-\phi_{x, 2} \delta^{2}\right) y
$$

The aggregate higher-order expectations for each type are:

$$
\begin{aligned}
& \bar{E}_{0}^{2}[\bar{p}]=\phi_{x, 0} m+\left(1-\phi_{x, 0}\right) y \\
& \bar{E}_{1}^{2}[\bar{p}]=\phi_{x, 1} \delta m+\left(1-\phi_{x, 1} \delta\right) y \\
& \bar{E}_{2}^{2}[\bar{p}]=\phi_{x, 2} \delta^{2} m+\left(1-\phi_{x, 2} \delta^{2}\right) y
\end{aligned}
$$

The average higher-order expectation is then:

$$
\bar{E}^{2}[\bar{p}]=\sum_{k=0}^{2} \omega_{k} \bar{E}_{k}^{2}[\bar{p}] .
$$

As Section 4.3 outlines, managers can transform signals about the average first-order and higherorder inflation expectation (signals B and C) into signals about $m$. Signal B, in Equation (23), will be differently perceived by managers at different $k$ levels.

$$
\begin{aligned}
\tilde{s}_{B, 0} & =H_{B, 0} m+\xi_{B}=\phi_{x, 0} m+\xi_{B} \\
\tilde{s}_{B, 1} & =H_{B, 1} m+\xi_{B}=\phi_{x, 1} \delta m+\xi_{B} \\
\tilde{s}_{B, 2} & =H_{B, 2} m+\xi_{B}=\phi_{x, 2} \delta m+\xi_{B}
\end{aligned}
$$

Note that the interpretation of signals may be incorrect because agents' perception of the data generating process (DGP) may deviate from the actual DGP. For example, for level-0 firms perception of DGP is given by equation (B3a) while actual DGP is given by equation (B2). Indeed, only agents with the highest $k$ have the correct perception. As a result, although agents believe they should interpret signals as in equations (B8), the effective signals are different. For level-0 firms:

$$
\begin{aligned}
& \tilde{s}_{B, 0}=\left(\omega_{0}(1-\delta) \phi_{x, 0}+\bar{\phi}_{x} \delta\right) m+\left(1-\left(\omega_{0}(1-\delta) \phi_{x, 0}+\phi_{x} \delta\right)\right) y+\xi_{B}-\left(1-\phi_{x, 0}\right) y \\
& =\phi_{x, 0} m+\left(\left(\omega_{0}-1\right) \phi_{x, 0}+\delta\left(\omega_{1} \phi_{x, 1}+\omega_{2} \phi_{x, 2}\right)\right)(m-y)+\xi_{B} \\
& =\phi_{x, 0} m+\tilde{\xi}_{B, 0}
\end{aligned}
$$

where $\tilde{\xi}_{B, 0} \equiv\left(\left(\omega_{0}-1\right) \phi_{x, 0}+\delta\left(\omega_{1} \phi_{x, 1}+\omega_{2} \phi_{x, 2}\right)\right)(m-y)+\xi_{B}$. Thus, level-0 firms interpret $\tilde{\xi}_{B, 0}$ as 
uncorrelated noise, but in fact the "noise" is correlated with fundamental $m$ and public signal $y$. This interpretation of the signal means that, in the long run, level-0 firms may be overconfident in their expectations because $\operatorname{Var}\left(\tilde{\xi}_{B, 0}\right)>\operatorname{Var}\left(\xi_{B}\right)$ and, relatedly, these firms may have more disagreement because they may overreact to the perceived signals.

Likewise, for level-1 and level-2 firms:

$$
\begin{aligned}
& \tilde{s}_{B, 1}=H_{B, 1} m+\tilde{\xi}_{B, 1}=\phi_{x, 1} \delta m+\tilde{\xi}_{B, 1} \\
& \tilde{s}_{B, 2}=H_{B, 1} m+\tilde{\xi}_{B, 1}=\phi_{x, 2} \delta m+\tilde{\xi}_{B, 2}
\end{aligned}
$$

where $\tilde{\xi}_{B, 1} \equiv\left(\omega_{0} \phi_{x, 0}+\left(\bar{\phi}_{x}-\phi_{x, 1}\right) \delta\right)(m-y)+\xi_{B}$ and $\tilde{\xi}_{B, 2} \equiv\left(\omega_{0} \phi_{x, 0}+\left(\bar{\phi}_{x}-\phi_{x, 2}\right) \delta\right)(m-y)+$ $\xi_{B}$.

For each group, we can then show:

$$
\begin{aligned}
& E_{i, 0}^{\text {Post }}[m]=\left(\frac{\kappa_{B}^{-1}}{\kappa_{B}^{-1}+\left(\phi_{x, 0}\right)^{2} \delta \kappa^{-1}}\right) E_{i}^{\text {Pre }}[m]+P_{B, 0} \tilde{s}_{B, 0} \\
& E_{i, 1}^{\text {Post }}[m]=\left(\frac{\kappa_{B}^{-1}}{\kappa_{B}^{-1}+\left(\phi_{x, 1} \delta\right)^{2} \delta \kappa^{-1}}\right) E_{i}^{\text {Pre }}[m]+P_{B, 1} \tilde{s}_{B, 1} \\
& E_{i, 2}^{\text {Post }}[m]=\left(\frac{\kappa_{B}^{-1}}{\kappa_{B}^{-1}+\left(\phi_{x, 2} \delta\right)^{2} \delta \kappa^{-1}}\right) E_{i}^{\text {Pre }}[m]+P_{B, 2} \tilde{s}_{B, 2}
\end{aligned}
$$

where the coefficient on the prior corresponds to $(1-P H)$ in equation (25). Because $\phi_{x, 2}<\phi_{x, 1}<\phi_{x, 0}$, we can predict that the weight on the prior increases in level of thinking $k$.

Combining equations (B3), (B6) and (B9) gives:

$$
\begin{aligned}
& E_{i, 0}^{\text {Post }}\left[\begin{array}{c}
\bar{p} \\
\bar{E}[\bar{p}]
\end{array}\right]=\left(\frac{\left(\phi_{x, 0}\right)^{2} \delta \kappa^{-1}}{\kappa_{B}^{-1}+\left(\phi_{x, 0}\right)^{2} \delta \kappa^{-1}}\right)\left[\begin{array}{l}
1-\phi_{x, 0} \\
1-\phi_{x, 0}
\end{array}\right] y+\left(\frac{\kappa_{B}^{-1}}{\kappa_{B}^{-1}+\left(\phi_{x, 0}\right)^{2} \delta \kappa^{-1}}\right) E_{i, 0}^{\text {Pre }}\left[\begin{array}{c}
\bar{p} \\
\bar{E}[\bar{p}]
\end{array}\right]+\left[\begin{array}{l}
\phi_{x, 0} \\
\phi_{x, 0}
\end{array}\right] P_{B, 0} \tilde{s}_{B, 0} \\
& E_{i, 1}^{\text {Post }}\left[\begin{array}{c}
\bar{p} \\
\bar{E}[\bar{p}]
\end{array}\right]=\left(\frac{\left(\phi_{x, 1} \delta\right)^{2} \delta \kappa^{-1}}{\kappa_{B}^{-1}+\left(\phi_{x, 1} \delta\right)^{2} \delta \kappa^{-1}}\right)\left[\begin{array}{l}
1-\phi_{x, 1} \delta \\
1-\phi_{x, 1} \delta
\end{array}\right] y+\left(\frac{\kappa_{B}^{-1}}{\kappa_{B}^{-1}+\left(\Phi_{x, 1} \delta\right)^{2} \delta \kappa^{-1}}\right) E_{i, 1}^{\text {Pre }}\left[\begin{array}{c}
\bar{p} \\
\bar{E}[\bar{p}]
\end{array}\right]+\left[\begin{array}{l}
\phi_{x, 1} \delta \\
\phi_{x, 1} \delta
\end{array}\right] P_{B, 1} \tilde{S}_{B, 1} \\
& E_{i, 2}^{\text {Post }}\left[\begin{array}{c}
\bar{p} \\
\bar{E}[\bar{p}]
\end{array}\right]=\left(\frac{\left(\phi_{x, 2} \delta\right)^{2} \delta \kappa^{-1}}{\kappa_{B}^{-1}+\left(\phi_{x, 2} \delta\right)^{2} \delta \kappa^{-1}}\right)\left[\begin{array}{c}
1-\phi_{x, 1} \delta \\
\left(1-\delta\left(\omega_{0}(1-\delta) \phi_{x, 0}+\bar{\phi}_{x} \delta\right)\right)
\end{array}\right] y+\left(\frac{\kappa_{B}^{-1}}{\kappa_{B}^{-1}+\left(\phi_{x, 2} \delta\right)^{2} \delta \kappa^{-1}}\right) E_{i, 1}^{\text {Pre }}\left[\begin{array}{c}
\bar{p} \\
\bar{E}[\bar{p}]
\end{array}\right]+ \\
& {\left[\begin{array}{c}
\phi_{x, 2} \delta \\
\phi_{x, 2} \delta^{2}
\end{array}\right] P_{B, 2} \tilde{S}_{B, 2}}
\end{aligned}
$$

Note that the difference in weight on priors across $k$ is largely governed by variation in $H_{B, k}$ across $k$. Given our parameter estimates for $\alpha$ and $\delta$ as well as the distribution of types, we find that $\phi_{x, 0} \approx 0.80$, $\phi_{x, 1} \delta \approx 0.59, \phi_{x, 2} \delta \approx 0.55$. Thus, while the model predicts differentiated responses to signals across $k$, the differences could be rather small.

We can derive similar expressions for signal $\mathrm{C}$, which gives firms the average higher-order expectations. Because firms incorrectly perceive the DGP, signals must be translated into the effective signals: 


$$
\begin{aligned}
& \tilde{s}_{C, 0}=H_{C, 0} m+\tilde{\xi}_{C, 0}=\phi_{x, 0} m+\tilde{\xi}_{C, 0} \\
& \tilde{s}_{C, 1}=H_{C, 1} m+\tilde{\xi}_{C, 1}=\phi_{x, 1} \delta m+\tilde{\xi}_{C, 1} \\
& \tilde{s}_{C, 2}=H_{C, 2} m+\tilde{\xi}_{C, 2}=\phi_{x, 2} \delta^{2} m+\tilde{\xi}_{C, 2}
\end{aligned}
$$

where $\tilde{\xi}_{C, 0} \equiv\left[\left(1-\omega_{0}\right) \phi_{x, 0}+\omega_{1} \phi_{x, 1} \delta+\omega_{2} \phi_{x, 2} \delta^{2}\right](y-m)+\xi_{C}, \tilde{\xi}_{C, 1} \equiv\left[\omega_{0} \phi_{x, 0}+\left(1-\omega_{1}\right) \phi_{x, 1} \delta+\right.$ $\left.\omega_{2} \phi_{x, 2} \delta^{2}\right](y-m)+\xi_{C}$, and $\tilde{\xi}_{C, 2} \equiv\left[\omega_{0} \phi_{x, 0}+\omega_{1} \phi_{x, 1} \delta+\left(1-\omega_{2}\right) \phi_{x, 2} \delta^{2}\right](y-m)+\xi_{C}$.

Firms then update their expectations of the fundamental according to:

$$
\begin{aligned}
& E_{i, 0}^{\text {Post }}[m]=\left(\frac{\kappa_{C}^{-1}}{\kappa_{C}^{-1}+\left(\phi_{x, 0}\right)^{2} \delta \kappa^{-1}}\right) E_{i}^{\text {Pre }}[m]+P_{C, 0} \tilde{s}_{C, 0} \\
& E_{i, 1}^{\text {Post }}[m]=\left(\frac{\kappa_{C}^{-1}}{\kappa_{C}^{-1}+\left(\phi_{x, 1} \delta\right)^{2} \delta \kappa^{-1}}\right) E_{i}^{\text {Pre }}[m]+P_{C, 1} \tilde{s}_{C, 1} \\
& E_{i, 2}^{\text {Post }}[m]=\left(\frac{\kappa_{C}^{-1}}{\kappa_{C}^{-1}+\left(\phi_{x, 2} \delta^{2}\right)^{2} \delta \kappa^{-1}}\right) E_{i}^{\text {Pre }}[m]+P_{C, 2} \tilde{s}_{C, 2}
\end{aligned}
$$

Equations (B11a) and (B11b) imply that, provided $\kappa_{B}=\kappa_{C}$, the weight on priors for level-0 and level-1 firms is the same when firms are presented with signals $B$ and $C$ because these firms cannot perform a second iteration on expectations.

Combining equations (B3), (B6) and (B11) gives:

$$
\begin{aligned}
& E_{i, 0}^{\text {Post }}\left[\begin{array}{c}
\bar{p} \\
\bar{E}[\bar{p}]
\end{array}\right]=\left(\frac{\left(\phi_{x, 0}\right)^{2} \delta \kappa^{-1}}{\kappa_{c}^{-1}+\left(\phi_{x, 0}\right)^{2} \delta \kappa^{-1}}\right)\left[\begin{array}{l}
1-\phi_{x, 0} \\
1-\phi_{x, 0}
\end{array}\right] y+\left(\frac{\kappa_{C}^{-1}}{\kappa_{C}^{-1}+\left(\phi_{x, 0}\right)^{2} \delta \kappa^{-1}}\right) E_{i, 0}^{\text {Pre }}\left[\begin{array}{c}
\bar{p} \\
\bar{E}[\bar{p}]
\end{array}\right]+\left[\begin{array}{l}
\phi_{x, 0} \\
\phi_{x, 0}
\end{array}\right] P_{C, 0} \tilde{s}_{C, 0} \\
& E_{i, 1}^{\text {Post }}\left[\begin{array}{c}
\bar{p} \\
\bar{E}[\bar{p}]
\end{array}\right]=\left(\frac{\left(\phi_{x, 1} \delta\right)^{2} \delta \kappa^{-1}}{\kappa_{c}^{-1}+\left(\phi_{x, 1} \delta\right)^{2} \delta \kappa^{-1}}\right)\left[\begin{array}{l}
1-\phi_{x, 1} \delta \\
1-\phi_{x, 1} \delta
\end{array}\right] y+\left(\frac{\kappa_{C}^{-1}}{\kappa_{C}^{-1}+\left(\phi_{x, 1} \delta\right)^{2} \delta \kappa^{-1}}\right) E_{i, 1}^{\text {Pre }}\left[\begin{array}{c}
\bar{p} \\
\bar{E}[\bar{p}]
\end{array}\right]+\left[\begin{array}{l}
\phi_{x, 1} \delta \\
\phi_{x, 1} \delta
\end{array}\right] P_{C, 1} \tilde{s}_{C, 1} \\
& E_{i, 2}^{\text {Post }}\left[\begin{array}{c}
\bar{p} \\
\bar{E}[\bar{p}]
\end{array}\right]=\left(\frac{\left(\phi_{x, 2} \delta^{2}\right)^{2} \delta \kappa^{-1}}{\kappa_{C}^{-1}+\left(\phi_{x, 2} \delta^{2}\right)^{2} \delta \kappa^{-1}}\right)\left[\begin{array}{c}
1-\phi_{x, 2} \delta \\
1-\phi_{x, 2} \delta^{2}
\end{array}\right] y \\
&+\left(\frac{\kappa_{C}^{-1}}{\kappa_{C}^{-1}+\left(\phi_{x, 2} \delta^{2}\right)^{2} \delta \kappa^{-1}}\right) E_{i, 1}^{\text {Pre }}\left[\begin{array}{c}
\bar{p} \\
\bar{E}[\bar{p}]
\end{array}\right]+\left[\begin{array}{c}
\phi_{x, 2} \delta \\
\phi_{x, 2} \delta^{2}
\end{array}\right] P_{C, 2} \tilde{s}_{C, 2}
\end{aligned}
$$

Given our parameter estimates for $\alpha$ and $\delta$ as well as the distribution of types, we find that $\phi_{x, 0} \approx 0.80$, $\phi_{x, 1} \delta \approx 0.59, \phi_{x, 2} \delta^{2} \approx 0.44$. These estimates determine the difference in the weight given to priors across $k$.

Firms in Group D receive both signals. If the noise terms in both signals are uncorrelated

$$
E_{i, k}^{\text {post }}(m)=\left(1-P_{D, k} H_{D, k}\right) E_{i}^{\text {pre }}(m)+P_{D, k} \tilde{s}_{D, k},
$$

where $H_{D, 0}=\left[\begin{array}{ll}\phi_{x, 0} & \phi_{x, 0}\end{array}\right]^{\prime}, H_{D, 1}=\left[\begin{array}{ll}\phi_{x, 1} \delta & \phi_{x, 1} \delta\end{array}\right]^{\prime}, H_{D, 2}=\left[\begin{array}{ll}\phi_{x, 2} \delta & \phi_{x, 2} \delta^{2}\end{array}\right]^{\prime}, \quad R_{D}=\operatorname{diag}\left\{\kappa_{B}^{-1}, \kappa_{C}^{-1}\right\}$, and $P_{D, k}=\delta \kappa^{-1} H_{D, k}^{\prime}\left(R_{D}+\delta \kappa^{-1} H_{D, k} H_{D, k}^{\prime}\right)^{-1}$.

All thinking types are able to correctly process Signal E, which contains an estimate of past inflation. Intuitively, signal E provides direct information about the fundamental and updating beliefs does 
not require thinking about the behavior of other agents in the economy. We therefore do not expect to see any difference between responses to this signal across $k$. 


\section{Appendix C: Sampling Frame and Response Rate}




\begin{tabular}{|c|c|c|c|c|c|c|}
\hline & $\begin{array}{c}\text { Number of Firms } \\
6-9 \text { Workers }\end{array}$ & 10-19 Workers & 20-49 Workers & 50-99 Workers & $100+$ Workers & $>6$ Workers \\
\hline Manufacturing & 1737 & 1791 & 1248 & 420 & 312 & 5508 \\
\hline Rental, Hiring and Real Estate & 528 & 330 & 153 & 15 & 36 & 1062 \\
\hline Professional, Technical, Scientific Services \& & & & & & & \\
\hline Administrative Support Services & 2595 & 2016 & 1188 & 357 & 336 & 6492 \\
\hline Financial and Insurance Services & 267 & 159 & 96 & 42 & 69 & 633 \\
\hline Construction & 2487 & 1821 & 837 & 204 & 93 & 5442 \\
\hline Wholesale Trade & 1284 & 1107 & 657 & 222 & 120 & 3390 \\
\hline Retail Trade & 2172 & 1704 & 678 & 258 & 315 & 5127 \\
\hline Accommodation and Food Services & 2601 & 2511 & 1230 & 201 & 108 & 6651 \\
\hline Transport, Postal, Warehousing \& Information & & & & & & \\
\hline Media & 744 & 681 & 438 & 171 & 156 & 2190 \\
\hline Total & 14415 & 12120 & 6525 & 1890 & 1545 & 36495 \\
\hline
\end{tabular}

Source: Statistics New Zealand

\section{Appendix Table B.2: Percentage of Firms by Sector and Size in NZ, 2016}

\begin{tabular}{|c|c|c|c|c|c|c|}
\hline & $\begin{array}{c}\text { Percentage of Firms } \\
\text { 6-9 Workers } \\
(\%)\end{array}$ & $\begin{array}{c}\text { 10-19 Workers } \\
(\%)\end{array}$ & $\begin{array}{c}\text { 20-49 Workers } \\
(\%)\end{array}$ & $\begin{array}{c}\text { 50-99 Workers } \\
(\%)\end{array}$ & $\begin{array}{c}100+\text { Workers } \\
(\%)\end{array}$ & $\begin{array}{c}>6 \text { Workers } \\
(\%)\end{array}$ \\
\hline Manufacturing & 31.54 & 32.52 & 22.66 & 7.63 & 5.66 & 100 \\
\hline Rental, Hiring and Real Estate & 49.72 & 31.07 & 14.41 & 1.41 & 3.39 & 100 \\
\hline Professional, Technical, Scientific Services \& & & & & & & \\
\hline Administrative Support Services & 39.97 & 31.05 & 18.30 & 5.50 & 5.18 & 100 \\
\hline Financial and Insurance Services & 42.18 & 25.12 & 15.17 & 6.64 & 10.90 & 100 \\
\hline Construction & 45.70 & 33.46 & 15.38 & 3.75 & 1.71 & 100 \\
\hline Wholesale Trade & 37.88 & 32.65 & 19.38 & 6.55 & 3.54 & 100 \\
\hline Retail Trade & 42.36 & 33.24 & 13.22 & 5.03 & 6.14 & 100 \\
\hline Accommodation and Food Services & 39.11 & 37.75 & 18.49 & 3.02 & 1.62 & 100 \\
\hline Transport, Postal, Warehousing \& Information & & & & & & \\
\hline Media & 33.97 & 31.10 & 20.00 & 7.81 & 7.12 & 100 \\
\hline
\end{tabular}

Source: Statistics New Zealand 
Appendix Table B.3: Number of Firms by Sector and Size in the Population of our Survey, 2017

\begin{tabular}{|c|c|c|c|c|c|c|}
\hline & $\begin{array}{c}\text { Number of Firms } \\
6-9 \text { Workers }\end{array}$ & 10-19 Workers & 20-49 Workers & 50-99 Workers & $100+$ Workers & $>6$ Workers \\
\hline Manufacturing & 946 & 975 & 680 & 420 & 312 & 3333 \\
\hline Rental, Hiring and Real Estate & 200 & 125 & 58 & 15 & 36 & 433 \\
\hline Professional, Technical, Scientific Services \& & & & & & & \\
\hline Administrative Support Services & 868 & 674 & 397 & 357 & 336 & 2633 \\
\hline Financial and Insurance Services & 80 & 47 & 29 & 42 & 69 & 267 \\
\hline Construction & 241 & 177 & 81 & 204 & 93 & 796 \\
\hline Wholesale Trade & 65 & 56 & 33 & 222 & 120 & 496 \\
\hline Retail Trade & 84 & 66 & 26 & 258 & 315 & 750 \\
\hline Accommodation and Food Services & 272 & 263 & 129 & 201 & 108 & 973 \\
\hline Transport, Postal, Warehousing \& Information & & & & & & \\
\hline Media & 20 & 32 & 48 & 164 & 156 & 420 \\
\hline Total & 2776 & 2415 & 1481 & 1883 & 1545 & 10100 \\
\hline
\end{tabular}

Appendix Table B.4: Percentage of Firms by Sector and Size in the Population of our Survey, 2017

\begin{tabular}{|c|c|c|c|c|c|c|}
\hline & $\begin{array}{c}\text { Percentage of Firms } \\
\text { 6-9 Workers } \\
(\%)\end{array}$ & $\begin{array}{c}\text { 10-19 Workers } \\
(\%)\end{array}$ & $\begin{array}{c}\text { 20-49 Workers } \\
(\%)\end{array}$ & $\begin{array}{c}\text { 50-99 Workers } \\
(\%)\end{array}$ & $\begin{array}{c}100+\text { Workers } \\
(\%)\end{array}$ & $\begin{array}{c}>6 \text { Workers } \\
(\%)\end{array}$ \\
\hline Manufacturing & 28 & 29 & 20 & 13 & 9 & 100 \\
\hline Rental, Hiring and Real Estate & 46 & 29 & 13 & 3 & 8 & 100 \\
\hline \multicolumn{7}{|l|}{ Professional, Technical, Scientific Services \& } \\
\hline Administrative Support Services & 33 & 26 & 15 & 14 & 13 & 100 \\
\hline Financial and Insurance Services & 30 & 18 & 11 & 16 & 26 & 100 \\
\hline Construction & 30 & 22 & 10 & 26 & 12 & 100 \\
\hline Wholesale Trade & 13 & 11 & 7 & 45 & 24 & 100 \\
\hline Retail Trade & 11 & 9 & 4 & 34 & 42 & 100 \\
\hline Accommodation and Food Services & 28 & 27 & 13 & 21 & 11 & 100 \\
\hline \multicolumn{7}{|l|}{ Transport, Postal, Warehousing \& Information } \\
\hline Media & 5 & 8 & 11 & 39 & 37 & 100 \\
\hline
\end{tabular}


Appendix Table B.5: Survey Framework of Main Wave, Number of Firms According to Employment Size Group

\begin{tabular}{|c|c|c|c|c|c|c|c|c|c|c|c|c|c|c|c|}
\hline & 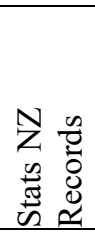 & 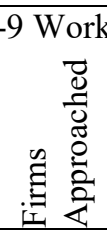 & 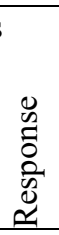 & 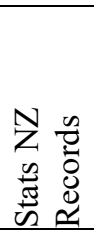 & 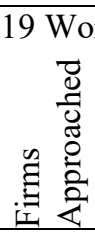 & 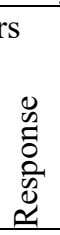 & 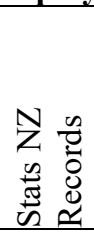 & 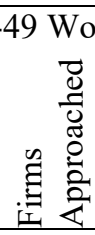 & 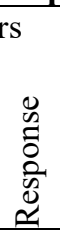 & 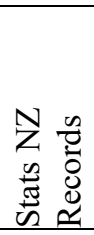 & 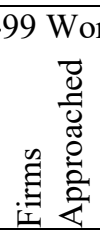 & 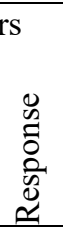 & 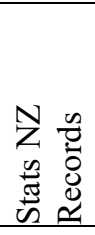 & 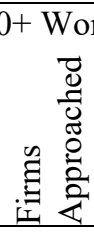 & 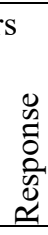 \\
\hline Manufacturing & 1737 & 946 & 73 & 1791 & 975 & 94 & 1248 & 680 & 83 & 420 & 420 & 44 & 312 & 312 & 25 \\
\hline $\begin{array}{l}\text { Rental, Hiring and Real Estate } \\
\text { Professional, Technical, } \\
\text { Scientific Services \& } \\
\text { Administrative Support }\end{array}$ & 528 & 200 & 14 & 330 & 125 & 13 & 153 & 58 & 13 & 15 & 15 & 9 & 36 & 36 & 0 \\
\hline $\begin{array}{l}\text { Services } \\
\text { Financial and Insurance }\end{array}$ & 2595 & 868 & 41 & 2016 & 674 & 46 & 1188 & 397 & 66 & 357 & 357 & 36 & 336 & 336 & 5 \\
\hline Services & 267 & 80 & 21 & 159 & 47 & 17 & 96 & 29 & 29 & 42 & 42 & 10 & 69 & 69 & 4 \\
\hline Construction & 2487 & 241 & 18 & 1821 & 177 & 19 & 837 & 81 & 24 & 204 & 204 & 16 & 93 & 93 & 3 \\
\hline Wholesale Trade & 1284 & 65 & 12 & 1107 & 56 & 14 & 657 & 33 & 17 & 222 & 222 & 11 & 120 & 120 & 2 \\
\hline $\begin{array}{l}\text { Retail Trade } \\
\text { Accommodation and Food }\end{array}$ & 2172 & 84 & 32 & 1704 & 66 & 27 & 678 & 26 & 35 & 258 & 258 & 14 & 315 & 315 & 15 \\
\hline $\begin{array}{l}\text { Services } \\
\text { Transport, Postal, } \\
\text { Warehousing \& Information }\end{array}$ & 2601 & 272 & 9 & 2511 & 263 & 12 & 1230 & 129 & 14 & 201 & 201 & 5 & 108 & 108 & 1 \\
\hline Media & 744 & 20 & 13 & 681 & 32 & 23 & 438 & 48 & 33 & 171 & 164 & 12 & 156 & 156 & 8 \\
\hline
\end{tabular}




\begin{tabular}{|c|c|c|c|c|c|c|c|c|c|c|c|c|c|c|c|}
\hline & \multicolumn{3}{|c|}{ 6-9 Workers } & \multicolumn{3}{|c|}{ 10-19 Workers } & \multicolumn{3}{|c|}{ 20-49 Workers } & \multicolumn{3}{|c|}{ 50-99 Workers } & \multicolumn{3}{|c|}{ 100+ Workers } \\
\hline & 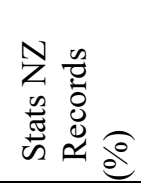 & 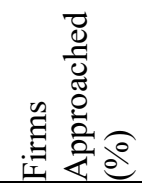 & 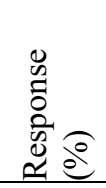 & 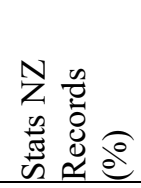 & 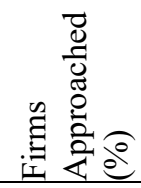 & 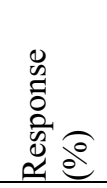 & 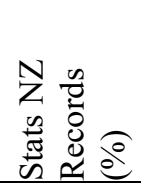 & 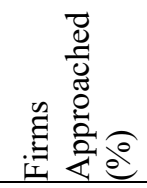 & 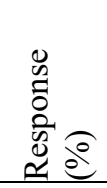 & 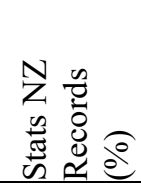 & 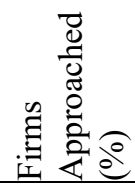 & 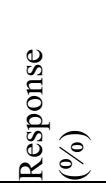 & 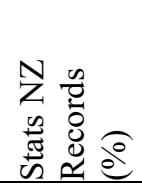 & 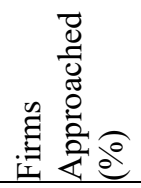 & 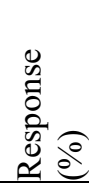 \\
\hline Manufacturing & 32 & 28 & 23 & 33 & 29 & 29 & 23 & 20 & 26 & 8 & 13 & 14 & 6 & 9 & 8 \\
\hline $\begin{array}{l}\text { Rental, Hiring and Real Estate } \\
\text { Professional, Technical, } \\
\text { Scientific Services \& } \\
\text { Administrative Support }\end{array}$ & 50 & 46 & 29 & 31 & 29 & 27 & 14 & 13 & 27 & 1 & 3 & 18 & 3 & 8 & 0 \\
\hline $\begin{array}{l}\text { Services } \\
\text { Financial and Insurance }\end{array}$ & 40 & 33 & 21 & 31 & 26 & 24 & 18 & 15 & 34 & 5 & 14 & 19 & 5 & 13 & 3 \\
\hline Services & 42 & 30 & 26 & 25 & 18 & 21 & 15 & 11 & 36 & 7 & 16 & 12 & 11 & 26 & 5 \\
\hline Construction & 46 & 30 & 23 & 33 & 22 & 24 & 15 & 10 & 30 & 4 & 26 & 20 & 2 & 12 & 4 \\
\hline Wholesale Trade & 38 & 13 & 21 & 33 & 11 & 25 & 19 & 7 & 30 & 7 & 45 & 20 & 4 & 24 & 4 \\
\hline $\begin{array}{l}\text { Retail Trade } \\
\text { Accommodation and Food }\end{array}$ & 42 & 11 & 26 & 33 & 9 & 22 & 13 & 4 & 28 & 5 & 34 & 11 & 6 & 42 & 12 \\
\hline $\begin{array}{l}\text { Services } \\
\text { Transport, Postal, } \\
\text { Warehousing \& Information }\end{array}$ & 39 & 28 & 22 & 38 & 27 & 29 & 18 & 13 & 34 & 3 & 21 & 12 & 2 & 11 & 2 \\
\hline Media & 34 & 5 & 15 & 31 & 8 & 26 & 20 & 11 & 37 & 8 & 39 & 13 & 7 & 37 & 9 \\
\hline
\end{tabular}




\begin{tabular}{|c|c|c|c|c|c|c|}
\hline & \multicolumn{3}{|c|}{ Number of Firms } & \multicolumn{3}{|c|}{ Percentage of Firms } \\
\hline & 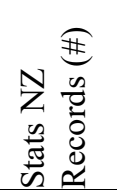 & 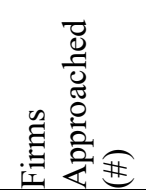 & 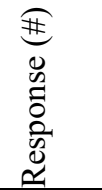 & 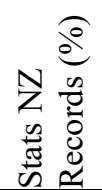 & 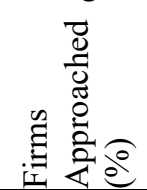 & 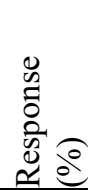 \\
\hline Manufacturing & 5508 & 3333 & 319 & 100 & 61 & 10 \\
\hline Rental, Hiring and Real Estate & 1062 & 433 & 49 & 100 & 41 & 11 \\
\hline Professional, Technical, Scientific Services \& Administrative Support Services & 6492 & 2633 & 194 & 100 & 41 & 7 \\
\hline Financial and Insurance Services & 633 & 267 & 81 & 100 & 42 & 30 \\
\hline Construction & 5442 & 796 & 80 & 100 & 15 & 10 \\
\hline Wholesale Trade & 3390 & 496 & 56 & 100 & 15 & 11 \\
\hline Retail Trade & 5127 & 750 & 123 & 100 & 15 & 16 \\
\hline Accommodation and Food Services & 6651 & 973 & 41 & 100 & 15 & 4 \\
\hline Transport, Postal, Warehousing \& Information Media & 2190 & 420 & 89 & 100 & 19 & 21 \\
\hline Total & 36495 & 10100 & 1032 & 100 & 27.64 & 10.22 \\
\hline
\end{tabular}




\begin{tabular}{|c|c|c|c|c|c|c|c|c|c|c|c|c|}
\hline & 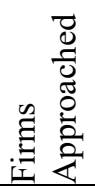 & 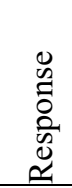 & 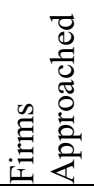 & 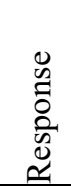 & 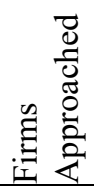 & 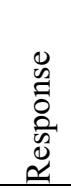 & 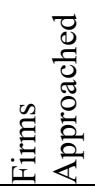 & 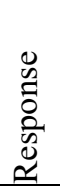 & 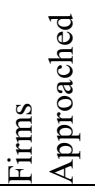 & 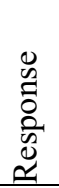 & 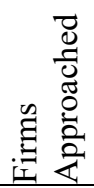 & 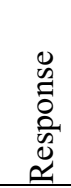 \\
\hline Manufacturing & 73 & 36 & 94 & 43 & 83 & 42 & 44 & 26 & 25 & 10 & 319 & 157 \\
\hline Rental, Hiring and Real Estate & 14 & 6 & 13 & 8 & 13 & 4 & 9 & 2 & 0 & 0 & 49 & 20 \\
\hline $\begin{array}{l}\text { Professional, Technical, Scientific } \\
\text { Services \& Administrative Support }\end{array}$ & & & & & & & & & & & & \\
\hline Services & 41 & 22 & 46 & 22 & 66 & 38 & 36 & 17 & 5 & 0 & 194 & 99 \\
\hline Financial and Insurance Services & 21 & 10 & 17 & 10 & 29 & 15 & 10 & 4 & 4 & 2 & 81 & 41 \\
\hline Construction & 18 & 6 & 19 & 11 & 24 & 13 & 16 & 7 & 3 & 2 & 80 & 39 \\
\hline Wholesale Trade & 12 & 7 & 14 & 6 & 17 & 9 & 11 & 3 & 2 & 1 & 56 & 26 \\
\hline Retail Trade & 32 & 15 & 27 & 14 & 35 & 14 & 14 & 11 & 15 & 10 & 123 & 64 \\
\hline Accommodation and Food Services & 9 & 5 & 12 & 6 & 14 & 8 & 5 & 2 & 1 & 0 & 41 & 21 \\
\hline Transport, Postal, Warehousing \& & & & & & & & & & & & & \\
\hline Information Media & 13 & 6 & 23 & 13 & 33 & 18 & 12 & 6 & 8 & 5 & 89 & 48 \\
\hline Total & 233 & 113 & 265 & 133 & 314 & 161 & 157 & 78 & 63 & 30 & 1032 & 515 \\
\hline
\end{tabular}


Appendix Table B.9: Survey Framework of Follow-up Wave, Response Rates

6-9 Workers

10-19 Workers

20-49 Workers

50-99 Workers

100+ Workers

Manufacturing

49

Response Rates

Response Rates

Response Rates

Rental, Hiring and Real Estate

51

59

Response Rates

Professional, Technical, Scientific Services \& Administrative

Support Services

43

62

31

22

40

Financial and Insurance Services

48

Construction

Wholesale Trade

54

48

Retail Trade

33
58

59

58

43

52

Accommodation and Food Services

47

Transport, Postal, Warehousing \& Information Media

46

58

52

54

53

40

50
57

47

50

$44 \quad 67$

27

79

57

55

50

50

67 